


\title{
Produktion von monoklonalen Antikörpern und Phagenantikörpern gegen das Rinder-Prionprotein durch SFV Partikel-vermittelte Immunisierung von $\operatorname{PrP}^{0 / 0}$-Mäusen
}

\author{
Dissertation \\ zur Erlangung des Doktorgrades \\ der Mathematisch-Naturwissenschaftilichen Fakultäten \\ der Georg-August-Universität zu Göttingen
}

Vorgelegt von

Omar Ahmad-Omar

aus Ghinda/Eritrea

Göttingen 2001 
D7

Referent: Prof. Dr. G. Gottschalk

Korreferent: Prof. Dr. B. Bowien

Tag der mündlichen Prüfung: 26.10.2001 


\title{
Produktion von monoklonalen Antikörpern und Phagenantikörpern gegen das Rinder-Prionprotein durch SFV Partikel-vermittelte Immunisierung von $\operatorname{PrP}^{0 / 0}$-Mäusen
}

\author{
Dissertation \\ zur Erlangung des Doktorgrades \\ der Mathematisch-Naturwissenschaftilichen Fakultäten \\ der Georg-August-Universität zu Göttingen
}

Vorgelegt von

Omar Ahmad-Omar

aus Ghinda/Eritrea

Göttingen 2001 


\section{Inhaltsverzeichnis}

\section{Abkürzungsverzeichnis}

Abbildungsverzeichnis

IX

Tabellenverzeichnis

1 Einleitung

1.1 Transmissible Spongiforme Enzephalopathien (TSE) ............................

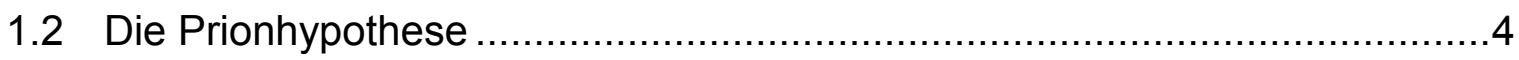

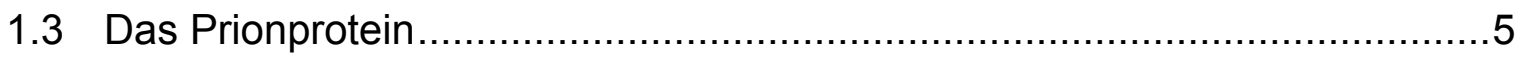

1.4 Prionprotein defiziente $\mathrm{Pr}^{0 / 0}$-Mäuse …................................................. 10

1.5 TSE Diagnose mit Hilfe von Antikörpern .............................................11

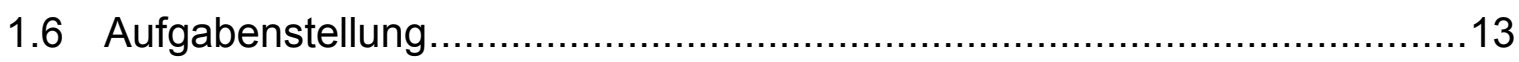

2 Material und Methoden $\quad 15$

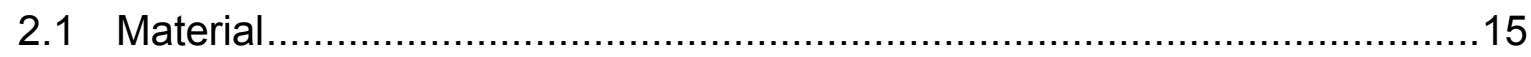

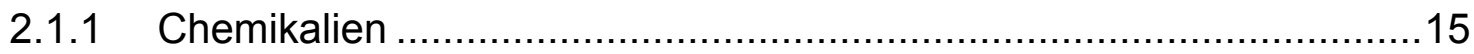

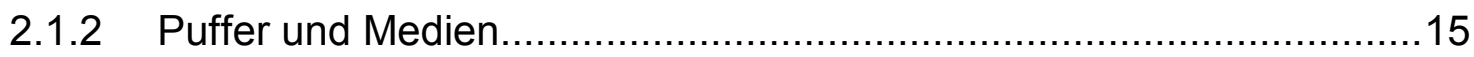

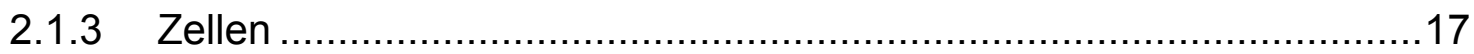

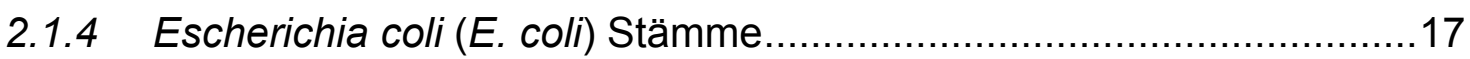

2.2 Molekulargenetische Methoden...............................................................17

2.2.1 Agarosegelelektrophorese und Extraktion von Nukleinsäuren

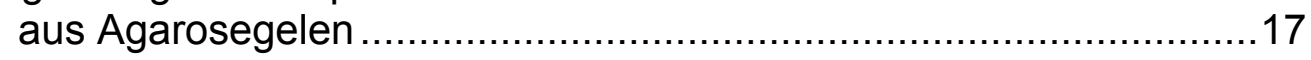

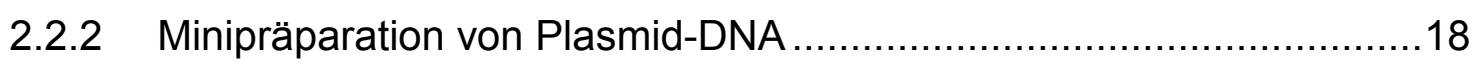

2.2.3 Midi- und Maxipräparation von Plasmid-DNA …..............................19

2.2.4 Phenol-Chloroform-Extraktion zur DNA Reinigung ...........................20

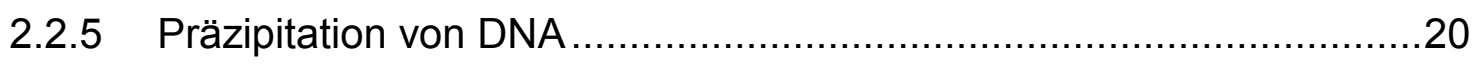

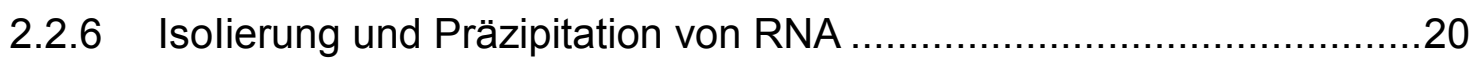

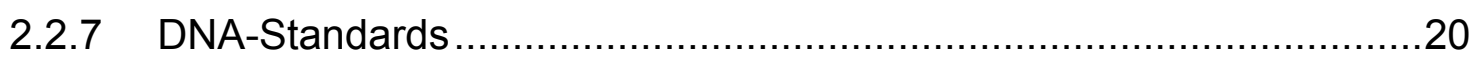

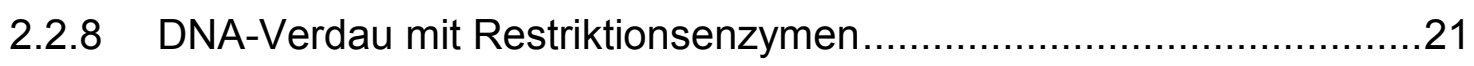

2.2.9 Ligation von DNA-Fragmenten...................................................21

2.2.10 Bestimmung von Reinheit und Konzentration der 


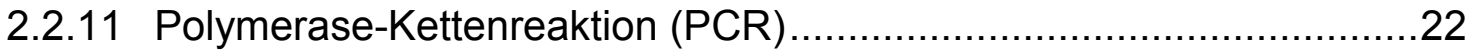

2.2.12 Herstellung kompetenter E. coli Zellen ......................................24

2.2.12.1 Transformationskompetente E. coli-Zellen........................................ 24

2.2.12.2 Elektrokompetente E. coli-Zellen ................................................ 24

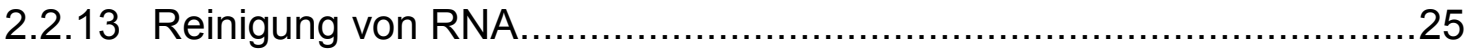

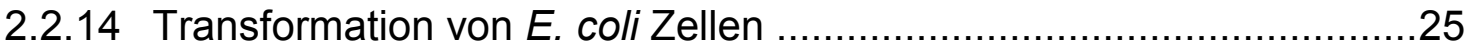

2.2.15 Expression von Prionproteinen mit Semliki Forest Virus

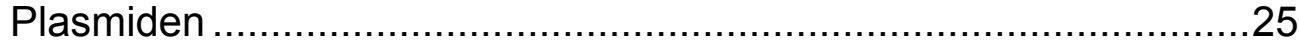

2.2.15.1 In vitro Transkription von Semliki Forest Virus (SFV) Plasmiden .......... 26

2.2.15.2 Elektroporation von BHK-Zellen................................................... 27

2.2.15.3 Herstellung rekombinanter Viruspartikel ........................................ 27

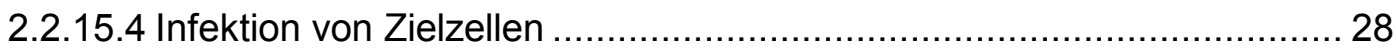

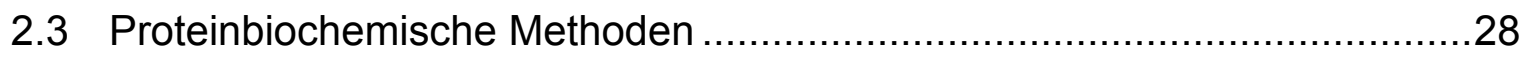

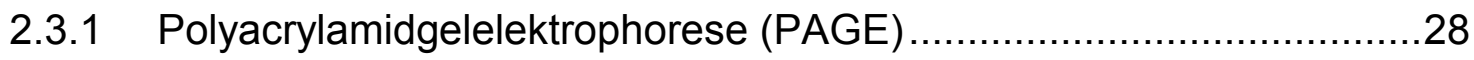

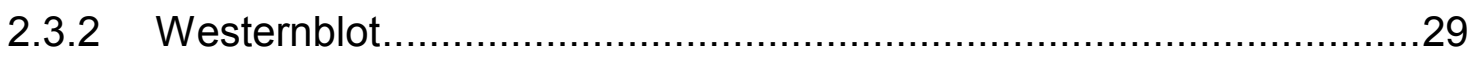

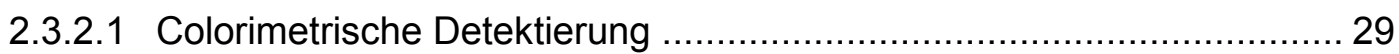

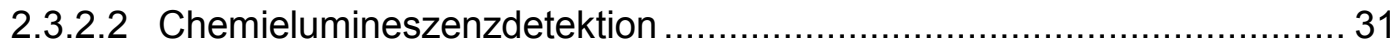

2.3.3 Immunfluoreszenzmikroskopie.......................................................

2.3.4 Herstellung markierter Proteine im Kaninchen-Reticulozyten-

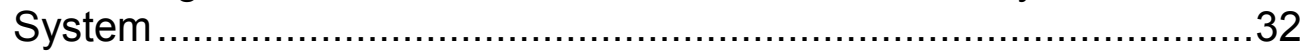

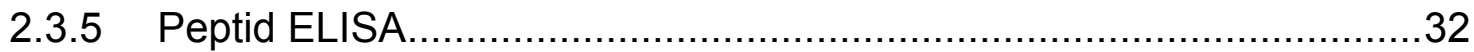

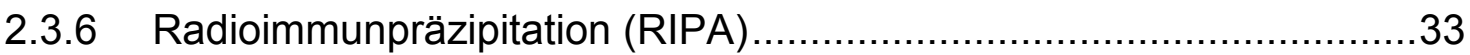

2.4 Fusion von Milzzellen mit permanent wachsenden Myelomzellen ...............34

2.4.1 Präparation von Mausperitonealmakrophagen als Feederzellen

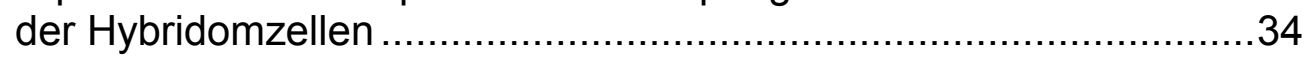

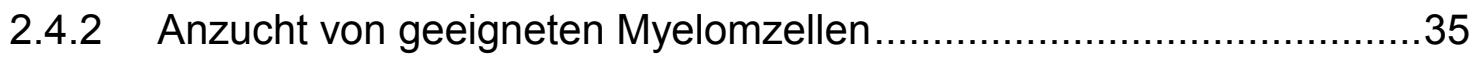

2.4.3 Präparation der Milzzellen einer immunisierten Maus.........................35

2.4.4 Fusion von Maus-Milzzellen mit Myelomzellen ................................36

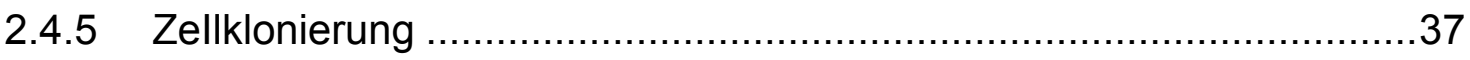

2.4.6 Massenproduktion monoklonaler Antikörper...................................37

2.4.7 Bestimmung der Antikörperklasse und Subklasse ..............................38

2.5 Produktion von rekombinanten Phagenantikörpern ................................... 38

2.5.1 Herstellung von cDNA aus RNA durch reverse Transkription ..............39

2.5.2 Isolierung der ScFv-Fragmenten .................................................. 40

2.5.3 Isolierung rekombinanter Phagenantikörper .....................................40 


\section{Experimente und Ergebnisse}

3.1 Isolierung und Untersuchung von monoklonalen Antikörpern gegen bovines PrP

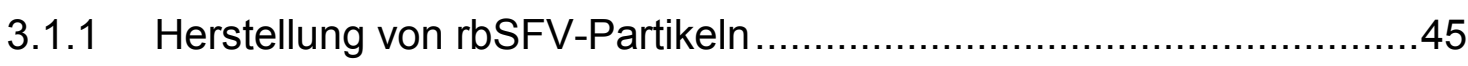

3.1.2 Immunisierung von $\mathrm{PrP}^{0 / 0}$-Mäusen mit rbSFV Partikeln......................48

3.1.3 Fusion von Myelom- und Milzzellen zu Hybridomzellen.....................48

3.1.4 Isolierung von mAk sezernierenden Hybridomzellen .........................51

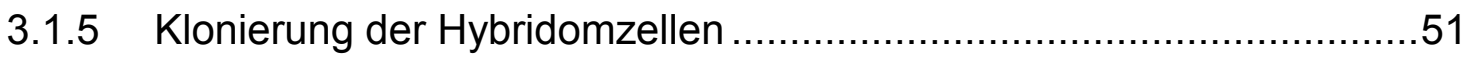

3.1.6 Kultivierung mAk-produzierender Hybridklone zu hohen

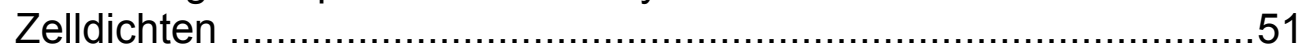

3.2 Molekulare Charakterisierung der monoklonalen Antikörper ......................52

3.2.1 Antiseren immunisierter Mäuse binden an das bovine Prionprotein

3.2.2 Nachweis der monoklonalen Antikörper mit der Immunfluoreszenz.

3.2.3 Untersuchung der Bindungseigenschaften der monoklonalen Antikörper mit Hilfe von Peptiden.

3.2.3.1 Reaktion der mAk mit einem Gemisch der PrP-Peptide im ELISA. 55

3.2.3.2 Epitopspezifische Bindung von Antikörpern im Peptid-ELISA 57

3.2.3.3 Epitop-Kartierung der Antikörper mit einem 114 Peptide enthaltenden Gridded-Arrays.

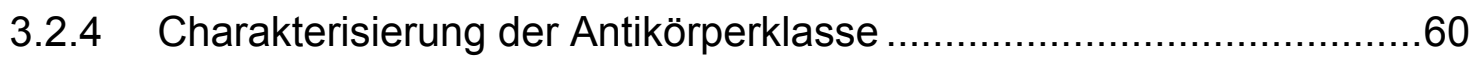

3.2.5 In vitro Synthetisierung von bovinen PrP im Retikulozytenlysat..........61

3.3 Isolierung von Einzelketten-Phagenantikörpern (ScFv) gegen bovine Prionproteine

3.3.1 Klonierung und Sequenzierung der variablen Gen-Domänen der Hybridomzellinien .

3.3.2 Expression und Nachweis der ScFv-Antikörper .................................69

3.3.3 Spezifische PrP-Erkennung im Westernblot ....................................70

4 Diskussion

4.1 Immunisierung von $\mathrm{PrP}^{0 / 0}$-Mäusen mit rbSFV Partikeln und Isolierung von monoklonalen Antikörpern .75

4.2 Charakterisierung der Bindungseigenschaften der monoklonalen Antikörper

4.3 Isolierung und Charakterisierung von ScFv-Phagenantikörpern 
5 Zusammenfassung

$\begin{array}{ll}6 \text { Ausblick } & 87\end{array}$

$\begin{array}{lc}7 \text { Literaturverzeichnis } & 88\end{array}$

Anhang

Tab. A1: Für den "gridded array assay“ im ELISA verwendete bovine PrP-

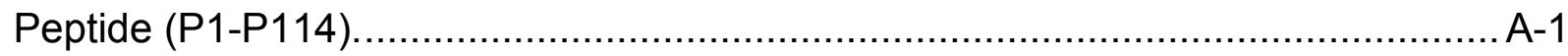

Tab. A2: Im ELISA verwendete Schaf PrP-Peptide (P1-P16). ............................... A-2

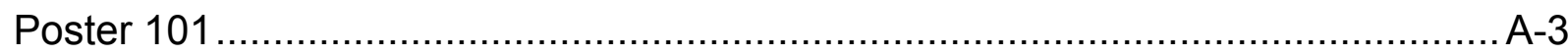




\section{Abkürzungsverzeichnis}

Abkürzung

A

A

ad

Abb.

APS

AS

ATP

BCIP

BHK

$\mathrm{H}_{2} \mathrm{O}$-bidest

bp

BSA

BSE

bzw

C

${ }^{\circ} \mathrm{C}$

CDR

$\mathrm{Ci}$

CJD

CWD

d

dd

DMSO

DNA

DNAse

dNTPs

DPZ

ds

\section{Bedeutung}

Ampere

Purinbase Adenin

adjust

Abbildung

Ammoniumpersuftat

Aminosäure

Adenosintriphosphat

5-Bromo-4-Chloro-3-Indolyl-Phosphat

Hamster Nierenzellen (engl.: baby hamster kidney)

dopellt destilliertes Wasser oder aqua bidestillata

Basenpaare

Rinderserumalbumin (engl.: bovine serum albumine)

Bovine Spongiforme Enzephalopathie

beziehungsweise

Pyrimidinbase Cytosin

Grad Celsius

complement determining region

Curie

Creutzfeldt-Jakob-Erkrankung (engl.: disease)

Chronic Waste Disease

desoxy

didesoxy

Dimethylsulfoxid

Desoxyribonukleinsäure

Desoxyribonuklease

Desoxyribonukleosidtriphosphate

Deutsches Primatenzentrum

doppelstrang 


\begin{tabular}{|c|c|}
\hline DTT & Dithiothreitol \\
\hline E. coli & Escherichia coli \\
\hline EDTA & Ethylendiamintetraessigsäure \\
\hline ELISA & Enzyme-Linked-Immunosorbent-Assay \\
\hline ERG & Eppendorf-Reaktionsgefäß \\
\hline et al. & et alteres \\
\hline $\mathrm{F}$ & Forward Primer in der PCR \\
\hline FCS & Fötales Kälberserum (engl.: fetal calf Serum) \\
\hline $\mathrm{FFI}$ & Fatale Familiäre Insomnie \\
\hline FITC & Fluoreszinisothiocyanat \\
\hline${ }^{35} \mathrm{~S}$ & Radioaktiv markierter Schwefel \\
\hline$g$ & Gramm \\
\hline G & Purinbase Guanin \\
\hline GSS & Gerstmann-Sträussler-Scheinker-Syndrom \\
\hline GTP & Guanosintriphosphat \\
\hline HAT & Hypoxanthin, Aminopterin, Thymin \\
\hline $\mathrm{HAz}$ & Hypoxanthin Azaguanin \\
\hline HGPRT & Hypoxanthin-Guanin-Phosphoribosyl-Transferase \\
\hline IF & Immunfluoreszenz Untersuchung \\
\hline IL-6 & Interleukin-6 \\
\hline kB & Kilobasenpaare \\
\hline $\mathrm{kDa}$ & Kilodalton \\
\hline 1 & Liter \\
\hline LB & Luria Bertani \\
\hline m- & milli $\left(1 \times 10^{-3}\right)$ \\
\hline M & molar \\
\hline mAk & monoklonale Antikörper \\
\hline Min & Minute(n) \\
\hline MOPS & Natriumsalz der 3-N-Morpholino-Propansulfon Säure \\
\hline mRNA & Boten(messenger) Ribonukleinsäure \\
\hline$\mu-$ & mikro $\left(1 \times 10^{-6}\right)$ \\
\hline $\mathrm{n}$ & nano $\left(1 \times 10^{-9}\right)$ \\
\hline $\mathrm{NaAc}$ & Natriumacetat \\
\hline $\mathrm{nt}$ & Nukleotide \\
\hline
\end{tabular}




\begin{tabular}{|c|c|}
\hline NBT & Nitroblau Tetrazolium Salz \\
\hline NP-40 & Nonidet P40 \\
\hline nt & Nukleotid \\
\hline NTP & Nukleosidtriphosphat \\
\hline OD & Optische Dichte \\
\hline OPD & ortho-Phenyldiamin \\
\hline ORF & Offner Leserahmen (engl.: Open Reading Frame) \\
\hline PAGE & Polyacrylamid Gelelektrophorese \\
\hline PBS & $\begin{array}{l}\text { Phosphatgepufterte Kochsalzlösung (engl.: phosphate } \\
\text { buffered salins) }\end{array}$ \\
\hline PCR & $\begin{array}{l}\text { Polymerase Kettenreaktion (engl.: polymerase chain } \\
\text { reaction) }\end{array}$ \\
\hline pfu & plaque forming unit \\
\hline $\mathrm{pH}$ & $\begin{array}{l}\text { Negativer dekadischer Logarithmus der Protonenkonze- } \\
\text { tration }\left(-\log \left[\mathrm{H}^{+}\right]\right)\end{array}$ \\
\hline $\operatorname{PrP}$ & Prionprotein \\
\hline $\operatorname{PrP}^{\mathrm{C}}$ & Prionprotein, Wildtyp \\
\hline $\mathrm{PrP}^{\mathrm{SC}}$ & mit Erkrankung assoziiertes ("Scrapie“") Prionprotein \\
\hline Prion & $\begin{array}{l}\text { proteinöses infektiöses Partikel (engl.: proteinaceous } \\
\text { infectious particle) }\end{array}$ \\
\hline $\mathrm{R}$ & Reverse-Primer in der PCR \\
\hline rbSFV & Rekombinantes bovines SFV \\
\hline RIPA & Radioimmunpräzipitation \\
\hline RNA & Ribonukleinsäure \\
\hline RNAse & Ribonuklease \\
\hline rpm & Umdrehungen pro Minute (engl.: rotations per minute) \\
\hline RPMI & Zellkulturmedium (Roswell Park Memorial Institut) \\
\hline Rt & Raumtemperatur \\
\hline RT & Reverse Transkription \\
\hline SDS & Natriumlaurylsulfat (engl.: Sodiumdodecylsulfat) \\
\hline Sek & Sekunde(n) \\
\hline ss & einzelstrang (engl.: single strand) \\
\hline Std. & Stunde(n) \\
\hline $\mathrm{T}$ & $\begin{array}{c}\text { Pyrimidinbase Thymidin } \\
\text { VII }\end{array}$ \\
\hline
\end{tabular}


Tab.

Tabelle

TAE

Tris-Acetat-EDTA

Taq

Thermus aquaticus

TBE

Tris-Borsäure-EDTA

TBS

Tris gepufferte Salzlösung

TE

Tris-EDTA

TME

Übertragbare Enzephalopathie der Nerze

TEMED

$\mathrm{N}, \mathrm{N}, \mathrm{N}$ ',N'-Tetramethylethylendiamin

Tris

Tris(hydroxymethyl)-aminomethan

TSE

Transmissible Spongiforme Enzephalopathien

U

Enzymaktivitätseinheiten (engl.: units)

UTP

Uracil-5'-triphosphat

UV

Ultraviolett

V

Volumen

V

Volt

w

Gewicht (engl.: weight)

$w / v$

Gewicht pro Volumen

$\times g$

$\mathrm{x}$-fache Erdbeschleunigung $\left(9,81 \mathrm{~m} / \mathrm{s}^{2}\right)$

zB

zum Beispiel 


\section{Abbildungsverzeichnis}

Abb. 1.1: Struktur und Organisation des chromosomalen Prionprotein-Gens bei der Maus.

Abb. 1.2: NMR Struktur und Organisation von Maus $\operatorname{PrP}^{\mathrm{C}}$ und $\operatorname{PrP}^{\mathrm{SC}} \ldots \ldots \ldots \ldots . . . .10$

Abb. 2.1: Herstellung von rekombinanten Phagenantikörpern ........................ 42

Abb. 3.1: Herstellung von monoklonalen Antikörpern ...................................... 45

Abb. 3.2: In vitro Transkription von rbSFV und SFV Helfer II Vektoren ............ 46

Abb. 3.3: Herstellung von rbSFV Partikeln .................................................... 47

Abb. 3.4: Phasenkontrast-Darstellung von Ag8-, Hybridom- und Feederzellen 50

Abb. 3.5: MAk 15G8 reagiert mit bovinem Prionprotein .................................. 54

Abb. 3.6: Aminosäure Sequenzen der Prionproteine ….................................. 56

Abb. 3.7: Reaktivität der acht zu stabilen Ziellinie etablierten Hybridomzellen

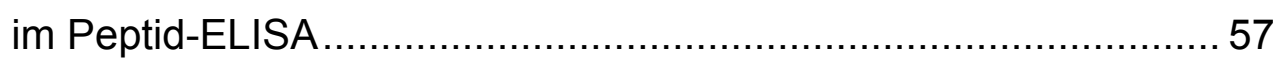

Abb. 3.8: Reaktivität von mAk 15G8 und 17G5 im Peptid ELISA. …............... 58

Abb. 3.9: Epitop-Detektion mit unterschiedlichen monoklonalen Antikörpern. . 60

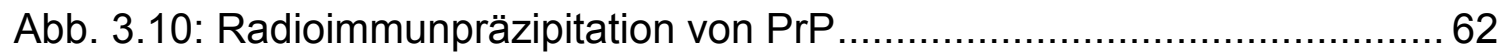

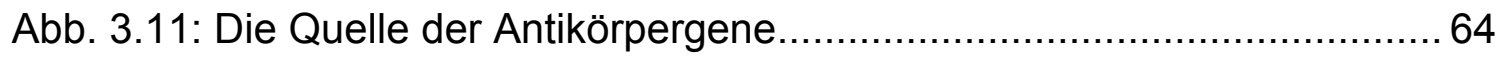

Abb. 3.12: Gesamt-RNA der Hybridomzellen.................................................. 66

Abb. 3.13: Die schweren und leichten Ketten der Hybridome und Nachweis

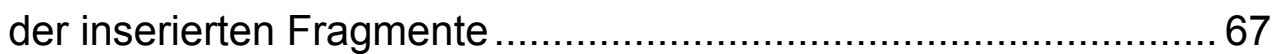

Abb. 3.14: DNA-Sequenz der ScFv-Fragment von pC16G8 …....................... 68

Abb. 3.15: Proteinsequenz des ScFv-Fragmentes pC16G8 ……................... 68

Abb. 3.16: Proteinsequenz der ScFv-Fragmente pC16G8 und 26B8 …...........69

Abb. 3.17: ECL-Westernblot mit rekombinantem humanen PrP ...................... 71 


\section{Tabellenverzeichnis}

Tab. 2.1 Häufig verwendete Puffer und Bakterienmedien................................. 15

Tab. 2.2 Häufig verwendete Zellkulturmedien ............................................ 16

Tab. 2.3 Verwendete Zellinien .......................................................... 17

Tab. 2.4: Zur Transformation wurden folgende Bakterienstämme verwendet. . 17

Tab. 2.5: Die Konzentrationen der Reaktionskomponenten der $V_{S^{-}}$und $V_{L^{-}}$

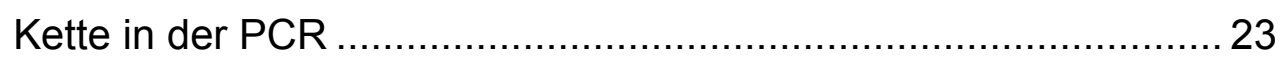

Tab. 3.1 Eigenschaften der der gewonenen PrP-spezifischen monoklonalen

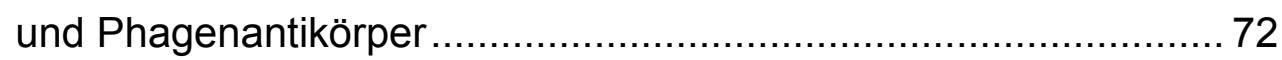

Tab. 4.1 Epitop-Kartierung der mAk und Phagenantikörper ........................... 81

Tab. A1: Für den „gridded array assay“ im ELISA verwendete bovine PrPPeptide (P1-P114)...........................................................

Tab. A2: Im ELISA verwendete Schaf PrP-Peptide (P1-P16)........................A-2 


\section{Einleitung}

\subsection{Transmissible Spongiforme Enzephalopathien (TSE)}

Transmissible Spongiforme Enzephalopathien (TSE) bilden eine Sonderform der übertragbaren Erkrankungen (Prusiner 1987, 1989 und 1991b). Histologisch findet sich eine Degeneration und Verlust von Neuronen. Es kommt zu einer Astrozytenvermehrung und Vernarbung der Glia. Die TSE sind gekennzeichnet durch Vakuolenbildung in den Neuronen sowie durch extrazelluläre Amyloid Ablagerungen ähnlich wie bei Morbus Alzheimer, unterscheiden sich aber von diesen deutlich durch ihre immunologischen Eigenschaften. Spongiforme Enzephalopathien zeichnen sich durch lange Inkubationszeiten aus, die Jahre bis mehrere Jahrzehnte dauern können. Der Erreger ist extrem resistent gegenüber chemischen und physikalischen Faktoren insbesondere gegenüber Hitze, ionisierenden und UV-Strahlen sowie Nukleinsäure-modifizierenden Chemikalien (McKinley et al., 1983b, Bellinger-Kawahara et al., 1987b). Der infizierte Organismus entwickelt keine meßbare humorale oder zellvermittelte Immunantwort gegen den Erreger. Unter experimentellen Bedingungen können TSE auf ein breites Spektrum an Wirten übertragen werden. Eine weitere Besonderheit der TSE Erkrankungen ist es, daß sie sowohl sporadisch übertragbar als auch hereditär auftreten können. Sie unterscheiden sich dabei von allen bisher bekannten Erkrankungen. Sämtliche TSE verlaufen tödlich.

Beim Menschen werden fünf Erkrankungen beobachtet: Die Creutzfeldt-Jakob Erkrankung (CJD) (Creutzfeldt, 1920, Jakob, 1921a und 1921b), die seit 1996 auftretende Variante CJD (vCJD) (Will et al., 1996), das Gerstmann-SträusslerScheinker-Syndrom (GSS) (Gerstmann et al., 1939), die Fatale Familiäre Insomnie (FFI) (Lugaresi et al., 1986, Medori et al., 1992a, 1992b, Mednick et al., 1994) und die Kuru Erkrankung des Fore Stammes im Hochland von Papua-Neuguinea (Klatzo et al., 1957). Auch bestimmte Muskeldystrophien, so die spontane und hereditäre Myositis bzw Myopathie könnten den TSE zugerechnet werden (Sarkozi et al., 1994). 
Klinisch zeigen CJD Patienten am häufigsten Gedächtnisverluste, Demenz, Myoklonien und Ataxien (Roos et al., 1973, Brown et al., 1986 und Gertz et al., 1988). Etwa 85\% der Fälle treten sporadisch auf (Masters et al., 1981, Goldfarb et al., 1990b), die restlichen sind familiäre Fälle (Brown et al., 1986, Masters et al., 1979 und Masters et al., 1981). Neben der iatrogenen Transmission durch kontaminierte Hormonpräparate aus menschlichen Hypophysen (Buchanan et al., 1991) sind auch Infektionen durch die Transplantation der Dura mater und anderer Gewebe von infizierten Patienten (Gibbs et al., 1985 und Fradkin et al., 1991) beschrieben worden. Das Alter von Spontanerkrankten liegt meist zwischen der fünften und siebten Lebensdekade. Der Krankheitsverlauf erstreckt sich über wenige Wochen bis zu 18 Monaten und hängt vornehmlich vom Zeitpunkt der Diagnose ab. Die endgültige Diagnose CJD ist bei lebenden Patienten auf Grund der uncharakteristischen Klinik nur bedingt möglich und kann erst post mortem histologisch erfolgen. Die Einteilung der Patienten erfolgt in mögliche und wahrscheinliche Fälle, wobei eine Vielzahl von Differentialdiagnosen gestellt werden muß, bevor die Diagnose CJD in Betracht gezogen werden darf.

Eine erstmals in Großbritannien und in Frankreich aufgetretene neue Variante von CJD (vCJD) hat seit 1996 mehr als hundert Menschen das Leben gekostet. Diese Erkarankung wird bei verhältnismäßig jungen Patienten (Durchschnittsalter 28 Jahre) mit untypischem Krankheitsbild diagnostiziert (Will et al., 1996, Chazot et al., 1996). Die neue Variante wird zu den spontanen CJD Fällen gerechnet, unterscheidet sich aber von ihnen durch das Fehlen charakteristischer EEG Veränderungen und durch große Plaques, wie sie sonst nur bei übertragbaren Formen vorkommen (Aguzzi und Weissmann,1996a). Diese Variante wird als vCJD bezeichnet. Die Krankheit dauert typischerweise länger als 18 Monate. Ein Zusammenhang mit der Übertragbarkeit von boviner spongiformen Enzephalopathie (BSE) in Großbritannien auf diese vCJD Patienten wurde vermutet (Aguzzi und Weissmann 1996a, Collinge et al., 1996) und indirekt auf Grund neuerer Untersuchungen als wahrscheinlich angenommen (Corth et. al., 1997, Bruce et al., 1997 und 1999, Hill et al., 1997, Knight, 1998, Anderson, 1996).

Bei GSS Patienten kommt es eher zu spinozerebellären Ataxien mit nachfolgender Demenz (Cathala und Baron, 1987). GSS ist gekennzeichnet durch Hypobis Areflexie in den unteren Extremitäten (Farlow et al., 1989). Die Krankheitsdau- 
er liegt normalerweise zwischen zwei und sechs Jahren. GSS ist als autosomal dominant vererbte Krankheit beschrieben worden, allerdings gibt es auch einige wenige sporadische Fälle. Das GSS-Syndrom wurde erstmals von Gerstmann 1936 beschrieben (Gerstmann et al., 1936). Übertragbare Formen sind nicht bekannt.

Die Fatale Familiäre Insomnie (FFI) (Lugaresi et al., 1986) ist ausschließlich eine autosomal dominant vererbte Erkrankung. Es kommt zu schwersten Schlafstörungen und Ataxien. Das Alter der Patienten schwankt zwischen 35 und 61 Jahren. Die Lebenserwartung nach Ausbruch der Krankheit liegt zwischen 7 und 36 Monaten. Die FFI konnte auf Mäuse übertragen (Tateishi et al., 1995) werden.

Die Kuru Erkrankung (Klatzo et al., 1957) wird durch rituellen Kannibalismus übertragen und tritt endemisch im Fore Stamm im Hochland von PapuaNeuguinea auf. Kuru ist gekennzeichnet durch Tremor, Dysarthrie, zerebelläre Ataxie und Demenz. Die Erkrankung dauert zwischen 6 und 16 Monaten und trifft auch Kinder und Jugendliche. Nachdem der Kannibalismus verboten wurde, sind Neuerkrankungen kaum mehr aufgetreten (Alpers et al., 1987).

Bei den Tieren sind vor allem die übertragbaren Erkrankungen bei Rindern BSE (engl. bovine spongiform encephalopathy), Schafen und Ziegen (Scrapie), Katzen FSE (engl.: feline spongiform encephalopathy) Nerzen TME (engl.: transmissible mink encephalopathy) zu nennen (Zlodnik, 1963, Burger et al., 1965, Wells et al.,1987, Pattison, 1988, Wyatt et al., 1990). Zu den bekanntesten TSE der Tiere gehören Scrapie bei Schafen und Ziegen und die Bovine Spongiforme Enzephalopathie (BSE; "Rinderwahnsinn"). Scrapie wurde bereits 1750 erstmals beschrieben, ist aber wahrscheinlich schon länger bekannt (Parry, 1983). Schon 1939 wurde durch experimentelle Übertragung von Schaf zu Ziege gezeigt, daß es sich bei Scrapie um eine übertragbare Erkrankung handelt (Cuille und Chelle, 1939). Ab 1966 wurde kontrovers dazu eine genetische Komponente diskutiert (Gordon, 1966). Der erste BSE Fall wurde 1985 in Großbritannien beobachtet und 1987 zum erstenmal beschrieben (Wells et al., 1987). Es gilt heute als gesichert, daß BSE durch die Verfütterung von unzureichend hitzeinaktiviertem Tierkörperfuttermehl von Scrapie-verseuchten Schafen auf Rinder übertragen wurde (Wilesmith und Wells, 1991). 
Auch bei der FSE und TME wird die Verfütterung von Produkten Scrapieinfizierter Schafe bzw BSE-Rinder als Erkrankungsursache vermutet. Des weiteren kennt man das CWD (engl.: chronic wasting disease) bei Schwarzwedel- Wapitihirschen und (Williams und Young., 1982a,b) und die TSE bei Paarhufern wie zB Kudu und Oryx (Jeffrey und Wells, 1988, Fleetwood und Furley, 1988 und Kirkwood et al., 1990). Unter Laborbedingungen sind die TSE auf eine Vielzahl von Arten zu übertragen (Kimberlin et al., 1990b) darunter auch auf Nagetiere (Chandler und Fisher., 1963 und Zlotnik, 1963) und Menschenaffen (Gajdusek et al., 1966, Gibbs et al., 1968 und Goldfarb et al., 1991a).

\subsection{Die Prionhypothese}

Zunächst ging man unter anderem auf Grund der langen Inkubationszeit davon aus, daß es sich bei dem Erreger um ein bisher unbekanntes sogenanntes "unkonventionelles" oder "slow" Virus handelt (Gajdusek, 1977). Die Suche nach einem herkömlichen Krankheitserreger für die TSE ist bis heute nicht erfolgreich gewesen (Pattison, 1988). Obwohl die infektiösen Gewebe mit Methoden behandelt wurden, die sowohl Viren (Detergenzien, Bestrahlen mit UV-Licht) als auch Bakterien (Autoklavieren bei $120^{\circ} \mathrm{C}$ ) zerstören, konnte weiterhin Infektiösität nachgewiesen werden (Prusiner, 1987, 1989 und 1991b). Ebenfalls war es nicht möglich, eine Nukleinsäure zu isolieren, die man in Zusammenhang mit der Krankheit hätte bringen können (Meyer et al., 1991). Obwohl einige Autoren (Masters et al., 1979, Manuelidis et al., 1988 und 1995, Diringer et al., 1988) von TSE assoziierten Nukleinsäuren berichtet haben, waren ihre Ergebnisse nicht reproduzierbar. Dieses unkonventionelle, Nukleinsäure enthaltende Virus soll sich auf Grund seiner geringen Größe und Komplexität experimentellen Nachweisverfahren bisher entzogen haben (Kimberlin et al., 1990a). Die Akkumulation von beobachtetem Protein wäre nach dieser Theorie nur ein Sekundärprozeß als Konsequenz einer bereits vorher stattgefundenen Virusinfektion und Zellschädigung. Eine Nukleinsäure, die mit den TSE assoziiert wäre, dürfte ein Größe von etwa 50 Basenpaaren nicht überschreiten (Prusiner, 1987, 1989 und 1991b). Dagegen konnte gezeigt werden, daß die Hydrolyse oder Modifikation von Proteinen die Scrapie-Infektiösität deutlich herabsetzt (Prusiner, 1982, Prusiner et al., 1981). 
Stanley B. Prusiner entwickelte daraufhin eine Hypothese, die ein einzelnes Protein für die Krankheit verantwortlich macht (Prusiner, 1982). Die Hypothese besagt, daß das infektiöse Agens ausschließlich oder weitestgehend nur aus einem einzigen Protein oder proteinähnlichen Bestandteil besteht. In Anlehnung an die Abkürzung seiner Hypothese (proteinaceous infectious particle) nannte er das infektiöse Agens Prion. Die Hypothese wurde dementsprechend als Prionhypothese bekannt. Die TSE werden daher auch als Prionerkrankungen bezeichnet.

Die Prionhypothese wird von der Mehrzahl der Wissenschaftler anerkannt. Es ist aber unklar, ob das Prionprotein als alleinige Ursache für die TSE ausreicht. Es wurden Experimente durchgeführt, bei denen man BSE auf Mäuse übertragen hat, obwohl keine abnormen Prionproteine nachgewiesen werden konnten (Lasmezas et al., 1997). Nach der Theorie dieser Autoren erfolgt die Übertragung durch ein noch nicht indentifiziertes Agens. Das Prionprotein ist nur noch bei der Adaption auf eine andere Spezies mit einbezogen. Die Trennung des infektiösen Agens in Gestalt der PrP ${ }^{\mathrm{SC}}$ (engl.: SC; Scrapie) Isoform scheint erstmalig gelungen. Andere Autoren diskutieren, ob ein Kofaktor nötig ist, mit dem aus dem Prionprotein ein Holoprotein gebildet wird (Weissmann, 1991b). Manche Wissenschaftler postulieren auch weiterhin TSE-spezifische Nukleinsäuren als Auslöser für die Erkrankung (Masters et al., 1981, Manuelidis, et al., 1988 und 1995, Diringer et al., 1988).

\subsection{Das Prionprotein}

In den infektiösen Fraktionen konnte als Hauptbestandteil tatsächlich ein Protein identifiziert werden. Nach Anreicherung aus infektiösen Geweben konnte das Protein aufgereinigt und dessen Aminosäuresequenz teilweise bestimmt werden (Bolton et al., 1982). Später wurde dieses Protein als Prionprotein (PrP) oder PrP 27-30 bezeichnet (McKinley et al., 1983a). Nachfolgende Arbeiten zeigten, daß PrP 27-30 von einem größeren Vorläuferprotein mit einem Molekulargewicht von 33-35 kDa (PrP 33-35) stammt (Oesch et al., 1985, Meyer et al., 1986). Mit Hilfe dieser Sequenz wurde eine DNA-Sonde erstellt und das dazugehörige Gen isoliert (Kretzschmar et al., 1986 und Liao et al., 1986). Es zeigte sich, daß es sich um ein endogenes Gen handelte, das für ein $25 \mathrm{kDa}$ Protein kodiert. Dieses Protein wird konstitutiv transkribiert und translatiert, ohne daß Erkrankungen auftreten. Dieser scheinbare Widerspruch konnte dadurch erklärt werden, daß es eine normale und 
eine pathogene Form des Proteins gibt (Basler et al., 1986). Das zelluläre Protein wurde zur besseren Unterscheidung als $\operatorname{PrP}^{\mathrm{C}}\left(\mathrm{C}\right.$; engl. cellular) bezeichnet. $\operatorname{PrP}^{\mathrm{C}}$ ist Protease $\mathrm{K}$ sensitiv. Dagegen ist PrP 27-30 Protease resistent und entsteht durch den partiellen Abbau der mit der Erkrankung assoziierten Form des Prionproteins PrP 33-35 oder auch PrP ${ }^{\mathrm{SC}}$. Weitere Untersuchungen zeigten, daß $\operatorname{PrP}^{\mathrm{C}}$ hochkonserviert und bei vielen Spezies vorhanden ist.

$\mathrm{PrP}^{\mathrm{C}}$ ist ein Sialoglykoprotein mit 253 Aminosäuren (As) bei Menschen, 254 As bei Maus und Hamster, 256 As bei Schaf und Nerz, sowie 264 As bei Rind (Bolton et al., 1985), wobei der gesamte offene Leserahmen (ORF) in nur einem Exon liegt (Basler et al., 1986, Westaway et al., 1987). Das humane Gen ist auf dem Chromosom 20p lokalisiert und besteht aus 2 Exons (Kretzschmar et al., 1986, Puckett et al., 1991). Von diesen beiden kodiert nur das Exon 2 für das Prionprotein. Das Gen der Maus ist auf dem Chromosom 2 lokalisiert und umfaßt 3 Exons, wobei das dritte Exon die kodierende Sequenz enthält. Die anderen beiden Exons werden nicht translatiert (Westaway et al., 1991). Die Abb. 1.1 zeigt schematisch die Struktur des Maus-Priongens. Die posttranslationalen Modifikationen des Proteins finden im endoplasmatischen Retikulum und anschließend im Golgi Apparat statt. Dabei wird vom primären Translationsprodukt das Signalpeptid von $22 \mathrm{~N}$ terminalen Aminosäuren abgespalten. Die letzten 20 Aminosäuren am C-Terminus des Proteins werden durch einen Glykosylphosphatidylinositol-Anker ersetzt (Safar et al., 1990, Stahl et al., 1987, 1990a und 1990b), der über ein Ethanolamin an die Aminosäure 234 (Serin) gebunden wird. Das $\operatorname{PrP}^{C}$ ist zweimal über Asparagin (AS 193 und AS 209) mit N-Acetyl-Glucosamin, Galaktose und sialinsäurehaltigen Zuckerresten N-glykosyliert (Haraguchi et al., 1989, Stahl et al., 1992). Das doppelt glykosylierte $\operatorname{PrP}^{\mathrm{C}}$ besitzt ein Molekulargewicht von etwa $35 \mathrm{kDa}$, die einfach glykosylierte Form ein Molekulargewicht von 29 kDa und die nicht glykosylierte Form ist etwa 25 kDa groß (Endo et al., 1989). Zwischen den Cysteinresten an Position 191 und 226 wird eine Disulfidbrücke ausgebildet. Das Protein wird von der Trans-Golgiseite in Vesikel verpackt und anschließend zur Zellmembran transportiert (Hay et al., 1987b). Die Halbwertzeit beträgt etwa zwei Std. (Caughey und Raymond, 1991). Das Protein ist Protease K sensitiv. Über seine Funktion gibt es keine gesicherten Erkenntnisse. Diskutiert wird eine Funktion bei der interzellulären Erkennung oder der synaptischen Signalübermittlung (Collinge et al., 1994) 
und des Tag-Nacht Rhythmuses (Lugaresi et al., 1986, Medori et al., 1992a und 1992b). Das PrP ist ein kupferbindendes Protein (Wardsworth, et al., 1999, Derer, Dissertation DPZ, 1999, Whittal et al., 2000) das am Schutz vor oxidativem Stress oder synaptischer Interaktion beteiligt ist (Windl et al., 1999). Neulich wurde die Fähigkeit von $\mathrm{PrP}^{\mathrm{C}}$ als Signal transduktor beschrieben (Mouillet-Richard, et al., 2000).

Im Gegensatz dazu ist die pathogene, proteaseresistente Form des Proteins $\left(\mathrm{PrP}^{\mathrm{SC}}\right)$ im Zytoplasma der Zellen lokalisiert (McKinley et al., 1991, Borchelt et al., 1990 und 1992, Caughey et al., 1991 und Caughey und Raymond 1991). Obwohl die Menge an produzierter mRNA in Vergleich zu PrPC konstant ist, erfolgt seine Synthese innerhalb von fünf Std. (Prusiner, 1987). Das PrP ${ }^{\mathrm{SC}}$ Protein ist zusätzlich stark in extrazellulären Plaques angereichert. In diesen Plaques befinden sich oft 6-10 nm Fibrillen aus PrP ${ }^{\mathrm{SC}}$. Diese Akkumulation als endosomale Fibrillen ist eine Folge der angenommenen Degradation durch Proteasen (Taraboulos et al., 1990b und 1992). Ähnliche Fibrillen werden auch bei Alzheimer Patienten gefunden. Eine Degradation durch Proteasen betrifft nur die ersten 69 Aminosäuren des pathogenen Prionproteins. Sämtliche anderen Modifikationen, die bei der normalen PrP 33-35 Form vorkommen, werden bei der $\mathrm{PrP}^{\mathrm{SC}}$-Form ebenfalls durchgeführt. Als Ursache für das Auftreten der $\mathrm{PrP}^{\mathrm{SC}}$-Form konnte alternatives Spleißen der RNA bisher ausgeschlossen werden (Westaway et al., 1987 und 1991). Ein RNAEditing kann grundsätzlich nicht ausgeschlossen werden, auch wenn nach Ansequenzierung des Proteins keine Hinweise dafür gefunden wurden (Blum et al., 1990, Kane et al., 1990). Außer bei den hereditären Formen der übertragbaren spongiformen Enzephalopathien, die durch Mutationen hervorgerufen werden, konnte kein Unterschied zwischen dem Wildtyp und der pathogenen Form festgestellt werden (Tarabolous et al., 1990a und 1990b).

Nach NMR-Untersuchungen der verschiedenen Isoformen konnten Unterschiede in der Tertiärstruktur festgestellt werden. Das PrPC besteht etwa zu 42\% aus $\alpha$-helikalen und zu weniger als $3 \%$ aus $ß$-Faltblatt Strukturen. Im Gegensatz dazu beträgt der $\alpha$-helikale Anteil bei der $\mathrm{PrP}^{\mathrm{SC}}$-Isoform nur $21 \%$ und der $ß$ Faltblatt-Anteil 51\% (Caughey et al., 1991, Huang et al., 1994, Telling et al., 1994). Der Mechanismus des Überganges von der PrPC- zu der PrP ${ }^{\mathrm{SC}}$-Isoform erfolgt demnach durch eine posttranslationale Strukturänderung, die möglicherweise von 
Chaperonen abhängig ist (Liautard, 1991, Carr, 1993, Edenhofer et al., 1996, Priola et al., 1995). Diese vollzieht sich normalerweise spontan, während sie bei der hereditären Form durch die Mutationen begünstigt werden könnte.

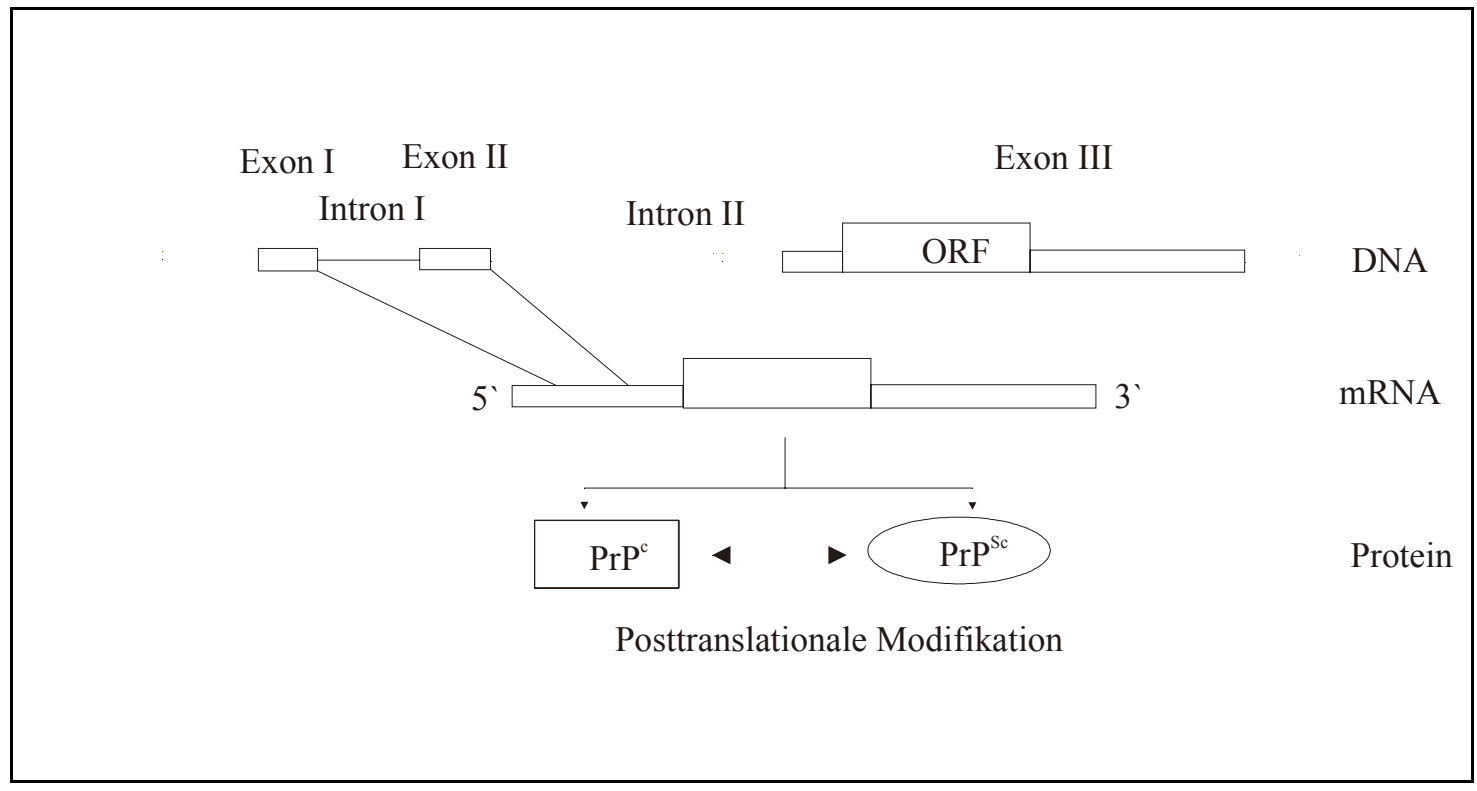

\section{Abb. 1.1: Struktur und Organisation des chromosomalen Prionprotein-Gens} bei der Maus.

Der gesamte offene Leserahmen (ORF) liegt im Exon III. Die Aminosäuresequenzen von $\operatorname{PrP}^{\mathrm{C}}$ und $\operatorname{PrP} \mathrm{P}^{\mathrm{SC}}$ sind identisch. Eine chemische Modifikation, die die beiden Formen unterscheidet, konnte nicht nachgewiesen werden. Die hypothetische Bildung von $\operatorname{PrP}^{\mathrm{SC}}$ aus der zellulären Form $\operatorname{PrP}^{\mathrm{C}}$ durch eine posttranslationale Konformationsänderung ist hier schematisch dargestellt (modifiziert nach Prusiner, 1991).

Alle bisher beschriebenen Mutationen des humanen Priongens liegen in $\mathrm{Re}-$ gionen, die die statistische Wahrscheinlichkeit für eine Umwandlung der räumlichen Faltung des Proteins von einer $\alpha$-Helix in eine $\beta$-Faltblattstruktur erhöhen (Pan et al., 1993). Der autosomal dominante Erbgang bestimmter Prionerkrankungen (GSS, FFI und die familliären Formen der CJD) eröffnete nach der Entdekkung des Priongens beim Menschen die Möglichkeit einer Mutationsannalyse. 1989 konnte gezeigt werden, daß eine Mutation an Kodon 102 des PrP-Gens genetisch mit GSS verknüpft ist (Hsiao et al., 1989). Diese Mutation wurde inzwischen bei mehreren verschiedenen GSS Familien aus 9 unterschiedlichen Län- 
dern nachgewiesen (Dohura et al., 1989, Hsiao et al., 1992, Dlouhy et al., 1992). Die Entdeckung einer Mutation an Position 200 bei CJD-Patienten libyschen Ursprungs folgte (Goldfarb et al., 1990a). Bis heute sind 5 Punktmutationen für CJD (Tyr $145 \rightarrow$ Stop, Asp $178 \rightarrow$ Asn in Kombination mit Val 129 Glu $200 \rightarrow$ Lys, Val $210 \rightarrow$ Ile, Met $232 \rightarrow$ Arg) (Goldfarb et al., 1990c und 1991b, Brown et al., 1992) und 6 bei GSS bekannt (Pro $102 \rightarrow$ Leu, Pro $105 \rightarrow$ Leu, Ala $117 \rightarrow$ Val, Val 180 $\rightarrow$ Met zusammen mit Met $232 \rightarrow$ Arg, Phe $198 \rightarrow$ Ser, Glu $217 \rightarrow$ Arg) (Collinge et al., 1989, Dohura et al., 1989, Kretzschmar et al., 1991). Im Bereich zwischen As 51 und As 91 befinden sich beim gesunden Menschen 5 Oktapeptid Repeatmotive. Bedingt durch Insertionsereignisse wurden bis zu 14 zusätzliche Repeats bei CJD bzw GSS ausgeprägt (Goldfarb et al., 1991a, Owen et al., 1989, 1990, 1991 und 1992, Krasemann et al., 1995). Bei allen bisher bekannten Mutationen im PrP-Gen gibt es eine klare Genotyp-Phänotyp-Assoziation. An Position 129 befindet sich ein verbreiteter Polymorphismus (Methionin zu Valin). Bei einer zusätzlichen Mutation an Kodon 178 (Asp zu Asn) entscheidet jedoch dieser an sich apathogene Polymorphismus darüber, ob der betroffene Patient CJD (Val an As 129) oder aber FFI (Met an As 129) ausprägt (Medori et al., 1992a und 1992b). Zudem konnte gezeigt werden, daß Menschen, die an Kodon 129 homozygot sind, offenbar suszeptibler für iatrogen übertragbare TSE sind als heterozygote (Collinge et al., 1991, Palmer et al., 1991). In der Zwischenzeit wird die Proteaseresistenz der $\mathrm{PrP}^{\mathrm{SC}}$-Form für eine molekulare Zuordnung der Patienten verwendet (Collinge et al., 1996, Aguzzi und Weissmann, 1996). Die drei Formen des Prionproteins (doppelt glykosyliert, einfach glykosyliert und unglykosyliert) zeigen nach Proteaseverdau und anschließendem Nachweis im Westernblot drei Banden. Je nach Ausprägung und Höhe der Banden im Gel ist eine Zuordnung zu den klinischen Fällen der Creutzfeldt-Jakob Erkrankung möglich (Collinge et al., 1996, Aguzzi und Weissmann, 1996). Es wird diskutiert, ob eine solche Diagnose auch an Lymphozyten zB in einer Biopsie der Mandeln durchgeführt werden könnte (Collinge et al., 1997). 


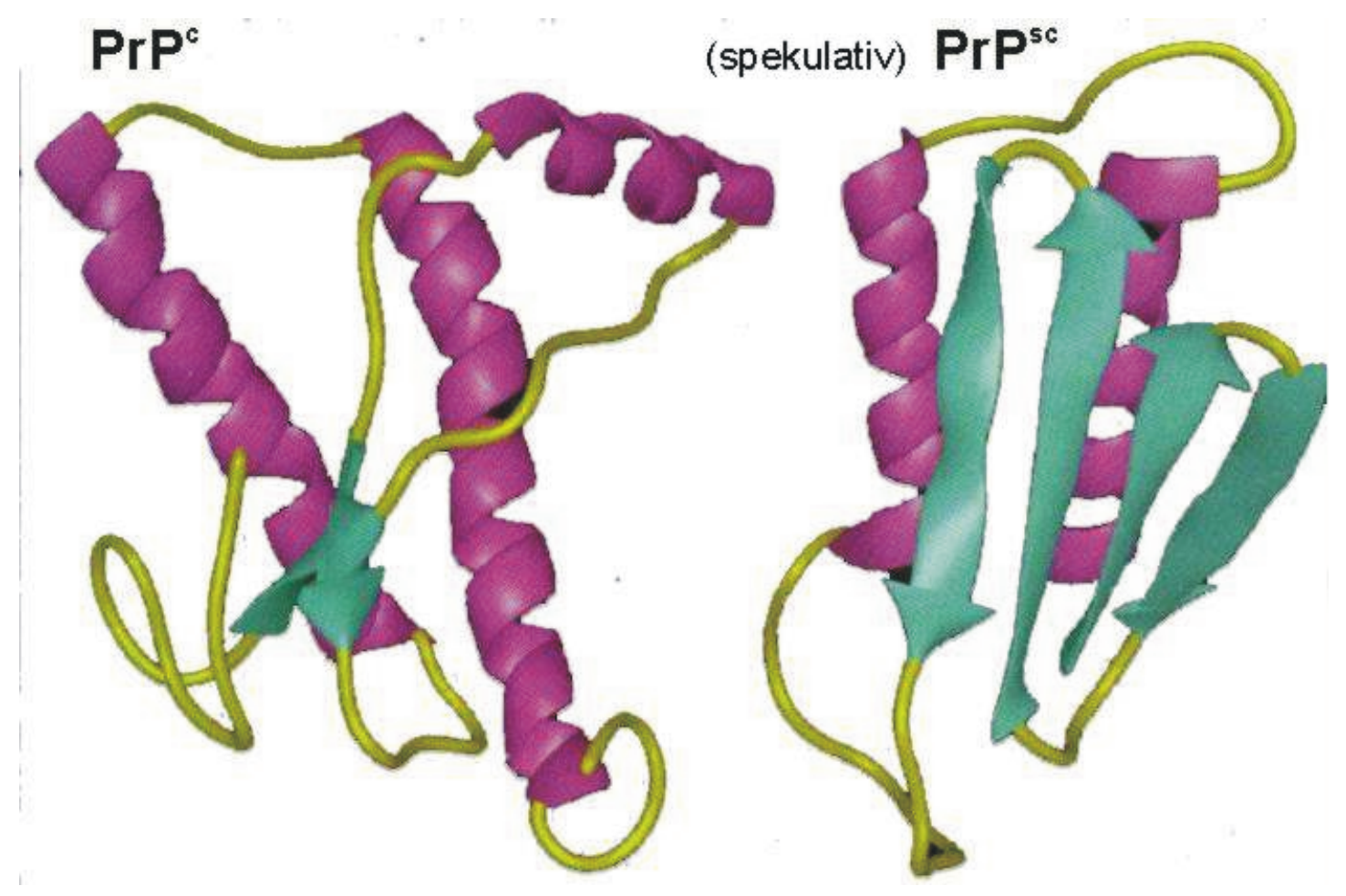

Abb. 1.2: NMR Struktur und Organisation von Maus $\operatorname{PrP}^{\mathrm{C}}$ und $\operatorname{PrP}^{\mathrm{SC}}$

3D Anordnung des Prionproteins von AS 121 bis 231. Die drei Helices sind als violette, die antiparallelbeta-Faltblätter als hellgrüne Pfeile und die Verbindungssequenzen als gelbe Fäden dargestellt. Von NMR abgeleitete Modelle des PrP (Riek et al., 1996). (NMR) kernmagnetische Resonanz. (engl.: nuclear magnetic resonance)

\subsection{Prionprotein defiziente $\operatorname{PrP}^{0 / 0}-$ Mäuse}

Um die Funktion des Proteins $\mathrm{PrP}^{\mathrm{C}}$ im Organismus zu untersuchen, wurden Mäuse hergestellt, deren PrP-Gen durch eine Insertion zerstört worden war (Bueler et al., 1992). Eine für diesen Defekt homozygote, sogenannte $\operatorname{PrP}^{0 / 0}-$ Maus sollte auf Grund des fehlenden Genprodukts Störungen irgendeiner Art aufweisen, die Hinweise auf die Funktion des Prionproteins geben. Wider Erwarten entwikkelten sich die $\mathrm{PrP}^{0 / 0}$-Mäuse aber normal (Bueler et al., 1992). Sie zeigten weder Auffälligkeiten der Physiologie noch im Verhalten. Auch auf die Fertilität hat der Gendefekt keinen Einfluß. Der einzige bisher bekannte Unterschied zu normalen Mäusen ist eine leichte Verzögerung des Aktionspotentials bei der Reizübertra- 
gung zwischen Nervenzellen (Collinge et al., 1994). PrP ${ }^{0 / 0}$-Mäuse, wie die Zürich I (Bueler et al., 1993) und Edinburgh I (Manson et al., 1993), lassen sich nicht mit Prionen infizieren. In Gegensatz dazu entwickelten $\mathrm{PrP}^{0 / 0}$-Mäuse wie die Nagasaki (Sakaguchi et al., 1996) und Rcm0 (Moore et al., 1999) Ataxia bedingt durch den Verlust cerebellarer Purkinje-Zellen. In den ersten zwei Null-Mäusen wurde nur die ORF-Region durch ein Neomycin-resistentes Gen ersetzt, während bei der letzteren zusätzlich zur ORF-Region $0.9 \mathrm{~kb}$ vom Intron II und $0.45 \mathrm{~kb}$ von der nicht kodierenden 3، Region Deletionen eingeführt worden waren. Das neulich entdeckte Prnd-Gen das ein PrP-ähnliches Protein (PrP-doppel) kodiert, konnte diesen Widerspruch erklären (Moore et al., 1999). Für den Defekt heterozygote Mäuse haben gegenüber normalen Wildtyp-Mäusen eine deutlich verlängerte Inkubationszeit (Bueler et al., 1993). Versuche an $\operatorname{Prp}^{0 / 0}$-Mäusen, die Hirngewebstransplantate von $\mathrm{PrP}^{\mathrm{C}}$-überexprimierenden Mäusen erhalten hatten, zeigten, daß nach einer Infektion mit $\mathrm{PrP}^{\mathrm{SC}}$ die Transplantate typische spongiforme Degenerationen entwickelten (Brandner et al., 1996). Das umgebende PrP-defiziente Hirngewebe der $\mathrm{PrP}^{0 / 0}$-Maus zeigte keinerlei pathogene Veränderungen. Deutlich nachweisbare Mengen an $\mathrm{PrP}^{\mathrm{SC}}$ wandern vom Transplantat in das umliegende Gewebe ein. Aber auch nach Einwanderung von $\operatorname{PrP}^{\mathrm{SC}}$ zeigte sich in dem PrP-freien Gewebe kein neurotoxischer Effekt. Damit scheint bestätigt, daß das endogene Prionprotein einen für die Suszeptibilität gegenüber $\mathrm{PrP}^{\mathrm{SC}}$ und für die Replikation von infektiösen Prionen essentiellen Faktor darstellt.

\subsection{TSE Diagnose mit Hilfe von Antikörpern}

Die heute bekannten Tests zur Diagnose der Prionerkrankungen sind nur post mortem einzusetzen (Narang et al. 1987, Wells et al. 1989, Moynagh und Schimmel 1999). Sie konnten bisher jedoch nicht dazu eingesetzt werden, um infizierte Tiere, die sich in der symptomlosen Phasen befinden, aus der Nahrungskette des Menschen auszuschließen. Für einen ante mortem Test hatten verschiedene Arbeitsgruppen versucht neben dem $\mathrm{PrP}^{\mathrm{SC}}$ auch Markerproteine wie 14-3-3 und S100 in der Rückenmarkflüssigkeit nachzuweisen. Leider wurden diese Markerproteine auch während anderer Nervenerkrankungen in großen Mengen im Körper produziert. Daher konnten sie nicht erfolgreich zur spezifischen Diagnose von Prionerkrankung eingesetzt werden (Johns et al. 1996, Lee und Harrington 1997, 
Green et al. 1999, Beekes et al. 1999, Zerr et al 2000). Ohne einen speziesspezifischen und $\mathrm{PrP}^{\mathrm{SC}}$ spezfischen monoklonalen Antikörper ist die rechtzeitige Diagnose der Prionenerkrankungen schwierig. Neulich wurde die Fähigkeit des im Blutserum vorkommenden Proteins Plasminogen spezifisch an $\operatorname{PrP}^{\mathrm{SC}} \mathrm{zu}$ binden von Fischer et al. (2000) beschrieben.

Bisherige Befunde zeigen, daß es keine spezifische oder unspezifische Immunantwort des mit $\mathrm{PrP}^{\mathrm{SC}}$ infizierten Organismus gibt. Gleiches gilt auch für nicht humane TSE. Es gibt zur Zeit keine Therapie für die Prionerkrankungen und daher verlaufen alle tödlich. Modifizierte Antikörper könnten aber in Zukunft zur Therapie eingesetzt werden. Hybridomantikörper aus der Maus können bisher für menschliche Anwendungen nicht wirkungsvoll eingesetzt werden, da die humane anti-Maus Antikörper Immunantwort (HAMA-Imunnantwort) nach kurzer Zeit zu einer Ausschaltung des Maus-Antikörpers führt. Da sich die Wirkung des menschlichen Immunsystems gegen den Fc-Teil des Antikörpers richtet, kann der Austausch des Maus-Fc-Teils gegen eine Domäne vom Menschen zu einer deutlich abgeschwächten HAMA-Antwort führen. Solche Chimäre binden aber noch spezifisch an das Antigen. Andererseits kann man aber auch die hypervariablen Bereiche eines Mausantikörpers in einen menschlichen Antikörper verpflanzen. Auch in diesem Fall wird das menschliche Immunsystem keine Abwehrmechanismen einleiten. Für viele therapeutische Anwendungen ist es sinnvoll, modifizierte Antikörper zu verwenden, die neben dem Antikörper, der nur zum Andocken an Zielzellen dient, noch einen therapeutisch wirksamen Anteil mit sich führten. Dieser Teil wird auch als heterologer Fusionspartner bezeichnet und kann aus Toxinen, Enzymen, Cytokinen, und radioaktiven Nukleotiden bestehen. Fusioniert man zB ein Toxin mit einem tumorspezifischen Antikörper, so kann durch die spezifische Einwirkung auf die Zielzelle eine Abtötung erreicht werden, wobei gesunde Zellen aufgrund der Antikörperselektivität weitgehend verschont bleiben. (Vittetta et al., 1993, Reiter et al., 1996). 


\subsection{Aufgabenstellung}

Trotz vielfacher wissenschaftlicher Bemühungen ist es bislang immer noch nicht gelungen, mAk oder Phagenantikörper zu isolieren, um die Prionerkrankungen beim Menschen oder im Tier vor dem Ausbruch der Krankheit zu diagnostizieren. Auch der genaue Infektionsweg der Erkrankung und die Überwindung der Artengrenze vom Schaf zum Rind und die vom Rind zum Menschen sind bisher noch nicht umfassend geklärt (Hill et al., 2000). Obwohl es seit 1998 vier verschiedene post mortem BSE-Tests gibt, erkennen diese nur Erkrankungen, die mindestens drei Jahre alt und zudem schon hochinfektiös sind (Moynagh und Schimmel, 1999).

In dieser Arbeit sollen mAk und ScFv-Phagenantikörper (engl.: single chain variable fragment) hergestellt werden, die in späteren Arbeiten zur Klärung diagnostischer und molekularbiologischer Fragen verwendet werden können. Wünschenswert wäre es, einen Antikörper zu erhalten, der sowohl speziesspezifisch ist, als auch zwischen den beiden Isoformen $\mathrm{PrP}^{\mathrm{C}}$ und $\mathrm{PrP}^{\mathrm{SC}}$ unterscheiden kann. Die Anwendung von in Bakterien hergestellten rekombinanten Phagenantikörpern und die von diesen abgeleiteten kleineren löslichen ScFv-Fragmenten können zu einem besseren Verständnis des Krankheitsablaufes und zur Entwicklung neuer Diagnostik- und Therapieansätze beitragen. Diese ScFv-Fragmenete könnten auf Grund ihrer Größe auch zur intrazellulären Verfolgung der PrP-Proteinbiosynthese in vivo eingesetzt werden.

Im ersten Teil der Dissertation sollen $\mathrm{PrP}^{0 / 0}$-Mäuse mit rekombinanten bovinen Semliki Forest Virus Partikeln (rbSFV) immunisiert werden. Die immunisierten Mäuse stellen polyklonale Antikörper gegen die fremden Prionproteine her, da sie kein eigenes Prionprotein besitzen und deshalb keine Toleranz gegen das PrP zeigen. Die rbSFV-Injektion als Immunisierungsmethode vermeidet den direkten Umgang mit pathogenen Proteinen. Die bovinen Priongene werden stattdessen intrazellulär exprimiert, prozessiert und dem Immunsystem präsentiert. Zu diesem Zweck soll der für das bovine Prionprotein kodierende Bereich in ein Semliki Forest Virus Plasmid (pSFV I) kloniert werden. Die Immunisierung soll durch Injektion der Mäuse mit rbSFV-Partikeln erfolgen, die bovines Prionprotein exprimieren. Zur Produktion der mAk sollen die Milzzellen mit Myelomzellen fusioniert werden. Die 
Antikörperproduktion soll zuerst in einem Immunfluoreszenztest und dann in einem Peptid ELISA untersucht werden. Der ELISA kann erste Hinweise liefern, ob die mAk zwischen $\operatorname{PrP}^{\mathrm{C}}$ und $\operatorname{PrP}^{\mathrm{SC}}$ unterscheiden können. Hybridklone, die mAk gegen bovines Prionprotein produzieren, sollen dann als stabile Zellinie etabliert werden. Im zweiten Teil der Arbeit sollen aus diesen Hybridomzellinien mit Hilfe der PCR die Gene für die schweren und leichten Antikörperketten isoliert und zu einem ScFv-Antikörper ligiert werden. Dieser soll in den pCANTAB Vektor ligiert werden. Um Phagenantikörper zu produzieren, sollen mit diesen Phagemid E. coli Bakterien elektroporiert werden. Die in Bakterien hergestellten Phagenantikörper sollen erst im Peptid-ELISA und dann im Westernblot auf ihre Eigenschaften PrP zu binden untersucht werden. Zudem bietet sich in der ScFv-Technik, im Gegensatz zur Hybridomtechnik, die Möglichkeit an, die Bindungseigenschaften des Antikörpers gentechnisch zu verändern und gegebenenfalls die Bindungsstärke zu modifizieren. 


\section{Material und Methoden}

\subsection{Material}

\subsubsection{Chemikalien}

Alle nicht gesondert aufgeführten Chemikalien wurden von den Firmen Merck (Darmstadt), Hoechst (Frankfurt) und Serva (Heidelberg) im jeweils höchsten Reinheitsgrad bezogen. Alle Lösungen, Medien und Puffer wurden mit $\mathrm{H}_{2} \mathrm{O}$-bidest angesetzt, anschließend sterilfiltriert oder, wenn möglich, bei $121^{\circ} \mathrm{C}$ für $45 \mathrm{Min}$ autoklaviert. Radioaktive Substanzen wurden von den Firmen Amersham-Buchler (Braunschweig) und Du Pont (Bad Homburg) bezogen.

\subsubsection{Puffer und Medien}

Tab. 2.1 Häufig verwendete Puffer und Bakterienmedien

\begin{tabular}{ll}
\hline Bezeichnung & Zusammensetzung \\
\hline PBS & $120 \mathrm{mM} \mathrm{NaCl}, 17 \mathrm{mM} \mathrm{Na}{ }_{2} \mathrm{HPO}_{4}, 3 \mathrm{mM} \mathrm{KH}_{2} \mathrm{PO}_{4}, \mathrm{pH} 7,2$ \\
TE & $10 \mathrm{mM}$ Tris-HCl, $1 \mathrm{mM}$ EDTA, $\mathrm{pH} 8,0$ \\
TAE & $40 \mathrm{mM}$ Tris-Acetat, $2 \mathrm{mM}$ EDTA, pH 8,0 \\
TBE & $0,1 \mathrm{M}$ Tris-HCl, 0,1 M Borsäure, $2 \mathrm{mM}$ EDTA, pH 8,0 \\
LB-Medium & $1 \%$ Bacto-Trypton, 0,5\% Hefeextrakt, 1\% NaCl (w/v) \\
LB-Agar & $1,5 \%$ Agar (w/v) in LB-Medium \\
\hline
\end{tabular}


Tab. 2.2 Häufig verwendete Zellkulturmedien

\begin{tabular}{|c|c|}
\hline Bezeichnung & Zusammensetzung \\
\hline BHK-Zell-Medium & $\begin{array}{l}\text { Roswell Park Memorial Institute Medium } 1640 \text { (RPM } \\
\text { 1640, Gibco, USA) mit 7\% (v/v) hitzeinaktiviertem FCS, } \\
2 \mathrm{mM} \text { Glutamin, } 50 \mathrm{U} / \mathrm{ml} \text { Penicillin und } 50 \mu \mathrm{g} / \mathrm{ml} \text { Strep- } \\
\text { tomycin }\end{array}$ \\
\hline $\begin{array}{l}\text { Elektroporations- } \\
\text { Medium für BHK }\end{array}$ & $\begin{array}{l}\text { Glasgow MEM (Gibco) mit 5\% (v/v) FCS, } 2 \text { mM Gluta- } \\
\text { min } 20 \mathrm{mM} \text { HEPES, } 10 \%(\mathrm{v} / \mathrm{v}) \text { Tryptose Phospat Brühe, } \\
50 \mathrm{U} / \mathrm{ml} \text { Penicillin, } 50 \mu \mathrm{g} / \mathrm{ml} \text { Streptomycin }\end{array}$ \\
\hline $\begin{array}{l}\text { BHK-Mangel- } \\
\text { medium }\end{array}$ & $\begin{array}{l}\text { MEM (Gibco) mit 0,2\% BSA, } 20 \mathrm{mM} \text { HEPES } 2 \mathrm{mM} \\
\text { Glutamin, } 50 \mathrm{U} / \mathrm{ml} \text { Penicillin, } 50 \mu \mathrm{g} / \mathrm{ml} \text { Streptomycin }\end{array}$ \\
\hline $\begin{array}{l}\text { Hybridom/-Ag8- } \\
\text { Medium }\end{array}$ & $\begin{array}{l}\text { RPMI 1640, } 20 \% \text { Medium 199, 10\% FCS, } 2 \mathrm{mM} 50 \\
\text { U/ml Penicillin, } 50 \mathrm{\mu g} / \mathrm{ml} \text { Streptomycin }\end{array}$ \\
\hline Medium 20 & Hybridommedium mit $20 \%$ FCS \\
\hline HAT-Medium & $\begin{array}{l}\text { Hybridommedium mit } 15 \% \text { FCS, } 100 \mu \mathrm{M} \text { Hypoxanthin, } \\
400 \mathrm{nM} \text { Aminopterin, } 16 \mu \mathrm{M} \text { Thymidin }\end{array}$ \\
\hline HT-Medium & $\begin{array}{l}\text { Hybridommedium mit 15\% FCS, } 100 \mu \mathrm{M} \text { Hypoxanthin, } \\
16 \mu \mathrm{M} \text { Thymidin }\end{array}$ \\
\hline
\end{tabular}

Alle Medien wurden mit $\mathrm{H}_{2} \mathrm{O}$-bidest angesetzt. Das LB-Medium und der LB-Agar wurden $45 \mathrm{Min}$ bei $121^{\circ} \mathrm{C}$ autoklaviert auf $50^{\circ} \mathrm{C}$ abgkühlt und je nach Verwendungszweck mit Antibiotikum versetzt. Zellkulturmedien wurden durch Filtrieren sterilisiert. 


\subsubsection{Zellen}

Tab. 2.3 Verwendete Zellinien

\begin{tabular}{lll}
\hline Zellinie & Ursprung & Bezugsquelle \\
\hline BHK-Zellen & Baby Hamster kidney & ATCC CL-13 \\
Ag8-Zellen & Maus Myelom & ATCC CRL-1580 \\
N2A-Zellen & Neuroblastom & ATCC-CCL-131 \\
\hline
\end{tabular}

\subsubsection{Escherichia coli (E. coli) Stämme}

Tab. 2.4: Zur Transformation wurden folgende Bakterienstämme verwendet.

JM 109 endA1, recA1, gyrA96, thi, hsdR17 $\left(r_{k}{ }^{-}, m_{k}^{+}\right)$, relA1, supE44, $\Delta$ (lac-proAB), [F', traD36, proAB, laqlqZ $\Delta \mathrm{M} 15]$

$\mathrm{DH}-5 \alpha$ supE44, $\Delta$ lacU169, (Ф80 $\Delta$ lacZ M15), relA1, hsdR17, recA1, end $A 1$, gyrA96, thi-1

TG-1 $\mathrm{K} 12, \Delta$ (lac-pro), supE, thi, hsdD5/F'traD36, $\operatorname{pro}^{+} \mathrm{B}^{+}$, laqlq, lacZ $\Delta \mathrm{M} 15$

\subsection{Molekulargenetische Methoden}

\subsubsection{Agarosegelelektrophorese und Extraktion von Nukleinsäuren aus Aga- rosegelen}

Die PCR-Amplifikate wurden auf 1\%igen Agarosegelen elektrophoretisch aufgetrennt (Sambrook et al., 1989). Die Agarose wurde in $130 \mathrm{ml}$ TBS-Puffer für (RNA-Gele) und in $130 \mathrm{ml}$ TAE-Puffer für (DNA-Gele) aufgekocht, $4 \mu \mathrm{l}$ Ethidiumbromidlösung $(0,1 \% \mathrm{w} / \mathrm{v})$ zugegeben und die Gel-Lösung zum Erkalten auf eine 
horizontale Gelbrücke gegossen. Die Proben wurden mit 0,1 Volumen Probenpuffer (50\% Glycerin, 100 mM EDTA, 0,1\% Bromphenolblau, 1\% SDS, (w/v)) versetzt und in die Geltaschen gegeben. Als Längenstandard wurde $1 \mu \mathrm{g} 1$ kB-DNA-Ladder (von 75-12218 bp Länge, Gibco) (Hartley und Gregor 1981) in Probenpuffer verwendet. Die Elektrophorese erfolgte bei einer konstanten Spannung von $100 \mathrm{~V}$ für 60-70 Min in einer Horizontalelektrophoresekammer (Biotec-Fischer) mit 1x TBE bzw 1x TAE als Laufpuffer. Die DNA-Banden wurden auf einem Transilluminator durch UV-Licht bei einer Wellenlänge von 302nm sichtbar gemacht und mit einer CCD-Kamera fotografiert.

DNA-Fragmente, die zur Klonierung eingesetzt werden sollten, wurden unter UV-Licht mit einem Skalpell aus dem Agarosegel ausgeschnitten und mit dem QIAEX II Gel Extraktions-Kit (Qiagen, Hilden) isoliert. Dazu wurden die Gelstücke mit dem dreifachen ihres Volumens mit Solubilisierungspuffer QX1 versetzt und bei $56^{\circ} \mathrm{C}$ in Thermoblock geschmolzen. Anschließend wurden $10 \mu$ l suspendierte Glasmilch zugegeben und der Ansatz für 30 Min unter gelegentlichem Schwenken bei $56^{\circ} \mathrm{C}$ inkubiert. Die mit DNA beladenen Glaspartikel wurden dann bei $11.000 \mathrm{x}$ g abzentrifugiert, einmal mit Puffer QX I und zweimal mit PE-Puffer gewaschen und getrocknet. Zur Elution der DNA wurden $20 \mu$ TE-Puffer zugesetzt und unter gelegentlichem Schütteln für 30 Min bei $56^{\circ} \mathrm{C}$ inkubiert. Die Glasmilch wurde schließlich durch Zentrifugation für 1 Min bei 11.000 x g aus dem Eluat entfernt.

Eine 1-5 $\mu$ l Probe des Eluats wurde auf ein 1\%iges Agarosegel aufgetragen und die Konzentration anhand bekannter Mengen von Marker-DNA geschätzt.

\subsubsection{Minipräparation von Plasmid-DNA}

Es wurden Einzelkolonien von einer Agarplatte entnommen, in $2 \mathrm{ml}$ LBMedium mit Ampicillin suspendiert und die Kultur über Nacht bei $37^{\circ} \mathrm{C}$ im Rundschüttler inkubiert. Die Bakteriensuspension wurde in $2 \mathrm{ml}$ EppendorfReaktionsgefäße (ERG) überführt und die Zellen durch 5-minütige Zentrifugation bei 1200 Upm geerntet. Der Überstand wurde verworfen und das Pellet in $200 \mu \mathrm{l}$ Lösung 1 (50 mM Glukose, 25 mM Tris pH 8,0 und 10 mM EDTA) mit 4 mg/ml Lysozym suspendiert, durchmischt und 5 Min bei Rt belassen. Anschließend wurden $400 \mu \mathrm{l}$ frisch angesetzte Lösung 2 (0,2 NaOH, 1\% SDS) zur Suspension gegeben, gemischt und die Probe 5 Min auf Eis gehalten. Es wurden dann $300 \mu l$ 7,5 
M Ammoniumacetatlösung zugemischt, 10 Min auf Eis inkubiert und 5 Min bei 1100 x g zentrifugiert.

Der Überstand wurde in ein Eppendorf-Reaktionsgefäß (ERG) pipettiert, mit 0,6-1 Volumen Isopropanol versetzt und für 10 Min bei Rt belassen. Nach der Zentrifugation für 30 Min bei 11000 x g wurde das Pellet mit $500 \mu \mathrm{l} 70 \%$ (v/v) Ethanol gewaschen getrocknet und in $100 \mu \mathrm{l}$ TE-Puffer $\mathrm{pH}$ 8,0 (10 mM Tris- $\mathrm{HCl}$ und $1 \mathrm{mM}$ EDTA) mit $1 \mu \mathrm{l}$ RNAse $(1 \mathrm{mg} / \mathrm{ml})$ aufgenommen.

\subsubsection{Midi- und Maxipräparation von Plasmid-DNA}

Präparationen von Plasmid-DNA aus E. coli Kulturen mit einem Volumen von 30-150 ml (Midi) bzw 500 ml (Maxi) wurden mit dem Quiagen-pack 100 bzw 500 (Qiagen, Hilden) nach Angaben des Herstellers durchgeführt.

Dazu wurden E. coli Bakterien 24 Std. kultiviert. Die Zellen wurden dann kurz zentrifugiert und das Bakterienpellet in 4 ml bzw 10 ml Puffer P1 (pH 8,0, RNAse A (100 $\mu \mathrm{g} / \mathrm{ml}), 50 \mathrm{ml}$ Tris/HCl, $10 \mathrm{mM}$ EDTA) suspendiert, mit 4 ml bzw $10 \mathrm{ml}$ Puffer $2(200 \mathrm{mM} \mathrm{NaOH}, 1 \%$ SDS) gemischt und 5 Min bei Rt inkubiert. Anschließend wurden $4 \mathrm{ml}$ bzw $10 \mathrm{ml}$ vorgekühlter Puffer 3 (pH 7,0, 2,55 M KAc) hinzugegeben, gemischt und das Lysat für $15 \mathrm{Min}$ auf Eis belassen. Nach Zentrifugation bei $4^{\circ} \mathrm{C}$ für 30 Min bei $3000 \times \mathrm{g}$ wurde der Überstand in ein neues ERG überführt und erneut für $15 \mathrm{Min}$ bei $4^{\circ} \mathrm{C}$ und $3000 \times \mathrm{g}$ zentrifugiert. Der erhaltene Überstand wurde auf eine mit $4 \mathrm{ml}$ bzw $10 \mathrm{ml}$ Puffer QBT (pH 7,0, $750 \mathrm{mM} \mathrm{NaCl}, 50 \mathrm{mM}$ MOPS, 15\% Ethanol) voräquilibrierte Quiagentip 100 Säule aufgetragen. Die Säule wurde $2 \times$ mit $10 \mathrm{ml}$ Puffer QC (pH 7,0,1 M NaCl, 50 mM MOPS, 15 mM Ethanol) gewaschen und die Plasmid-DNA mit $5 \mathrm{ml}$ bzw $15 \mathrm{ml}$ Puffer QF (pH 8,0, 1,2 M NaCl, $50 \mathrm{mM}$ MOPS, 15\% Ethanol) eluiert. Die DNA wurde mit 0,7 Volumen Isopropanol präzipitiert, pelletiert und mit 70\% (v/v) Ethanol gewaschen. Nach dem Trocknen wurde das Pellet in TE-Puffer mit $1 \mu \mathrm{l}$ RNAse $(1 \mathrm{mg} / \mathrm{ml})$ suspendiert. 


\subsubsection{Phenol-Chloroform-Extraktion zur DNA Reinigung}

Ein Phenol-Chloroform-Isoamylalkohol-Gemisch $(25: 24: 1, \mathrm{v} / \mathrm{v})$ wurde eingesetzt, um DNA von Proteinen zu reinigen. Die zu extrahierenden DNA-Proben wurden mit einem gleichen Volumen Phenol-Chloroform-Isoamylalkohol-Mischung versetzt und intensiv gemischt. Die Phasentrennung erfolgte in einer Eppendorftischzentrifuge bei $3000 \times \mathrm{g}$ für 2-5 Min. Die wäßrige Phase wurde in ein neues ERG überführt und die Extraktion solange wiederholt, bis keine Proteinreste mehr in der Interphase sichtbar waren. Um Phenolreste aus der DNA-Lösung zu entfernen, wurde diese in gleicher Weise dreimal mit Chloroform extrahiert. Anschließend wurde die DNA mit Ethanol präzipitiert.

\subsubsection{Präzipitation von DNA}

Um DNA zu konzentrieren und zu entsalzen, wurden die wäßrigen DNALösungen mit 1/10 Volumen $3 \mathrm{M}$ Na-Acetat und dem zweieinhalbfachen Volumen eiskaltem 96\%igem Ethanol versetzt. Nach der Präzipitation wurde die DNA für mindestens eine Stunde bei $-80^{\circ} \mathrm{C}$ aufbewahrt, anschließend 15 Min bei $4^{\circ} \mathrm{C}$ mit $11000 \times \mathrm{g}$ zentrifugiert und der Überstand verworfen. Zum Entsalzen wurde das Pellet mit 70\% (v/v) Ethanol gewaschen und getrocknet. Das DNA-Pellet wurde in einem geeignetem Volumen $\mathrm{H}_{2} \mathrm{O}$-bidest suspendiert.

\subsubsection{Isolierung und Präzipitation von RNA}

Zytoplasmatische RNA wurde aus kultivierten Hybridomzellen mit dem RNAesy RNA-Isolierungskit (Qiagen, Hilden) gemäß den Angaben des Herstellers isoliert. Um die RNA stabil zu lagern, wurde sie bis zur Weiterverarbeitung bei $20^{\circ} \mathrm{C}$ unter Ethanol aufbewahrt. Die Ausbeute an RNA lag pro $10^{6}$ Hybridomzellen bei durchschnittlich $1 \mu \mathrm{g}$ RNA.

\subsubsection{DNA-Standards}

Für die Analyse von DNA Fragmenten auf Agarosegelen wurden die DNAStandards $1 \mathrm{~kb}$ oder 100bp-DNA-Ladder (GibcoBRL Lifescience, Karlsruhe) verwendet. Die DNA-Standards enthalten verschieden große Fragmente, die bei der 
Elektrophorese entsprechend ihrer Masse unterschiedlich weit im Gel laufen. Anhand dieser Laufstufen läßt sich die Masse der PCR Produkte abschätzen.

\subsubsection{DNA-Verdau mit Restriktionsenzymen}

Der Verdau mit Restriktionsenzymen diente zur Spaltung von DNAFragmenten und zur Überprüfung ihrer Struktur. Es wurden jeweils 4-10 U Enzym pro Verdau eingesetzt. Die Restriktionsansätze wurden unter Verwendung der vom Hersteller mitgelieferten Reaktionspuffer für 1-2 Std. bei $50^{\circ} \mathrm{C}$ mit Sfi I und bei $37^{\circ} \mathrm{C}$ mit Not I inkubiert und anschließend zur visuellen Überprüfung im Agarosegel aufgetrennt. Sollte der Ansatz für eine Ligation weiter verwendet werden, wurde lediglich ein Teil durch Agarosegelelektrophorese aufgetrennt und die Effizienz des Verdaus visuell überprüft. Der Rest wurde für $30 \mathrm{Min}$ bei $85^{\circ} \mathrm{C}$ hitzeinaktiviert, dann direkt weiterverarbeitet oder durch Präzipitation der DNA von Salzen gereinigt. Bei Verdau mit mehreren Enzymen, deren Pufferbedingungen sich unterschieden, wurde zuerst mit dem bei einer niedrigen Salzkonzentration aktiven Enzym geschnitten, dann die Salzkonzentration entsprechend erhöht und mit dem zweiten Enzym weiterverdaut.

\subsubsection{Ligation von DNA-Fragmenten}

Für die Ligation von ScFv-DNA-Fragmenten in der pCANTAB $5 \mathrm{E}$ Phagemidvektor wurde ein Gemisch der entsprechenden Fragmente in Ligasepuffer (50 mM Tris- $\mathrm{HCl}, \mathrm{pH} 7,6,10 \mathrm{mM} \mathrm{MgCl} 2,1 \mathrm{mM}$ ATP, $1 \mathrm{mM}$ DTT, 5\% [w/v] PEG 8000) mit 5U T4-DNA-Ligase (Promega, Heidelberg) versetzt und über Nacht bei $14^{\circ} \mathrm{C}$ inkubiert. Es wurde ein molares Verhältnis von Vektor zu Insert-DNA von 1:2 eingesetzt. Der Ligationsansatz wurde anschließend direkt zur Elektroporation elektrokompetenter E. coli-Zellen verwendet. 


\subsubsection{Bestimmung von Reinheit und Konzentration der Nukleinsäurepräpa- rationen}

Die DNA- und RNA-Konzentration wurde durch Messung ihrer optischen Dichte (OD) bei 260nm und 280nm in einem Spektralphotometer (GeneQuant, Pharmacia Biotech) bestimmt. Der Quotient der bei 260nm und 280nm (0D260/280) gemessenen Absorptionskoeffizienten der Nukleinsäurelösungen gibt Aufschluß über die Reinheit der Präparation. Bei sehr reinen DNA-Lösungen liegt der Quotient zwischen 1,8 und 1,95, bei RNA-Lösungen zwischen 1,9 und 2,0. Eine $0 D_{260}$ entspricht $50 \mu \mathrm{g} / \mathrm{ml}$ doppelsträngiger DNA oder $37 \mu \mathrm{g} / \mathrm{ml}$ RNA oder $20 \mu \mathrm{g} / \mathrm{ml}$ kurzkettiger Oligonukleotide (Sambrook et al., 1989).

Für die Sequenzierungen wurde die DNA-Konzentration der Proben durch Vergleich mit einer Referenz-DNA bekannter Länge und Konzentration (zB $1 \mathrm{~kb}-$ Ladder) nach einer Agarosegelelektrophorese optisch abgeschätzt.

\subsubsection{Polymerase-Kettenreaktion (PCR)}

Die PCR ermöglicht eine Vervielfältigung spezifischer DNA- oder RNA- Sequenzen. Dabei binden zwei Oligonukleotidstartermoleküle (engl.: Primer) in vitro an die komplementären DNA-Sequenzen und flankieren die zu amplifizierende Region in der Ziel-DNA. Die vielfache Wiederholung des gleichen Reaktionszyklus von Denaturierungs-, Primeranlagerungs- und Polymerisationsschritten führt zu einer spezifischen, theoretisch exponentiellen Vermehrung des gewünschten DNAFragments, dessen Enden durch die Primer festgelegt sind (Mullis et al., 1987). Jedes Produkt eines Zyklus dient im nächsten Zyklus wieder als Matrize, so daß sich theoretisch die Anzahl der DNA-Fragmente in jedem Zyklus verdoppelt. Durch die Verwendung einer hitzestabilen DNA-Polymerase aus der aus Thermus aquaticus isolierten Taq-Polymerase (Chien et al., 1976) und eines Thermocyclers läßt sich dieses Verfahren leicht automatisieren.

Mit Hilfe der PCR wurden in dieser Arbeit bestimmte Bereiche des AntikörperGens aus den monoklonale Antikörper-produzierenden Hybridomzellen vervielfältigt. Bei der RT-PCR (Reverse Transkriptase -PCR) wird im Gegensatz zur DNAPCR cDNA als Template verwendet. Dadurch konnte die mRNA von antikörper spezifischen Genen aus den Hybridomzellen isoliert und daraus der für die leichte 
und schwere Kette kodierende Bereich amplifiziert werden. Um bestimmte DNAAbschnitte zu amplifizieren, (variable Regionen aus cDNA) (RT-PCR) wurde zunächst nach dem Standard PCR-Protokoll der Taq DNA-Polymerase (Gibco) verfahren.

Um eine möglichst gleichmäßige Temperaturverteilung in den einzelnen PCRAnsätzen zu erzeugen, und um ein Kondensieren der Lösung am Deckel der Reaktionsgefäße zu verhindern, wurden alle PCR-Ansätze mit $80 \mu$ l Mineralöl überschichtet. Die Zugabe der Matrizen-DNA erfolgte durch die Mineralölschicht hindurch erst kurz vor Beginn der Temperaturreaktionen. Zur Steigerung der Spezifität der Reaktion wurde eine vereinfachte Hot-Start PCR durchgeführt, indem die PCR-Ansätze möglichst gleichzeitig erst in den Thermocycler gestellt wurden wenn die Denaturierungstemperatur schon erreicht war. Die hohe Sensitivität der PCR macht diese Methode äußerst anfällig für Kontaminationen. Aus diesem Grund wurde eine strikte räumliche Trennung der Arbeitsbereiche RNA/DNA-Gewinnung, Probenansatz und Amplifikation eingehalten. Alle PCR Reaktionen erfolgten in einem $50 \mu$ l-Gesamtansatz. Tab. 2.5 zeigt die Konzentrationen der Komponenten.

Tab. 2.5: Die Konzentrationen der Reaktionskomponenten der $\mathrm{V}_{\mathrm{S}^{-}}$und $\mathrm{V}_{\mathrm{L}}$ Kette in der PCR

\begin{tabular}{|c|c|c|c|c|c|}
\hline cDNA & $\mathrm{H}_{2} \mathrm{O}$ & Polymerase & Reaktionspuffer dNTP & $\mathrm{MgCl}_{2}$ & Primer \\
\hline $1 \mu \mathrm{l}$ & Ad $50 \mu \mathrm{l}$ & $1,5-2,5 \cup$ & $10 \mathrm{mM}$ & $2 \mathrm{mM}$ & je20 pmol \\
\hline
\end{tabular}

Folgendes Thermocycler-Protokoll wurde verwendet: Vor dem ersten Zyklus wurden die Proben für $3 \mathrm{Min}$ auf $95^{\circ} \mathrm{C}$ erhitzt, um eine möglichst vollständige Denaturierung der DNA-Stränge zu gewährleisten. Dann folgte ein Zyklus von 45 Sek bei $94^{\circ} \mathrm{C}$ (Denaturieren), 60 Sek bei 50-65 $\mathrm{C}$ (Anlagern der verschiedenen Primer), 60 Sek bei $72^{\circ} \mathrm{C}$ (Strangverlängerung). Die Reaktionsfolge aus Denaturierung, Anlagerung der Primer und Verlängerung der DNA-Stränge wurde je nach dem zu amplifizierenden DNA-Fragment unterschiedlich oft wiederholt. Nach dem letzten Zyklus erfolgte ein zusätzlicher Schritt bei $72^{\circ} \mathrm{C}$ von $5 \mathrm{Min}$, um eine möglichst vollständige Verlängerung aller DNA Stränge sicherzustellen. 


\subsubsection{Herstellung kompetenter E. coli Zellen}

\subsubsection{Transformationskompetente E. coli-Zellen}

Zur Herstellung transformationskompetenter E. coli Zellen (Cohen et al., 1972) vom Stamm JM 109, TG1 und DH-5 $\alpha$ wurden 2 ml LB-Medium mit dem jeweiligen Stamm angeimpft und über Nacht bei $37^{\circ} \mathrm{C}$ im Rundschüttler (200 Upm) inkubiert. Diese Kultur wurde in $100 \mathrm{ml}$ LB-Medium gegeben und bei $200 \mathrm{Upm}$ und $37^{\circ} \mathrm{C}$ geschüttelt. Nach dem Erreichen einer $\mathrm{OD}_{550}$ von 0,25 wurden die Bakterien 15 Min auf Eis gehalten, durch 5 Min Zentrifugation $\left(4^{\circ} \mathrm{C}, 1200 \mathrm{Upm}\right)$ geerntet und anschließend in $50 \mathrm{ml} 50 \mathrm{mM}$ kaltem $\mathrm{CaCl}_{2}$ suspendiert. Nach Inkubation für 30 Min auf Eis wurden die Bakterien abzentrifugiert (5 Min, $4^{\circ} \mathrm{C}, 1200 \mathrm{Upm}$ ) und das Pellet in $10 \mathrm{ml} \mathrm{20 \%}$ Glyzerin (w/v) mit $50 \mathrm{mM} \mathrm{CaCl}_{2}$ aufgenommen. Die Bakterien wurden in Portionen von $500 \mu \mathrm{l}$ aufgeteilt, in flüssigem Stickstoff schockgefroren und bis zur weiteren Verwendung bei $-80^{\circ} \mathrm{C}$ aufbewahrt.

\subsubsection{Elektrokompetente E. coli-Zellen}

Zur Herstellung von elektrokompetenten E. coli-Zellen wurden die Zellen in 50 $\mathrm{ml}$ LB-Medium bis zu einer $\mathrm{OD}_{600}$ von 0,6 bei $37^{\circ} \mathrm{C}$ inkubiert. Die Zellen wurden dann 30 Min auf Eis gehalten, zentrifugiert (10 Min, $4^{\circ} \mathrm{C}, 1200 \mathrm{Upm}$ ) und das Pellet in $50 \mathrm{ml} \mathrm{H}$ O-bidest suspendiert. Nach einer 10-minütigen Inkubation auf Eis wurde erneut zentrifugiert (10 Min, $4^{\circ} \mathrm{C}, 1200$ Upm). Das Pellet wurde in $25 \mathrm{ml} \mathrm{H}_{2} \mathrm{O}$ suspendiert und für weitere 10 Min auf Eis inkubiert. Nach der Zentrifugation für 10 Min bei $4^{\circ} \mathrm{C}$ und $1200 \mathrm{Upm}$ wurden die Zellen in $5 \mathrm{ml}$ eiskaltem $\mathrm{H}_{2} \mathrm{O}$-bidest für 5 Min inkubiert. Anschließend wurde die Zellsuspension für 10 Min bei $4^{\circ} \mathrm{C} 1200$ Upm zentrifugiert, der Überstand vollständig abgenommen und das Pellet für 5 Min auf Eis inkubiert. Die Zellen wurden dann in eiskaltem $\mathrm{H}_{2} \mathrm{O}$-bidest suspendiert und portioniert bei $-80^{\circ} \mathrm{C}$ aufbewahrt. 


\subsubsection{Reinigung von RNA}

Um in vitro hergestellte RNA zu reinigen und zu konzentrieren, wurde der Qiagen RNA Purification Kit (Qiagen, Hilden) nach Angaben des Herstellers verwendet. Anschließend wurde die RNA gereinigt und in sterilem PBS suspendiert.

\subsubsection{Transformation von E. coli Zellen}

DNA wurde durch Transformation in kompetente E. coli Zellen eingeschleust. Zur Transformation wurde $10 \mu \mathrm{l}$ des Ligationsansatzes mit $200 \mu \mathrm{l}$ frisch aufgetaute kompetente E. coli Zellen gemischt. Dieser Ansatz wurde 30 Min auf Eis gehalten, für 45 Sek bei $42^{\circ} \mathrm{C}$ inkubiert und erneut 2 Min auf Eis belassen. Es wurden $450 \mu \mathrm{l}$ SOC-Medium (20 g Trypton, $5 \mathrm{~g}$ Hefeextrakt, 0,5 g NaCl, in 900 ml $\mathrm{H}_{2} \mathrm{O}$ gegeben und autoklaviert. Nach der Abkühlung der Lösung auf $50^{\circ} \mathrm{C}$ wurden $2,3 \mathrm{~g} \mathrm{MgCl}_{2}$, $1,2 \mathrm{~g} \mathrm{MgSO}_{4}$ und 3,6 $\mathrm{g}$ Glukose zugegeben) hinzugegeben und die Proben für 1 Std. bei $37^{\circ} \mathrm{C}$ geschüttelt. Unterschiedliche Volumina dieser Suspension wurden auf ampicillinhaltigen (50 $\mathrm{\mu g} / \mathrm{ml})$ LB-Agarplatten ausplattiert und diese über Nacht umgedreht bei $37^{\circ} \mathrm{C}$ gelagert.

JM83- und $\mathrm{DH}-5 \alpha$-Zellen sind nach Transformation mit geeigneten Vektoren zur $\alpha$-Komplementation fähig (Horwitz et al., 1964, Ullmann et al., 1967). Entsprechend entstehen blaue oder weiße Klone.

\subsubsection{Expression von Prionproteinen mit Semliki Forest Virus Plasmiden}

Das SFV gehört zu den Alphaviren, das ursprünglich 1944 aus Mücken des ugandischen Semliki Regenwaldes isoliert wurde. Das reife Viruspartikel enthält eine einzelne Kopie des ssRNA Genoms und ist in Kapsidproteine verpackt. Dieses Nukleokapsid ist von einer Lipid-Doppelmembran umhüllt, die die viralen Spikeproteine E1 bis E3 enthält. Die virale RNA ist von positiver Polarität. Nach Infektion werden 2/3 des Genoms in ein Polyprotein translatiert, das autokatalytisch in die vier Nichtstrukturproteine Ns1 bis Ns4 prozessiert wird. Diese Proteine sind für die Replikation des Genoms in einen Minusstrang verantwortlich. Der Minusstrang 
dient der Synthese neuer Genome, sowie einer subgenomischen RNA. Diese kodiert für alle Strukturproteine. Das SFV hat einige Eigenschaften, die es als Expressionssystem besonders geeignet erscheinen lassen: Die RNA in positiver Polarität dient direkt als mRNA. Die Replikation wird effektiv durch viruseigene Enzyme gesteuert. SFV repliziert und exprimiert zytoplasmatisch. Der zytopathogene Effekt tritt erst spät ein. Das Wirtsspektrum von SFV ist sehr breit.

Die SFV Expressionsplasmide basieren auf einem cDNA Klon von SFV, der eine Deletion der Strukturprotein-kodierenden Region aufweist, um für heterologe Sequenzen Platz zu schaffen (Liljeström und Garoff, 1991). Nach der Klonierung des gewünschten Fremdgens über einen Polylinker wird das Plasmid linearisiert, in vitro in RNA transkribiert und durch Elektroporation in die Zielzelle eingebracht. Es kommt dort zur Replikation des RNA-Genoms durch die Nichtstrukturproteine und zur Expression des gewünschten Fremdproteins. Da die Strukturproteine fehlen, werden keine Viruspartikel hergestellt.

Neben der Transkription von Zellen über Elektroporation ist außerdem die Herstellung rekombinanter Viruspartikel mit Hilfe eines Helfervirus möglich (Berglund et al., 1993). Dieses Helfervirus ist replikationsdefekt. Erst nach Ko-elektroporation seiner RNA mit rekombinanter SFV-RNA, die das gewünschte Fremdgen enthält, werden Partikel gebildet. Die rekombinanten Viruspartikel müssen vor einer Infektion von Zellen erst aktiviert werden, da eines ihrer Hüllproteine gezielt zu diesem Zweck modifiziert wurde. Die Infektion mit rekombinantem Semliki Forest Virus ist abortiv, es werden keine neuen Viruspartikel gebildet und es kommt nicht zu einer Mobilisierung von Priongensequenzen. Daher trägt dieses Expressionssystem neben seinen vielen Vorteilen erheblich zur biologischen Sicherheit bei.

\subsubsection{In vitro Transkription von Semliki Forest Virus (SFV) Plasmiden}

Die in vitro Transkription wurde mit DNA-Plasmiden durchgeführt, die aus cDNA-Sequenz des Semliki Forest Virus bestanden und als Fremdgen den ORF des bovinen Priongens enthalten.

Zunächst wurden die Plasmide mit dem Restriktionsenzym Spe I linearisiert, mit Phenol-Chloroform extrahiert, mit 70\%igem Ethanol gewaschen und in RNAse freiem $\mathrm{H}_{2} \mathrm{O}$-bidest suspendiert. Pro Transkriptionsansatz wurden 1,5 $\mu \mathrm{g}$ DNA eingesetzt, mit 1,5 $\mu 10$ x SP6-Puffer (400 mM HEPES-KOH, pH 7,4, 60 mM MgOAc, 
20 mM Spermidin-HCl), $5 \mu l 10 \mathrm{mM} \mathrm{m}^{7} \mathrm{G}\left(5^{\prime}\right)$ ppp(5')G, $5 \mu \mathrm{l} 10 \mathrm{mM}$ DTT, $5 \mu \mathrm{l}$ rNTPMischung (10 mM ATP, $10 \mathrm{mM}$ UTP, $10 \mathrm{mM}$ CTP, 5 mM GTP), 1,5 $\mu$ I RNAsin und 0,5 $\mu$ S SP6-Polymerase (30 Einheiten) gemischt und mit RNAse-freiem $\mathrm{H}_{2} \mathrm{O}$-bidest auf ein Volumen von $50 \mu$ leingestellt. Nach einer Inkubation von $1 \mathrm{Std}$. bei $37^{\circ} \mathrm{C}$ wurde der Erfolg der in vitro Transkription mit einem Teil des Ansatzes durch Agarosegelelektrophorese überprüft und der Rest bis zu weiteren Verwendung bei $80^{\circ} \mathrm{C}$ gelagert.

\subsubsection{Elektroporation von BHK-Zellen}

Für die Elektroporation von BHK-Zellen (ATCC CL 13) mit in vitro hergestellter RNA wurden $10^{7}$ Zellen pro $\mathrm{ml}$ benötigt. Die adhärenten Zellen wurden zunächst mit PBS gewaschen, von der Kulturflasche abgelöst und durch Zentrifugation für 5 Min bei 400 x g geerntet. Die Zellen wurden in PBS $^{-}$suspendiert und erneut zentrifugiert.

Anschließend wurden die Zellen mit PBS $^{-}(\mathrm{pH} 7,2,2,5 \mathrm{mM} \mathrm{KCl}, 1,5 \mathrm{mM}$ $\mathrm{KH}_{2} \mathrm{PO}_{4}, 140 \mathrm{mM} \mathrm{NaCl}, 8 \mathrm{mM} \mathrm{Na} \mathrm{HPO}_{4}$ ) auf eine Zelldichte von $10^{7}$ Zellen pro $\mathrm{ml}$ eingestellt. Die in vitro hergestellte RNA wurde mit 0,8 ml Zellsuspension gemischt, sofort in eine $0,4 \mathrm{~cm}$ Elektroporationsküvette transferiert und die Zellen zweimal mit $850 \mathrm{~V}$ und $25 \mu \mathrm{F}$ bei Rt elektroporiert. Die Zeitkonstante sollte 0,4 betragen. Die transfizierten Zellen wurden mit 15 ml BHK-21 Medium (5\% FCS, 10\% Tryptose-Phosphat-Medium, $20 \mathrm{mM}$ HEPES, $2 \mathrm{mM}$ Glutamin, 0,1 U/ml Penicillin, 0,1 $\mu \mathrm{g} / \mathrm{ml}$ Streptomycin) verdünnt und in Kulturgefäßen ausplattiert. Nach einer Wachstumszeit von 12 bis 36 Std. wurden entweder die Zellen für Westernblot oder für Imunfluoreszenzen verwendet oder aber der Zellkulturüberstand mit den rekombinanten Viruspartikeln durch Zentrifugation vollständig von Zellen getrennt und bei $-80^{\circ} \mathrm{C}$ gelagert.

\subsubsection{Herstellung rekombinanter Viruspartikel}

Zur Herstellung rekombinanter Viruspartikel wird ein replikationsdefektes Helfervirus benötigt, das die Hüllproteine von SFV zur Verpackung rekombinanter SFV-RNA-Sequenzen bereitstellt. Helfer 2 ist ein solches Verpackungsvirus (Berglund et al., 1993). 
Zunächst wurden sowohl das Helfer 2-Plasmid als auch das rekombinante pSFV1-Plasmid durch in vitro Transkription in RNA umgeschrieben. Die beiden RNAs wurden im Verhältnis 1:1 gemischt und durch Elektroporation in BHK-Zellen transfiziert. Nach 24 bis 30 Std. wurde der Viruspartikel enthaltende Zellkulturüberstand, der durch Zentrifugation von den Zellen getrennt, portioniert, auf Trokkeneis gekühlt und bis zur weiteren Verwendung bei $-80^{\circ} \mathrm{C}$ gefroren.

\subsubsection{Infektion von Zielzellen}

Da zur Verpackung rekombinanter Viruspartikel ein Helfervirus mit modifizierten Hüllproteinen verwendet wurde, müssen die Viruspartikel vor der Infektion von Zielzellen zunächst mit Chymotrypsin aktiviert werden (Berglund et al.,1993).

Dazu wurde das Virus entweder direkt verwendet oder eingefrorenes Virus schnell bei Rt aufgetaut. Zu dem Virusüberstand wurden 1/20 Volumen Chemotrypsin-Lösung (10 mg/ml Chymotrypsin in PBS $\left.{ }^{-}\right)$und 1/50 Volumen $50 \mathrm{mM}$ $\mathrm{CaCl}_{2}$ gegeben. Nach 30-minütiger Inkubation bei Rt wurden zur Hemmung des Chymotrypsins $25 \mu$ l einer Aprotinin-Lösung (2 mg/ml) zum Ansatz pepettiert und kurz auf Eis inkubiert. Parallel dazu wurden die zu infizierenden Zielzellen mit PBS gewaschen und anschließend in MEM (Gibco, Karlsruhe) mit 0,2\% BSA, 2 mM Glutamin und 20 mM HEPES aufgenommen. Das Medium enthält kein FCS , da es die Infektion der Zellen mit rekombinantem SFV hemmt. Die Virussuspension wurde zu den Zellen gegeben und diese für $1 \mathrm{Std}$. bei $37^{\circ} \mathrm{C}$ inkubiert. Anschließend wurde das Medium gegen komplettes BHK21-Medium oder Dulbecco's Medium ausgetauscht und die Zellen 12 bis 30 Std. zur Expression rekombinanter Proteine bei $37^{\circ} \mathrm{C}$ inkubiert.

\subsection{Proteinbiochemische Methoden}

\subsubsection{Polyacrylamidgelelektrophorese (PAGE)}

Die aus eukaryontischen Zellen extrahierten Proteine wurden im Westernblot elektrophoretisch in einem SDS-Polyacrylamidgel aufgetrennt. Das zugesetzte anionische Detergens Natriumdodecylsulfat (SDS) denaturiert die Proteine und belädt sie entsprechend ihres Molekulargewichtes mit negativen Ladungen. Die 
Auftrennung der Proteine im elektrischen Feld des Polyamidgels erfolgt nur auf Grund ihrer Größe, da die Eigenladungen der Proteine nach SDS-Behandlung vernachlässigbar sind. Um eine optimale Auftrennung der etwa 27-33 kDa großen Prionproteine zu erreichen, wurden 12,5\% Polyacrylamidgele verwendet $(12,5 \%$ (w/v) Acrylamid, $375 \mathrm{mM}$ Tris/ $\mathrm{HCl}, \mathrm{pH} 8,8 \mathrm{mit} 0,1 \%(\mathrm{w} / \mathrm{v})$ SDS und N,NMethylenbisacrylamid im Verhältnis 37,5:1). Die Polymerisation der Trenngellösung wurde mit $3 \mu \mathrm{l}$ N,N,N',N'-Tetramethylendiamin (TEMED) und $25 \mu \mathrm{l}$ Ammoniumpersulfat (APS) gestartet. Auf das über Nacht polymerisierte Trenngel wurde ein Sammelgel (375 mM Tris/HCl, pH 6,8, mit 0,1\% (w/v) SDS, 4\% Acrylamid und $0,1 \%$ N,N'-Methylenbisacrylamid) geschichtet, dessen Polymerisation ebenfalls mit TEMED und APS gestartet wurde. Etwa 20-40 $\mu$ g Protein wurde in $20 \mu$ Probenpuffer (50 mM Tris/HCl, pH 6,8, 250 DTT, 8 M Harnstoff, 0,5 M 2-Mercaptoethanol, 2,3\% (w/v) SDS, 0,05\% (w/v) Bromphenolblau) aufgenommen und für 3 Min bei $96^{\circ} \mathrm{C}$ vollständig denaturiert. Die Puffertanks der Elektrophoresekammer wurden mit Glyzinpuffer (25 mM Tris/HCl, pH 8,3, 200 mM Glyzin, 0,1\% (w/v) SDS) befüllt, die Proben aufgetragen und die Elektrophorese mit 20 mA in Sammelgel (Probenkonzentrierung) und $40 \mathrm{~mA}$ in Trenngel (Probenauftrennung, etwa 3-4 Std.) durchgeführt. Das Gel mit den aufgetrennten Proteinen wurde nach der Elektrophorese entweder mit Coomassie Blau gefärbt oder die Proteine durch einen Westernblot auf Nitrozellulosefilter übertragen.

\subsubsection{Westernblot}

\subsubsection{Colorimetrische Detektierung}

Der Westernblot (Towbin et al.,1979) ist eine Technik, mit der Proteine immunologisch nachgewiesen werden können. Dazu werden die Proteine bzw Proteingemische zuerst in einer SDS-PAGE aufgetrennt. Die aufgetrennten Proteine werden über Nacht mit einer Stromstärke von $250 \mathrm{~mA}$ auf eine Nitrozellulosemembran (Schleicher und Schüll, Dassel) transferiert und sind dort gut zugänglich.

Das Gel wurde nach der Polyacrylamidgelelektrophorese für Antikörper mit einer Nitrozellulosemembran bedeckt und luftblasenfrei zwischen zwei Lagen Whatman-Papier und zwei Lagen Schwammstoffmatten gelegt. Der Transfer wurde vertikal zwischen zwei Kunststoffgittern in einer Puffertank (20 mM NaH ${ }_{2} \mathrm{PO}_{4}$ ) 
$20 \mathrm{mM} \mathrm{Na}_{2} \mathrm{HPO}_{4}, 0,2 \%$ SDS (w/v), 20\% Methanol) so durchgeführt, daß die Nitrozellulosemembran zur Anode zeigt (250mA, $4^{\circ} \mathrm{C}, 16 \mathrm{Std}$.).

Durch die negative Ladung der Protein-SDS-Komplexe wandern diese im Verlauf des Transfers in Richtung der Anode bis auf die Nitrozellulosemembran, an die sie binden. Zur Blockierung von unspezifischen Bindungsstellen wurde die Nitrozellulosemembran zunächst mit einer Magermilchlösung (5\% (v/v) in PBS) abgesättigt. Um die Spezifität der monoklonalen Antikörper und der Phagenantikörper zu prüfen, wurden diese mit 3\% (w/v) Milchpulver auf die Nitrozellulose zugegeben, für 2 Std. bei $37^{\circ} \mathrm{C}$ unter ständiger Bewegung auf einem Taumelschüttler inkubiert und dreimal mit Inkubationspuffer zum Enfernen von ungebundenen Antikörper gewaschen. Zur Sichtbarmachung spezificher Banden wurde die Membran mit einem zweiten, alkalische Phosphatase-gekopelten Antikörper, der eine Spezifität für den ersten Antikörper aufwies, für $1 \mathrm{Std}$. bei $37^{\circ} \mathrm{C}$ inkubiert. Zur vollständigen Entfernung der nicht gebundenen Antikörper wurde die Membran auf dem Taumelschüttler fünfmal mit TBS-Puffer $(\mathrm{pH} \mathrm{7,5,} 20 \mathrm{mM}$ Tris- $\mathrm{HCl}, 500 \mathrm{mM}$ $\mathrm{NaCl}$ ) und einmal mit Carbonatpuffer ( $\mathrm{pH}$ 9,5, $100 \mathrm{mM} \mathrm{NaHCO} 1 \mathrm{mM} \mathrm{MgCl}$ ) gewaschen. Zur Farbreaktion wurden 30 mg p-nitro Blau Tetrazoliumchlorid (Biorad, München) in $1 \mathrm{ml} \mathrm{70 \%} \mathrm{Dimethylformamid} \mathrm{und} 15 \mathrm{mg}$ 5-Bromo-4-chloro-3Inodyl-Phosphat-Toluidensalz (Biorad, München) in $1 \mathrm{ml}$ Dimethylformamid gelöst. Diese Lösungen wurden zusammen mit der Membran in $50 \mathrm{ml}$ Carbonatpuffer gegeben und für 5 Min inkubiert. Das Abstoppen der Reaktion erfolgte mit $\mathrm{H}_{2} \mathrm{O}$ bidest.

Die Lokalisierung der Phagenantikörper-Prionprotein-Komplexe erfolgte mit dem ECL-System von Amersham. Dabei handelt es sich um ein Chemilumineszenz-System zur Detektion von Horse reddish peroxidase- (HRP)-gekoppelten Antikörpern.

Diese Nachweisreaktionen beschränken sich damit auf die Stellen, an denen der Antikörper an das Prionprotein auf der Membran gebunden ist. Durch die Schwärzung eines aufgelegten Films werden diese Stellen Sichtbar gemacht. 


\subsubsection{Chemielumineszenzdetektion}

Das ECL-Westernblot-System ist eine nicht-radioaktive Detektionsmethode für Proteine. Die zu detektierenden Proteine werden mit einem HRP-konjugierten Antikörper markiert. Durch die Oxidation von Luminol durch die an den Antikörper gebundene HRP in Gegenwart eines Katalysators kommt es zur Chemilumineszenz. Dabei wird Licht einer Wellenlänge von $428 \mathrm{~nm}$ emittiert, das durch die Belichtung eines Films sichtbar gemacht werden kann.

Dazu wird Nitrozellulosemembran für 1 Min im ECL-Reagenz inkubiert und mit saugfähigem Papier getrocknet, damit die überschüssige ECL-Reagenz nicht bei der Filmentwicklung stört. Anschließend wird die Membran zwischen zwei Klarsichtfolien in einer Filmkassette gelegt. Der Film wird direkt auf die Folie gelegt. Es erfolgt eine Exposition des Films für 1 Min bis maximal 15 Min. Bereits nach 60 Min läßt die Reaktivität der ECL-Reagenz so stark nach, daß eine weitere Exposition des Films nur noch unspezifische Hintergrundsignale verstärkt. Nach der Exposition des Films kann dieser direkt entwickelt werden (Kodak M35 Omat Processor).

\subsubsection{Immunfluoreszenzmikroskopie}

In der Immunfluoreszenzmikroskopie werden spezifische Proteine in und auf fixierten Zellen mit Fluoreszeinisothiozyanat- (FITC) markierten Antikörpern im Fluoreszenzmikroskop sichtbar gemacht.

Dazu wurden die mit rekombinantem Virus infizierten Zellen zunächst in PBS gewaschen. Die Fixierung erfolgte in organischen Lösungsmitteln (2/3 Methanol, $1 / 3$ Aceton) bei Rt oder $-20^{\circ} \mathrm{C}$ für 2 Min. Die fixierten Zellen wurden mit PBS mit $3 \%$ FCS gewaschen und anschließend mit dem ersten Antikörper mindestens 1 Std. bei $37^{\circ} \mathrm{C}$ inkubiert. Danach wurde erneut gewaschen und ein gegen den ersten Antikörper gerichteter FITC-konjugierter Antikörper auf die Zellen gegeben. Nach einer Inkubation von mindestens 30 Min bei $37^{\circ} \mathrm{C}$ wurden die Zellen gewaschen.

Der Objektträger wurde mit 20\%igem (v/v) Glyzerin in PBS überschichtet, mit einem Deckglas abgedeckt und unter dem Fluoreszenzmikroskop untersucht (Kamera MC 63, Belichtungssteuerung MC 63, Auflicht-Fluoreszenzmikroskop Stan- 
dard, Filtersatz 09 zur Blauanregung, Zeiss, Oberkochen). Für die fotografischen Aufnahmen wurde ein Fujichrome RTP 135-64T Kunstlichtfilm verwendet. Die Belichtungszeiten lagen je nach Fluoreszenzintensität zwischen 4 und 6 Min.

\subsubsection{Herstellung markierter Proteine im Kaninchen-Reticulozyten-System}

Riboprobe Vektoren enthalten Erkennungs- und Bindungsstellen für bestimmte RNA-Polymerasen. Diese DNA-Sequenzen werden sowohl in vivo als auch in vitro als Polymerase-Startmotive verwendet. Ein dahinter gelegener DNA-Abschnitt wird mit hoher Effizienz in RNA übersetzt. Die synthetisierte RNA kann zusammen mit Aminosäuren, Ribosomen und Translationsfaktoren im Kaninchen-ReticulozytenSystem in Protein translatiert werden. Reticulozytenextrakt enthält die gesamte Proteinbiosynthesemaschinerie der Zelle, ist aber weitgehend frei von endogener DNA und RNA.

Für die Transkription und Translation interessierender Genabschnitte wurde das $\mathrm{TNT}^{\mathrm{TM}}$ Coupled Reticulocyte Lysate System (Promega, Madison, USA) verwendet. Der Vorteil dieses Systems ist die Herstellung von Protein über DNA und RNA in nur einer gekoppelten Reaktion.

Zur Herstellung von Protein wurden $25 \mu \mathrm{l}$ TNT Rabbit Reticulocyte Lysate, $2 \mu \mathrm{l}$ TNT Reaktionspuffer, $1 \mu$ I TNT RNA-Polymerase, $1 \mu$ l Aminosäuremischung ohne Methionin, $4 \mu \mathrm{l}^{35}$ S-Methionin $(1000 \mathrm{Ci} / \mathrm{mmol}) \mathrm{mit} 10 \mathrm{mCi} / \mathrm{ml}$ und $1 \mu \mathrm{g}$ zirkulärem DNA-Template gemischt und mit nukleasefreiem $\mathrm{H}_{2} \mathrm{O}$-Bidest auf ein Volumen von $50 \mu \mathrm{l}$ aufgefüllt. Dieser Reaktionsansatz wurde $1-2$ Std. bei $30^{\circ} \mathrm{C}$ inkubiert und dann entweder direkt in weitere Versuche eingesetzt oder bei $-80^{\circ} \mathrm{C}$ gelagert.

\subsubsection{Peptid ELISA}

Der ELISA wurde für Schaf Prionpeptide von Dr. M. Groschup (Tübingen) etabliert und in dieser Arbeit für die Verwendung boviner Peptide angepaßt.

Als ELISA-Platten wurden Maxi-Sorb Flachbodenplatten von Nunc (Wiesbaden) verwendet. Je 200 ng Peptid pro Loch in $100 \mu$ l Belegungspuffer (pH 9,6, 10 mM $10 \mathrm{mM} \mathrm{Na}_{2} \mathrm{CO}_{3}, 35 \mathrm{mM} \mathrm{NaHCO}$ ) wurden über Nacht bei Rt an die Oberfläche der ELISA-Platte gebunden. Am nächsten Morgen wurden die Überstände durch Ausschlagen der Platte entfernt. Die Platten wurden mit Blockierungspuffer (PBS unter Zusatz von 0,1\% Tween, $5 \%$ Magermilch) für 30 Min bei $37^{\circ} \mathrm{C}$ abgesättigt 
und anschließend mit Waschpuffer gewaschen. Je nachdem, ob Überstand oder Serum verwendet wurde, wurde der erste Antikörper vor dem Belegen durch PBS mit 10\% FCS verdünnt. Pro Napf wurden $100 \mu$ Antikörpergemisch eingesetzt und die Platten für $2 \mathrm{Std}$. bei $37^{\circ} \mathrm{C}$ inkubiert. Danach wurde viermal mit Waschpuffer gewaschen. Als zweiter Antikörper diente ein Ziege-Anti-Maus Peroxidasekonjugierter Antikörper (Dianova, Hamburg). Dieser wurde 1:3000 in PBS mit 0,1\% Tween verdünnt und pro Napf $100 \mu \mathrm{l}$ von dieser Mischung für $1 \mathrm{Std}$. bei $37^{\circ} \mathrm{C}$ an den ersten Antikörper gebunden. Anschließend wurde dreimal mit Waschpuffer (PBS-Tween 0,1\%ig, $200 \mathrm{mM} \mathrm{NaCl}$ ) gewaschen. Die Entwicklung des ELISA erfolgte mit $100 \mu \mathrm{l}$ o-Phenylendiamin-Gebrauchslösung (zu $25 \mathrm{mM}$ Zitronensäure und $50 \mathrm{mM} \mathrm{Na} 2 \mathrm{HPO}_{4} \cdot 2 \mathrm{H}_{2} \mathrm{O}$ wurde $0,5 \mathrm{~g}$ OPD zugegeben und im Dunkeln gelöst). Für das Entwickeln wurde $\mathrm{H}_{2} \mathrm{O}_{2}$ in $\mathrm{H}_{2} \mathrm{O}$ 1:600 verdünnt und $1 \mathrm{ml}$ davon zu der obigen OPD-Stammlösung gegeben. Die Farbentwicklung wurde nach 5 Min mit einer $\mathrm{H}_{2} \mathrm{SO}_{4}$-Gebrauchslösung (konzentrierte $\mathrm{H}_{2} \mathrm{SO}_{4}$ 1:4 in $\mathrm{H}_{2} \mathrm{O}$ ) abgestoppt. Die Intensität der Farbreaktion wurde in einem Photometer (Titertec Multiscan MC, Flow Laboratories, Irvine, Schottland) bei einer Wellenlänge von $492 \mathrm{~nm}$ gemessen.

\subsubsection{Radioimmunpräzipitation (RIPA)}

Bei der RIPA werden Komplexe aus radioaktiv markierten Proteinen und spezifischen Antikörpern mit Protein A Sepharose (Pharmacia, Freiburg) präzipitiert (Yalow und Berson, 1960, Schneider et al., 1984).

Für die Bindung von spezifischen Antikörpern an Zielprionproteine wurden 20 $\mu \mathrm{l}$ des ungereinigten in vitro Translationsproduktes mit $10 \mu \mathrm{l}$ unterschiedlichen Überständen von Hybridomzellen und $20 \mu \mathrm{l}$ Reaktionspuffer $(0,2 \%$ (w/v) Ovalbumin in 1:1 PBS:LSEB-Puffer, LSEB-Puffer: $10 \mathrm{mM}$ Tris/HCl, pH 8,0, $140 \mathrm{mM} \mathrm{NaCl}$, $2 \mathrm{mM} \mathrm{MgCl}$, $1 \mathrm{mM}$ DTT, $2 \mathrm{mM}$ Phenylmethansulfonylfluorid, 0,5\%(v/v) NP-40) gemischt. Dieser Reaktionsansatz wurde zunächst für $4 \mathrm{Std}$. und nach Zugabe von $10 \mathrm{mg}$ Protein A Sepharose für weitere $30 \mathrm{Min}$ unter heftigem Schütteln bei $4^{\circ} \mathrm{C}$ inkubiert. Anschließend wurde die Sepharose kurz zentrifugiert und der Überstand verworfen. Das Sepharosepellet wurde jeweils zweimal in Hochsalz- $(20 \mathrm{mM}$ Tris/ $\mathrm{HCl}, \mathrm{pH} 7,6,0,5 \mathrm{M} \mathrm{NaCl}, 1 \mathrm{mM}$ EDTA, $1 \%$ (w/v) Natriumdesoxycholat, 0,5\% 
(v/v) NP-40, 30\% (w/v) Saccharose) und Niedrigsalzpuffer (10 mM Tris/ $\mathrm{HCl}, \mathrm{pH}$ 7,6, $10 \mathrm{mM} \mathrm{NaCl}$ ) gewaschen.

Das gereinigte Pellet wurde in $30 \mu$ Probenpuffer für Polyacrylamidgele suspendiert, für 5 Min bei $95^{\circ} \mathrm{C}$ erhitzt und erneut zentrifugiert. Der Überstand wurde auf ein 12\% SDS-PAGE geladen und die Proteine bei $50 \mathrm{~V}$ über Nacht aufgetrennt. Am nächsten Tag wurde das Gel kurz in Entfärber (166 ml 60\%ige technische Essigsäure, $450 \mathrm{ml}$ Ethanol, ad $1000 \mathrm{ml}$ mit $\mathrm{H}_{2} \mathrm{O}$-bidest) fixiert, in $\mathrm{H}_{2} \mathrm{O}$-bidest gespült und unter Vakuum getrocknet.

\subsection{Fusion von Milzzellen mit permanent wachsenden Myelom- zellen}

\subsubsection{Präparation von Mausperitonealmakrophagen als Feederzellen der Hybridomzellen}

Um Feederzellen aus dem Mausperitonealraum zu isolieren, wurden die Mäuse drei Tage vor der Präparation mit 10\%igem Thioglykolat intraperitoneal injiziert. Die Mäuse wurden dann durch $\mathrm{CO}_{2}$ getötet, auf dem Präparationsbrett fixiert, mit $70 \%$ Ethanol übergossen und die Bauchhöhle aseptisch geöffnet. In die Bauchhöhle wurden 1-2 ml eiskaltes PBS einpipettiert, die Eingeweide mit einer Pasteurpipette hin- und herbewegt, die Flüssigkeit abgesaugt und in ein eiskaltes Zentrifugenröhrchen gegeben. Makrophagen müssen eiskalt gehalten werden, da sie sich sonst an der Gefäßwand anheften. Nach der Bestimmung der Zellzahl wurden die Makrophagen zentrifugiert, das Pellet in Hybridomzell-Medium aufgenommen und in einer Dichte von $10^{3}$ bis $10^{4}$ Zellen/Napf auf Mikrotiterplatten ausplattiert. Die so gewonnenen Feederzellen können bis zu 4 Wochen im Brutschrank gehalten werden.

Feederzellen erfüllen zwei wesentliche Aufgaben bei der Fusion von Milzzellen einer immunisierten Maus mit permanent wachsenden Myelomzellen. Makrophagen entfernen durch Phagozytose die toten Zellen, die bei einer Fusion und anschließenden Selektion reichlich entstehen. Zusätzlich stellen sie lösliche Stoffwechselprodukte zur Verfügung, die das Wachsen der Hybridomzellen fördern (Hlinak et al., 1987). 


\subsubsection{Anzucht von geeigneten Myelomzellen}

Zur Fusion geeignete Myelomzellinien sollen gute Fusionseigenschaften aufweisen, damit eine mögliche große Zahl an Hybridomzellen entsteht. Um nach der Fusion selektiv eliminiert werden zu können, muß eine Enzymdefekt vorliegen. Ausserdem müssen keine kompletten Antikörper bzw Immunglobulin-Leicht- oder Schwereketten synthetisiert werden.

Für das Maussystem stehen etablierte Myelomlinien zur Verfügung, die diese Eigenschaften aufweisen. Für diese Arbeit wurde die Myelomzellinie Ag8 (P3x63Ag8.653) (Kearney et al., 1979) verwendet. Dieser Myelomzellinie fehlt das funkionelle Enzym Hypoxanthin-Guanin-Phosphoribosyl-Transferase (HGPRT) des Nukleinsäure-Reservestoffwechselwegs und ist Hypoxanthin-AminopterinThymidin (HAT) bzw Hypoxanthin-Azaserin (HAz) sensitiv. Durch die Selektionschemikalien HAT bzw HAz wird der Hauptstoffwechselweg der Purinsynthese blockiert und alle nicht fusionierten Myelomzellen sterben ab. Hybridomzellen sind aufgrund der genetischen Komplementation unempfindlich gegen diese Selektion, da sie die funktionelle HGPRT der Milzzelle enthalten.

Um eine genetische Reversion des Selektionsmarkers zu verhindern und davon betroffene Zellen zu eliminieren, wurden die Myelomzellen etwa 4 Wochen vor der geplanten Fusion für 8 Tage unter 8-Azaguanin gehalten (Evans und Vijayalaxmi, 1981). Durch diese Behandlung wird jede Zelle mit einem intakten Nukleinsäure Stoffwechselweg eliminiert.

\subsubsection{Präparation der Milzzellen einer immunisierten Maus}

Nach dem Töten der immunisierten Maus durch $\mathrm{CO}_{2}$ und der Fixierung auf der Präparationsplatte wurde die Bauchseite mit 70\% Ethanol desinfiziert. Zum sterilen Öffnen der Bauchhöhle wurde das Fell mit einer Pinzette erfaßt und mit einer Schere aufgeschnitten. Dabei wurde die Haut von der Bauchdecke so getrennt, daß das Gewebe zunächst intakt blieb. Die vom Fell befreite Bauchdecke wurde erneut mit 70\% Ethanol gespült und anschließend mit einem Schnitt in der Mittellinie geöffnet. Für die Milzpräparation wurde die im linken Oberbauch befindliche Milz durch Verschieben der Därme auf die rechte Seite des Tieres frei gelegt. Das empfindliche Organ wurde mit einer Pinzette vorsichtig angehoben, mit einer Sche- 
re von seiner bindegewebigen Verbindung abgeschnitten und in eine mit $10 \mathrm{ml}$ Hybridommedium befüllte Petrischale gelegt. Zur Herstellung einer Einzelzellsuspension wurde eine $5 \mathrm{ml}$ Spritze mit Hybridommedium gefüllt und die Kanüle von einem Ende her in die Milz eingestochen. Die Milz wurde mit Medium aufgeblasen, bis die Zellsuspension aus der Einstichöffnung herausquoll. Das Ausspritzen wurde solange wiederholt, bis der die Milz umgebende Bindegewebesack vollständig ausgespült war. Die Milzzellen wurden durch eine 5-minütige Zentrifugation bei 400 x g von größeren Gewebebröckchen befreit und der Überstand in ein frisches Gefäß überführt. Die Milzzellen wurden gezählt und zur Fusion mit Ag8 Zellen verwendet.

\subsubsection{Fusion von Maus-Milzzellen mit Myelomzellen}

Zur Vorbereitung der Fusion wurde zunächst $10 \mathrm{~g}$ Polyethylenglycol (PEG 4000, Sigma) steril in eine kleine Glasflasche abgewogen und autoklaviert. Zu dem noch flüssigen PEG wurde die gleiche Menge (v/w) $37^{\circ} \mathrm{C}$ warmes, serumfreies Medium gegeben und beide Flüssigkeiten bis zur Homogenität gemischt.

Am nächsten Tag wurden PBS und PEG-Medium auf $37^{\circ} \mathrm{C}$ erwärmt. Anschließend wurden Ag8 Zellen (etwa 50-100 ml Kulturvolumen) durch Zentrifugation geerntet, zweimal mit serumfreiem Medium proteinfrei gewaschen und eine Zählprobe entnommen. Nachdem die Milzzellen einer immunisierten Maus präpariert waren, wurden diese mit den Ag8-Zellen im Verhältnis 5:1 gemischt und zweimal mit serumfreien Medium proteinfrei gewaschen. Der Überstand wurde entfernt und das Zellpellet durch sanftes Schütteln suspendiert. Dem Zellgemisch wurde innerhalb einer Min $1 \mathrm{ml} 37^{\circ} \mathrm{C}$ warmes PEG-Medium tropfenweise unter ständiger Bewegung der Zellen zugegeben und die Zellen 1 Min sanft bei Rt geschwenkt. Anschließend wurde den Zellen tropfenweise unter sanftem Schütteln in der ersten Min $1 \mathrm{ml} 37^{\circ} \mathrm{C}$ warmes PBS, in der zweiten Min $3 \mathrm{ml} \mathrm{PBS}$ und in der dritten Min 16 ml PBS zugefügt. Die Zellen wurden sofort bei Rt mit 600 x g für 5 Min zentrifugiert und 5 Min bei Rt belassen. Der Überstand wurde vorsichtig abgesaugt und das Pellet vorsichtig in $20 \mathrm{ml}$ Medium 20 suspendiert. Die Zellen wurden erneut für 5 Min bei $600 \times \mathrm{g}$ zentrifugiert und dann in 5-10 $\mathrm{ml}$ reinem FCS aufgenommen. Der restliche Anteil an Zellen wurde zur Kryokonservierung mit 10\% Dimethylsulfoxid 
(DMSO) versetzt und portioniert. Die Zellen wurden über Nacht bei bei $-80^{\circ} \mathrm{C}$ und anschließend in flüssigem Stickstoff konserviert.

$10^{7}$ Zellen wurden in $75 \mathrm{ml}$ HAT-Medium aufgenommen und auf 96-LochPlatten ausgesät. Verschiedene Zellzahlen wurden ausplattiert, um die für eine Fusion optimale Dichte zu ermitteln. Die frisch fusionierten Zellen wurden in viertägigem Rhythmus mit frischem Medium versorgt (dreimal mit HAT-Medium, dreimal mit HT-Medium und anschließend mit Medium ohne Zusatz). Nachdem der entsprechende Klon etwa ein Drittel einer Vertiefung in der 96-Napf-Platte bewachsen hatte, wurde das Screening von potentiell Antikörper-produzierenden Klonen begonnen.

\subsubsection{Zellklonierung}

Um die Monoklonalität der Antikörper-produzierenden Zellen zu gewährleisten, sollten die Hybridomzellen im Medium so verdünnt werden, daß sich nach der Aussaat in jedem Napf höchstens eine Zelle befindet (Coller und Coller, 1983). Allerdings ist bei derart hohen Verdünnungen die Angehrate der Einzelzellen extrem gering (McCullough et al., 1983). Aus diesem Grund wurden verschiedene Verdünnungen zwischen 1 und 10 Zellen pro Napf ausgesät und der Erfolg dieser Aussaaten mikroskopisch kontrolliert. Die Näpfe mit einem, den gewünschten Antikörper produzierenden Klon und der geringsten Aussaatzelldichte wurden propagiert und später auf dieselbe Weise rekloniert.

\subsubsection{Massenproduktion monoklonaler Antikörper}

Um große Mengen monoklonaler Antikörper zu produzieren, wurden die entsprechenden Hybridomzellen in einem Miniperm Biofermenter für hohe Zelldichten (Heraeus, Hanau) kultiviert. Dieser Fermenter besteht aus einem Versorgungsund einem Produktionsmodul. Beide Kammern sind durch eine semipermeable Membran getrennt, die einen Nährstoffaustausch garantiert, aber die Hybridomzellen sowie die produzierten Antikörper im Produktionsmodul zurückhält. Dadurch kommt es zu einer starken Anreicherung der Hybridomzellen und demzufolge zu hohen Konzentrationen der gewünschten Antikörpern. 
Zur Kultivierung von Hybridomzellen wurde das Versorgungsmodul mit $350 \mathrm{ml}$ Medium befüllt. Das Produktionsmodul wurde mit $35 \mathrm{ml}$ Zellsuspension von etwa $10^{6}$ Zellen pro $\mathrm{ml}$ bestückt. Die Zellen wurden mit einer Geschwindigkeit von 5 Umdrehungen pro Min gerollt. Ein kompletter Mediumwechsel erfolgte zunächst nach vier Tagen, danach je nach erreichter Zelldichte alle zwei Tage.

\subsubsection{Bestimmung der Antikörperklasse und Subklasse}

Zur Identifizierung der Klasse und Subklasse von monoklonalen Antikörpern wurde der IsoStrip Mouse Monoclonal Antibody Isotyping Kit (Boehringer Mannheim) verwendet. Die Bestimmung erfolgte nach Angaben des Herstellers. Es wurde Zellkulturüberstand einer Hybridomkultur 1:100 mit PBS verdünnt. Von dieser Verdünnung wurden $150 \mu \mathrm{l}$ in das Entwicklerröhrchen pipettiert und für 30 Sek inkubiert. Anschließend wurde der Inhalt des Röhrchens gut durchmischt, um die mit Antikörper beschichteten farbigen Latexkugeln zu suspendieren. In diese Suspension wurde der Entwicklerstreifen eingetaucht und das Ergebnis nach 5 Min abgelesen. Die Bestimmung der Antikörperklasse bzw Subklasse ist entscheidend für die Auswahl geeigneter Reinigungsverfahren für den jeweiligen Antikörper. Zudem gibt sie Auskunft über die Natur der Immunantwort auf die Immunisierung.

\subsection{Produktion von rekombinanten Phagenantikörpern}

Die bemerkenswerte Antikörpervielfalt ist die Folge eines hochspezialisierten Mechanismus, durch den die in einer bestimmten Zelle exprimierten Antikörpergene zusammengebaut werden. Die Spezifität der Antigenbindung wird von den hypervariablen Domänen bestimmt. Bei den Antikörpersequenzen sind jeweils drei Abschnitte von 5-15 Aminosäuren diejenigen, die die eigentliche Kontaktstelle des Antikörpers zum Antigen darstellen. Man nennt sie CDR (engl. complementary determining regions), denn sie formen eine Struktur, die komplementär zum Antigen ist (Kabat et al.,1987).

Das rekombinante Phagenantikörpersystem basiert auf der Phage Display Technik, wobei Antikörperfragmente auf der Oberfläche filamentöser Bakteriophagen als Fusionsprotein der Phagenhüllproteine III exprimiert werden. Für diesen Zweck wurden verschiedene Phagemidvektoren konstruiert. Ein Phagemid ist ein 
normales Plasmid, das eine zusätzliche Eigenschaft besitzt: Es enthält eine etwa 500 bp große Sequenz aus dem Phagengenom, die alle Signale für die Verpakkung in Phagenpartikel enthält. Bei Anwesenheit von Helferphagen, die alle anderen Funktionen der filamentösen Phagen beisteueren, wird diese Phagemid-DNA in normale Phagenpartikel eingebaut. In dieser Arbeit wurde das Phagemid pCANTAB 5 E zusammen mit der Helferphage M13KO7 (Pharmacia Biotech) verwendet.

Die Herstellung, Isolierung und der Nachweis der rekombinanten Phagenantikörper wurde in Anlehnung an die Angaben der Firma Pharmacia durchgeführt und z.T. modifiziert.

\subsubsection{Herstellung von cDNA aus RNA durch reverse Transkription}

Das Enzym Reverse Transkriptase kann RNA in DNA umschreiben. Für die RT wurde die gesamte RNA aus $2 \times 10^{6}$ Zellen (entsprechen etwa $2 \mu \mathrm{g}$ ) eingesetzt. Als Primer für die Erststrangsynthese wurde Oligo-dT21 verwendet, so daß die gesamte prozessierte mRNA in cDNA umgeschrieben wurde. Die RNA wurde in 11,5 $\mu$ LEPC-behandeltem destilliertem $\mathrm{H}_{2} \mathrm{O}$ suspendiert und mit 100 pmol Oligo$\mathrm{dT}_{21}$ versetzt. Der Ansatz wurde 10 Min bei $65^{\circ} \mathrm{C}$ inkubiert und dann auf Rt abgekühlt. Danach wurde jedem Ansatz folgendes Gemisch zugesetzt:

$\begin{array}{ll}4 \mu \mathrm{l} & \text { 5x Reverse Transkriptase Puffer ( Gibco) } \\ 1 \mu \mathrm{l} & \text { dNTPs (25mM von jedem dNTP; Pharmacia) } \\ 0,5 \mu \mathrm{l} & \text { RNAse-Inhibitor (20U, Boehringer) } \\ 1 \mu \mathrm{l} & \text { Superscript II-RT (300U, Gibco) } \\ 2 \mu \mathrm{l} & \text { DTT }(0,1 \mathrm{M}, \text { Gibco) }\end{array}$

Der gesamte Ansatz wurde für eine Stunde bei $42^{\circ} \mathrm{C}$ inkubiert und anschließend die Reverse Transkriptase bei $70^{\circ} \mathrm{C}$ für 15 Min inaktiviert. Danach wurde die cDNA mit $8 \mu \mathrm{l} \mathrm{H}_{2} 0$-bidest auf $100 \mu$ verdünnt und bis zur PCR bei $-20^{\circ} \mathrm{C}$ gefroren. Für jede PCR-Reaktion wurden $5 \mu \mathrm{l}$ cDNA eingesetzt. 


\subsubsection{Isolierung der ScFv-Fragmenten}

Die aus Hybridomzellen-mRNA gewonnene cDNA enthält die Information des Antikörpergens. Je zwei Primer, die an die beiden Enden der Gene für leichte- $\left(\mathrm{V}_{\mathrm{L}}\right)$ bzw schwere Antikörperkette $\left(V_{S}\right)$ hybridisieren, vervielfältigten die Information mittels PCR.

Beide variablen Regionen $V_{S}$ und $V_{L}$, die in zwei unabhängigen PCRReaktionen von der cDNA gewonnen wurden, wurden in einem dritten PCR-Schritt (engl.: overlap-PCR, überlappende PCR) mit Hilfe eines Peptidlinkers zu einem DNA-Stück zusammengesetzt (siehe Abb. 2.1). Die hier verwendeten Oligonukleotidprimer kodieren Teile des Peptidlinkers zwischen den beiden variablen Regionen und überlappen gleichzeitig miteinander. In einem weiteren PCR-Schritt wurden zwei Restriktionsstellen für die Ligation an den Vektor pCANTAB 5 E hinzugefügt. Anschließend wurde der ScFv (engl.: single chain Fragment der variablen Antikörper Region) mit Hilfe der Restriktionsenzyme Sfi I und Not I verdaut und an den Vektor ligiert. Mit diesem Phagemid wurden E. coli TG1-Bakterien elektroporiert. In der Abb. 2.1 ist die Expression der rekombinanten Antikörper auf einer Oberfläche des Bakteriophage schematisch dargestellt

\subsubsection{Isolierung rekombinanter Phagenantikörper}

Um rekombinante Phagenantikörper zu isolieren, wurden 9,1 ml LB-Medium zu den $900 \mu$ l zuvor mit dem Phagemid transformierten Zellen gegeben und für 1 Std. bei $37^{\circ} \mathrm{C}$ auf dem Taumelschüttler (250 Upm) inkubiert. Zu diesem Ansatz wurden anschließend $100 \mu \mathrm{g} / \mathrm{ml}$ Ampicillin und $4 \times 10^{10} \mathrm{pfu}$ (engl.: plaque forming unit) des Helferphagens M13K07 (Pharmacia) gegeben, der eine Kanamycinresistenz und Verpackungsdefizienz aufweist. Die Kultur wurde erneut für $1 \mathrm{Std}$. bei $37^{\circ} \mathrm{C}$ auf dem Traumelschüttler inkubiert. Die Zellen wurden dann für 10 Min bei 2300 Upm zentrifugiert, das Pellet in 10 ml LB-Medium mit $100 \mu \mathrm{g} / \mathrm{ml}$ Ampcillin und $50 \mu \mathrm{g} / \mathrm{ml}$ Kanamycin suspendiert und über Nacht bei $37^{\circ} \mathrm{C}$ auf dem Taumelschüttler inkubiert. Anschließend wurde die Kultur für 20 Min bei $4{ }^{\circ} \mathrm{C}$ pelletiert.

Um die im Überstand enthaltenen rekombinanten Phagen zu fällen, wurde 1/5 Volumen PEG/NaCl (20\% Polyethylenglycol 6000, $2.5 \mathrm{M} \mathrm{NaCl}$ ) zugegeben. Nach 
einer Inkubation von 30 Min auf Eis wurden die Phagen 15 Min bei $10000 \times \mathrm{g}$ und $4{ }^{\circ} \mathrm{C}$ pelletiert und in TE-Puffer aufgenommen. Die Lösung wurde durch einen 0,45 $\mu \mathrm{m}$-Filter (Sartorius) filtriert, titriert und die Portionen bei $-20^{\circ} \mathrm{C}$ aufbewahrt. 
Hybridom-Zelle

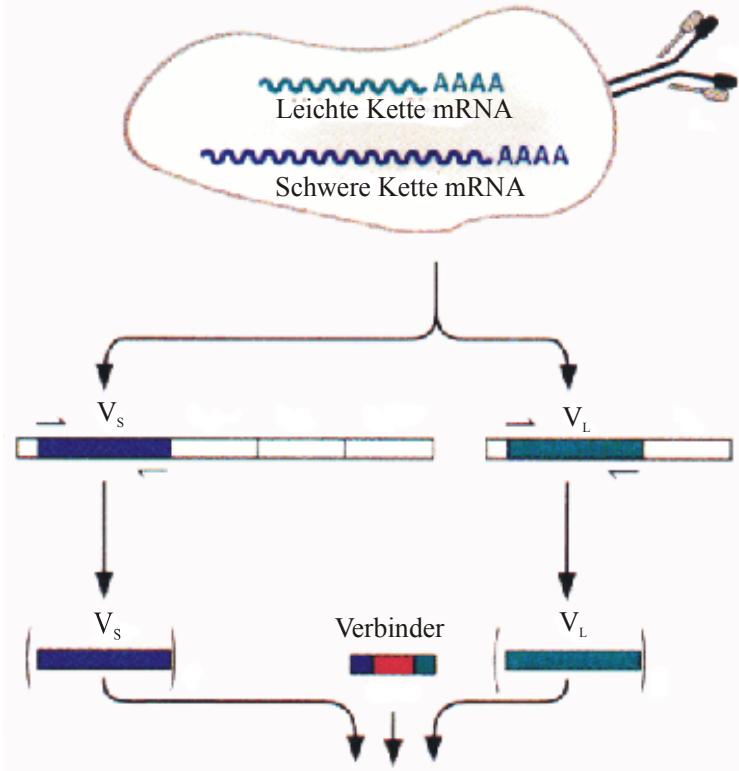

Phagenantikörper
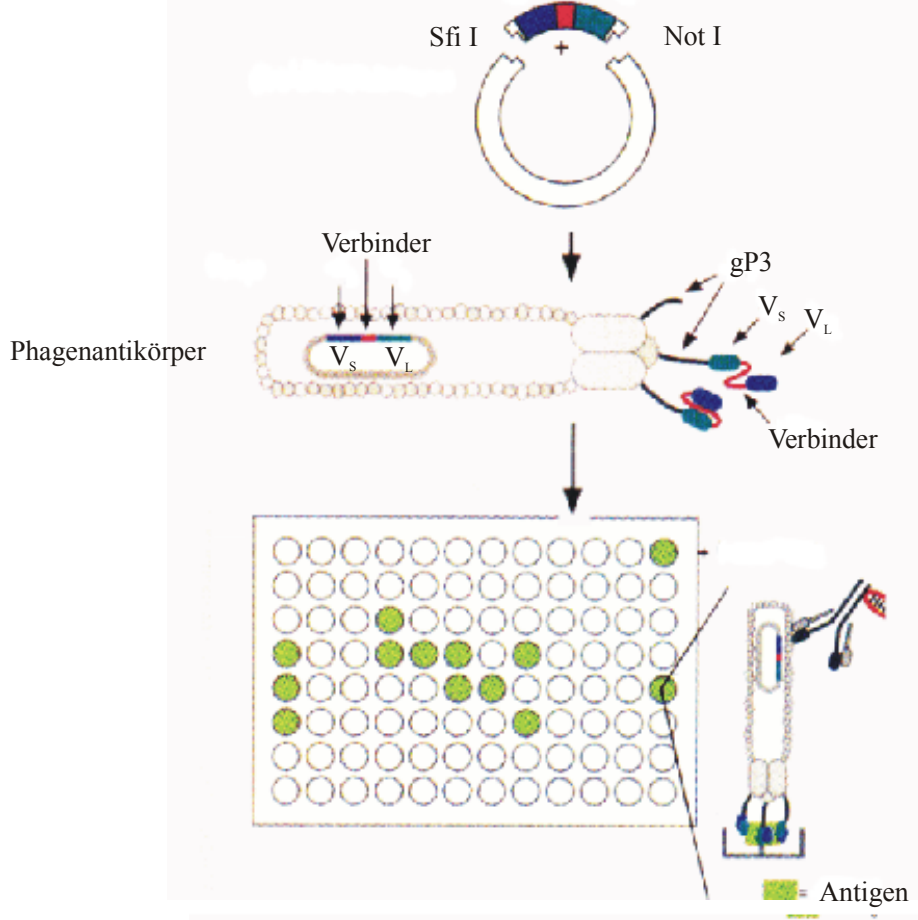

Abb. 2.1: Herstellung von rekombinanten Phagenantikörpern

(Verändert nach Pharmacia) 


\section{Experimente und Ergebnisse}

Das Ziel der Arbeit war es, monoklonale Antikörper gegen das bovine PrP herzustellen. Zur Darstellung der Ergebnisse wurde dieser Teil der Arbeit in drei Abschnitte gegliedert. Im ersten Abschnitt werden Ergebnisse aus der Immunisierung der $\mathrm{PrP}^{0 / 0}$-Mäuse dargestellt. Zur Produktion der monoklonalen Antikörper (mAk) wurden die Milzzellen entnommen und mit permanent wachsenden Myelomzellen fusioniert. Die daraus resultierenden Hybridklone wurden für eine Antikörperproduktion gegen bovine Prionproteine selektioniert.

Der zweite Abschnitt befaßt sich mit den Ergebnissen der molekularen Charakterisierung der mAk. Dafür wurde als ein schneller Test die Immunfluorezenztechnik verwendet. Dann wurden die Epitopspezifität der mAk in einem speziellen Peptid-ELISA untersucht. Insgesamt acht Klone, die mAk gegen bovines Prionprotein produzierten, wurden als eine stabile Zellinie etabliert.

Der dritte Abschnitt beschreibt die Herstellung von Phagenantikörpern aus den Hybridomzellen. Dazu wurde zuerst die gesamte RNA aus den Hybridomzellen isoliert und zu cDNA transkribiert. Anschließend wurden die DNA-Abschnitte, die für $V_{S}$ und $V_{L}$ kodieren, mit Hilfe eines Oligonukleotidlinkers zu einem ScFvAntikörper („single chain variable fragment“) verknüpft und in den Phagemidexpressionsvektor pCANTAB 5E ligiert. Um Phagenantikörper zu produzieren, wurden Bakterien in weiteren Experimenten mit den Klonen und SFV II Helferphagen koinfiziert. Die daraus isolierten Phagenantikörper wurden zuerst in einem Peptid ELISA und dann mit der Westernblot-Technik charakterisiert.

\subsection{Isolierung und Untersuchung von monoklonalen Antikörpern gegen bovines PrP}

Monoklonale Antikörper sind die Sekretionsprodukte einzelner Hybridomzellklone, die gegen ein definiertes Epitop eines Antigens gerichtet sind. Hybridomzellen werden wie in Abb. 3.1 schematisch dargestellt durch PEG-induzierte Fusion immunisierter Lymphozyten mit Myelomzellen gewonnen. Die resultierenden Hybridzellen besitzen sowohl die antikörperproduzierende Eigenschaft der 
Lymphozyten als auch die Langzeitüberlebensfähigkeit der Myelomzellen in Zellkultur (Köhler und Milstein, 1975).

Zur Induktion von Antikörpern gegen bovines $\operatorname{PrP}$ wurden $\mathrm{PrP}^{0 / 0}$-Mäuse mit in vitro hergestellten rekombinanten bovinen SFV Partikeln (rbSFV) immunisiert (3.1.1 und 3.1.2). Diese Mäuse wurden verwendet, da sie keine Toleranz gegen PrP besitzen. Zwei Monate nach der ersten Immunisierung wurden die Milzzellen der immunisierten Mäuse mit Myelomzellen fusioniert (3.1.3). Die in einem selektiven Medium wachsenden Fusionszellen wurden dann isoliert und weiter zu stabilen Zellinien etabliert (3.1.4 und 3.1.5). Zum Nachweis von mAk gegen bovines PrP wurden Immunfluoreszenztests (3.2.2), Radioimmunpräzipitationen (RIPA) mit in vitro synthetisiertem PrP (3.2.4), ein Westernblot sowie modifizierter PeptidELISAs (engl.: enzyme linked immunosorbent assay) durchgeführt. 


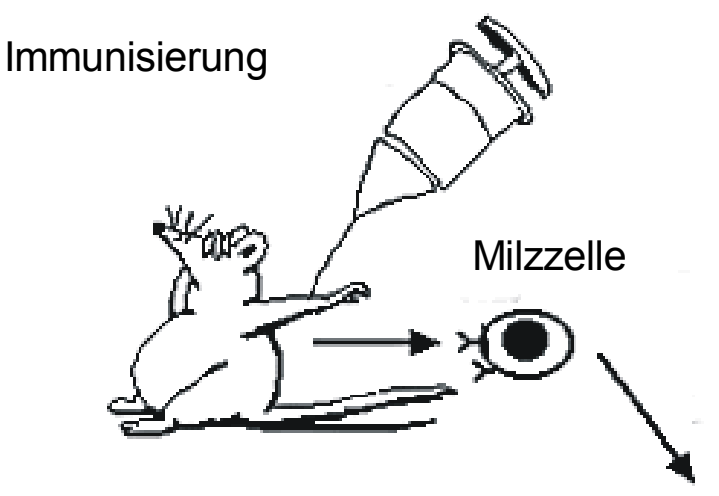

Myelom-Zelle

Hybridom-Zelle
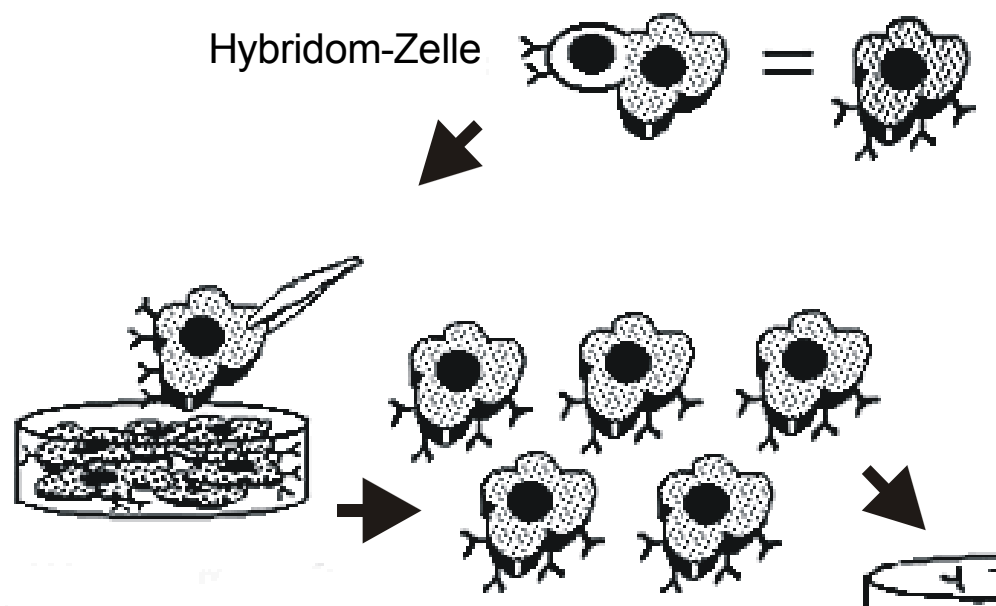

Selektion von

Antikörperproduzierende

Hybridom-Zelle
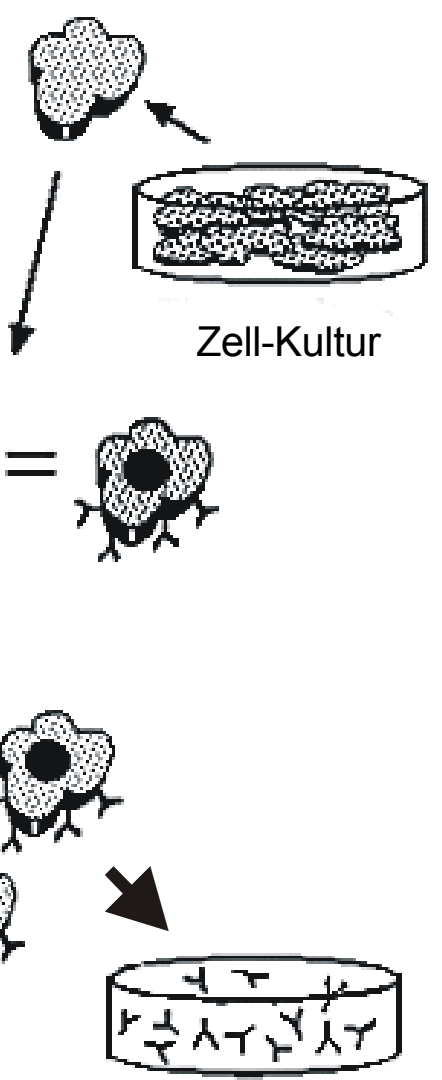

Antikörper im Überstand

\section{Abb. 3.1: Herstellung von monoklonalen Antikörpern}

Die Abbildung zeigt schematisch die Vorgehensweise bei der Herstellung von Antikörpern. Milzzellen von immunisierten Null-Mäusen wurden mit Ag8-Zellen, die vorher in Kultur gehalten worden waren, fusioniert, und in einem Selektionsmedium inkubiert. Anschließend wurde die Antikörperproduktion der Zellen untersucht.

\subsubsection{Herstellung von rbSFV-Partikeln}

Da mit rbSFV-Partikeln im Gegensatz zu einer DNA-Immunisierung eine stärkere Immunantwort induziert werden kann (Krasemann 1996), wurden in dieser Arbeit die Mäuse mit Partikeln immunisiert. Um rbSFV-Partikel herzustellen, wurde der offene Leserahmen (ORF) des bovinen Priongens in SFV kloniert, dessen 
Plasmid zuvor mit den Restriktionsendonukleasen Hind III und Xba I geschnitten worden war.

Dieses Konstrukt und der Helfer SFV II, der die Hüllproteine von SFV enthält und die Verpackung der SFV-RNA-Sequenzen ermöglicht, wurden mit Spe I linearisiert und durch in vitro Transkription in RNA umgeschrieben. Die Abb. 3.2 zeigt ein Agarosegel zur Überprüfung der in vitro Transkription.

Die beiden RNAs wurden im Verhältnis 1:1 gemischt, durch Elektroporation in BHK-Zellen eingebracht und die Zellen über Nacht inkubiert. Danach wurden die im Überstand enthaltenen rbSFV durch Zentrifugation von den BHK-Zellen getrennt und zur weiteren Produktion von rekombinanten Partikeln verwendet. In Abb. 3.3 ist das oben beschriebene Verfahren schematisch dargestellt.

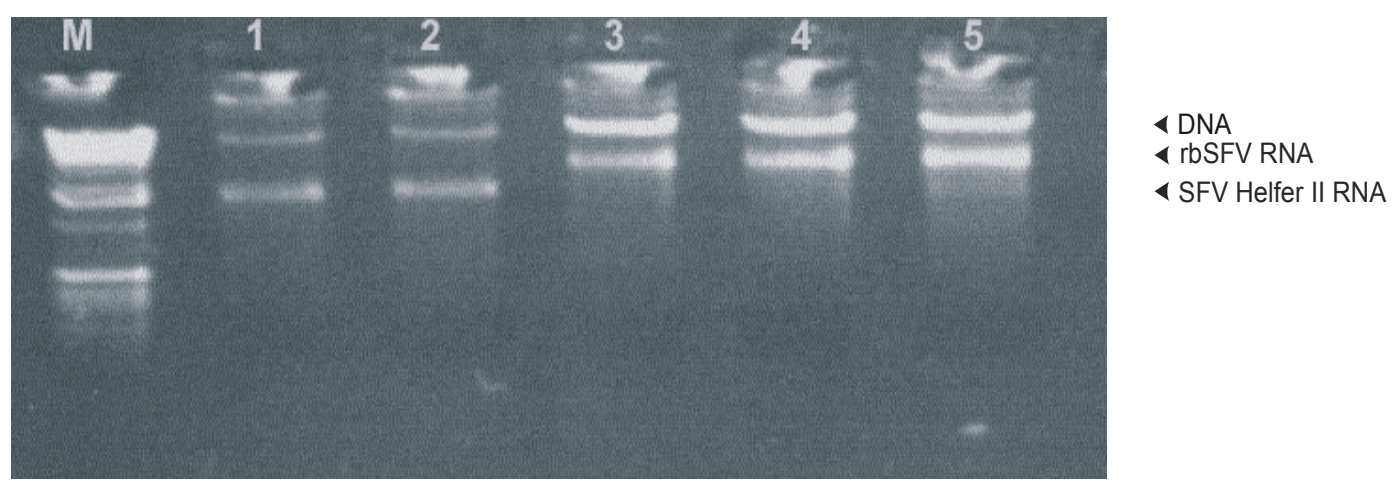

\section{Abb. 3.2: In vitro Transkription von rbSFV und SFV Helfer II Vektoren}

Zur Überprüfung des Erfolges der in vitro Transkription wurde 2\% des Reaktionsansatzes auf ein 1\%iges Agarosegel aufgetragen und anschließend elektrophoretisch getrennt. Die Länge der MarkerFragmente (M) zum Abschätzen der Massen sind in Kb angegeben. Die Spuren (1) und (2) zeigen SFV Helfer II Plasmide und die Spuren (3), (4) und (5) zeigen rbSFV. 
rbSFV (bovines PrP-Gen)

Spe I
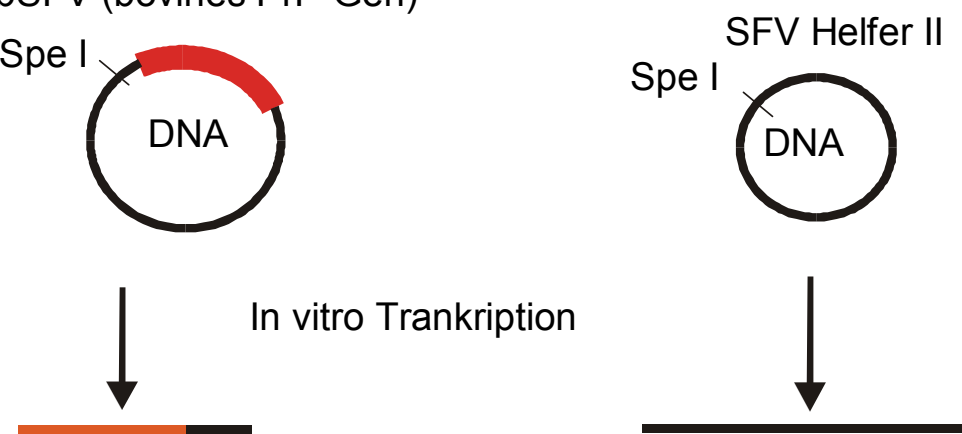

In vitro Trankription

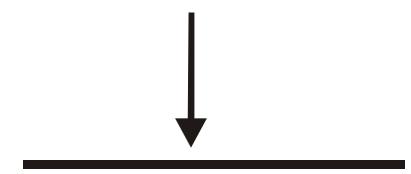

RNA

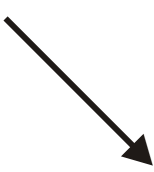

Transfektion
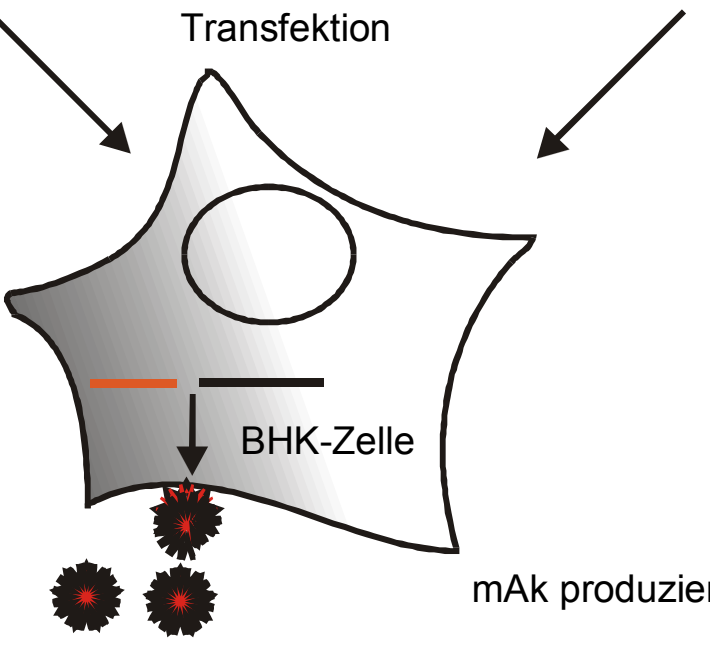

RNA

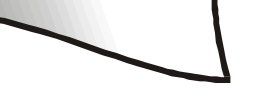

mAk produzierende Hybridomzellen

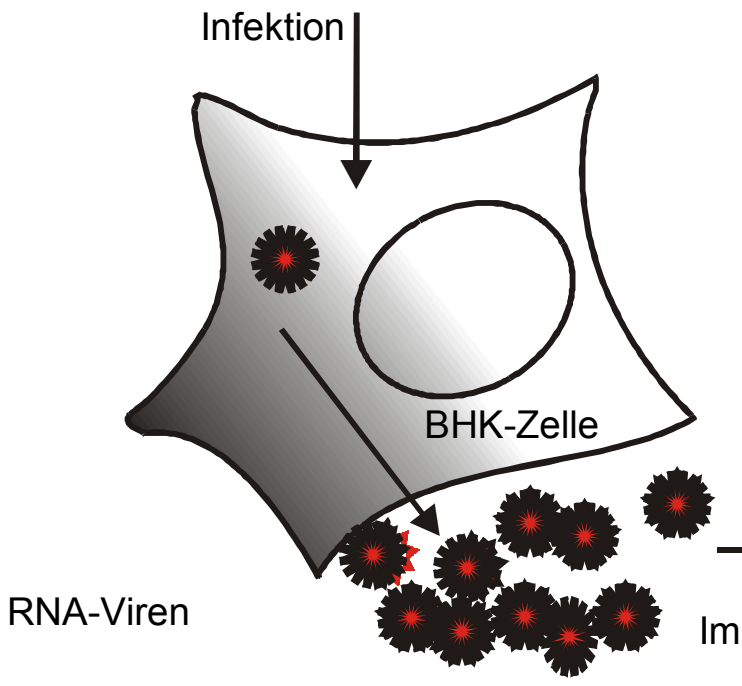

Immunisierung

Fusion von Milz- und Myelomzellen

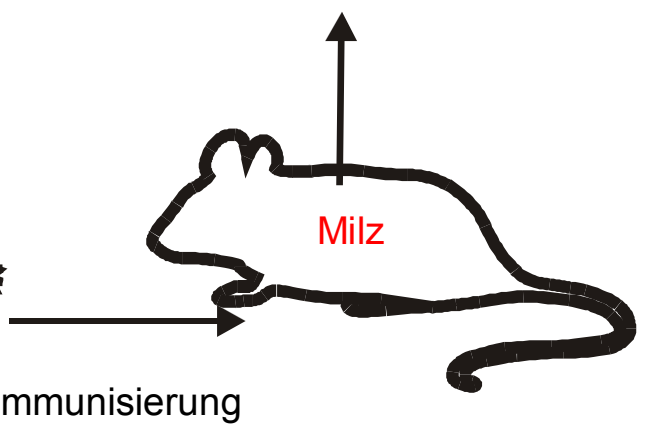

\section{Abb. 3.3: Herstellung von rbSFV Partikeln}

Die Abbildung zeigt schematisch die Herstellung der rbSFV Partikeln. Zunächst wurden sowohl das SFV Helfer II als auch das rbSFV durch in vitro Transkription in RNA umgeschrieben und in BHK-Zellen elektroporiert. Mit den Partikeln im Überstand der Zellen wurden Mäuse immunisiert und wie in der Abb. 3.1 beschrieben weiterverfahren. 


\subsubsection{Immunisierung von $\operatorname{PrP}^{0 / 0}$-Mäusen mit rbSFV Partikeln}

Mit den isolierten rbSFV-Partikeln, welche die genetische Information für das bovine Priongen enthielten, wurden $\mathrm{PrP}^{0 / 0}$-Mäuse immunisiert. Die $\mathrm{PrP}^{0 / 0}$-Mäuse sind gentechnisch verändert. Sie besitzen deshalb kein endogenes Prionprotein (engl.: knock out) und sind deswegen nicht dagegen immun-tolerant. Diese $\mathrm{PrP}^{0 / 0}$ Mäuse wurden von C. Weissmann, Zürich, zur Verfügung gestellt (Büeler et al., 1992).

Wie vorherige Experimente zeigten (Dissertation S. Krasemann, Göttingen, $\mathrm{DPZ}$ ), ergab eine Immunisierung mit der rekombinanten humanen SFV (rhSFV) DNA einen geringeren Antikörpertiter gegen PrP als diejenige mit rhSFV-Partikeln. Daher wurden zur Herstellung von rbSFV Partikeln etwa $3 \times 10^{6}$ BHK-Zellen mit rbSFV-RNA und mit SFV Helfer II RNA ko-elektroporiert. Mit den von diesen BHKZellen produzierten rbSFV Partikeln wurden dann weitere BHK-Zellen infiziert. Im Ergebnis konnte mit dieser Methode eine zwei- bis dreifache Anreicherung der Antigenmenge erzielt werden.

Zur Immunisierung von PrP ${ }^{0 / 0}$-Mäusen (Aguti C-57 black) mit rbSFV wurden 50 bis $100 \mu$ Überstand der elektroporierten BHK-Zellen den Mäuse intraperitoneal verabreicht. Als Kontrolle wurden $\mathrm{PrP}^{+/+}$-Mäuse (BALB/c) ebenfalls mit rbSFV immunisiert. Die Auffrischungsimmunisierungen erfolgten nach 2, 4 und 6 Wochen. Zwei Tage nach der letzten Immunisierung wurden in die Mäuse erneut rbSFV Partikel injiziert und nach zwei weiteren Tagen wurde die Milz entnommen. Insgesamt wurden $12 \mathrm{PrP}^{0 / 0}$-Mäuse und 4 Kontroll-Mäuse (BALB/c) immunisiert.

Nach der Fusion von Milzzellen der immunisierten Mäuse mit permanent wachsenden Myelomzellen wurden die Antikörperproduktion gegen Prionproteine der erhaltenen Hybridzellen untersucht.

\subsubsection{Fusion von Myelom- und Milzzellen zu Hybridomzellen}

Zwei Monate nach der Primärimmunisierung wurden die Tiere getötet und ihre Milzzellen mit Myelomzellen unter Zuhilfenahme von PEG fusioniert. Die Milz von Partikel-immunisierten Mäusen war zwei- bis dreifach größer als die von den

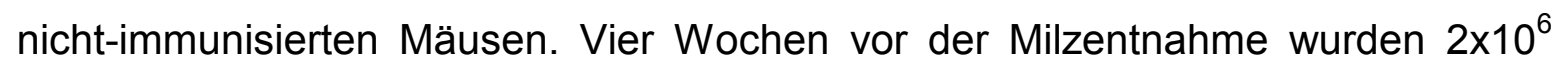


Feederzellen aus den Bauchhöhlen von nicht immunisierten Mäuse ausgespült, in 96-Napf-Platten verteilt und in Kultur gehalten. Außerdem wurden $2,5 \times 10^{7} \mathrm{Ag} 8$ Zellen vor der Fusion in Kultur bereitgehalten. Die durchschnittliche BLymphozytenzahl der Milz von mehrfach immunisierten Mäusen lag bei 2,1 $\times 10^{8}$ Zellen. Die Milzzellen und die Ag8-Zellen wurden im Verhältnis 5:1 mit Hilfe von PEG fusioniert. Ein Viertel der Fusionszellen wurden in fünf 96-Napf-Platten verteilt und in HAT-Medium selektioniert. Der Rest wurde für spätere Versuche sofort bei $-80^{\circ} \mathrm{C}$ eingefroren.

Nach vier bis sechs Wochen waren zahlreiche proliferierende Hybridklone zu beobachten. Eine Antikörperproduktion konnte erst nach sechs bis acht Wochen nachgewiesen werden. Die Abb. 3.4 zeigt die dicht zusammenwachsenden Ag8-Zellen (a), Hybridomklone, die rund und zwei- bis dreifach größer als die Myelomzellen sind (b) und Feederzellen, die im Gegenteil zu den Zelltypen in (a) und in (b) eine längliche Zellstruktur mit Fortsätzen aufweisen (c). 


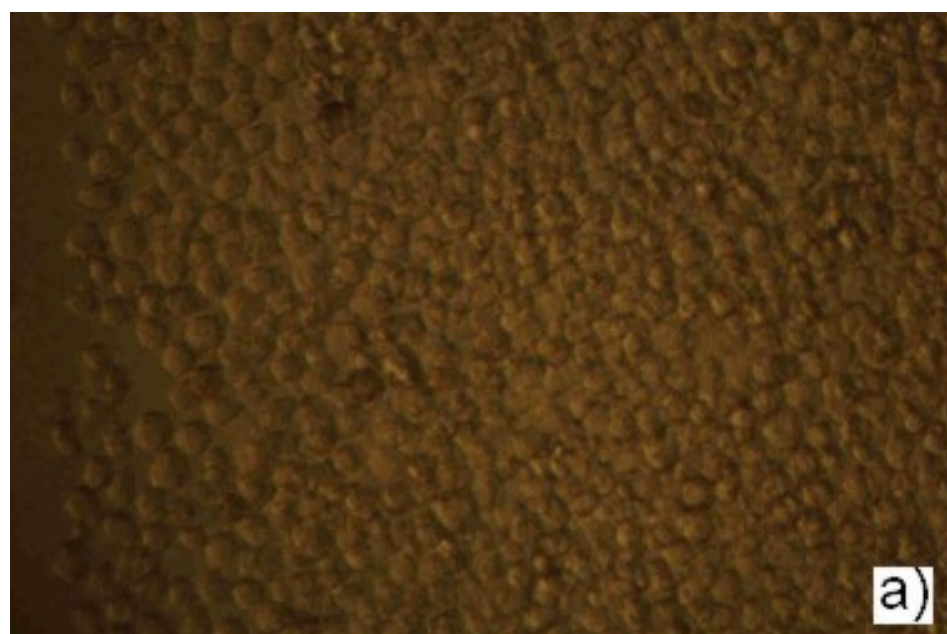

b)

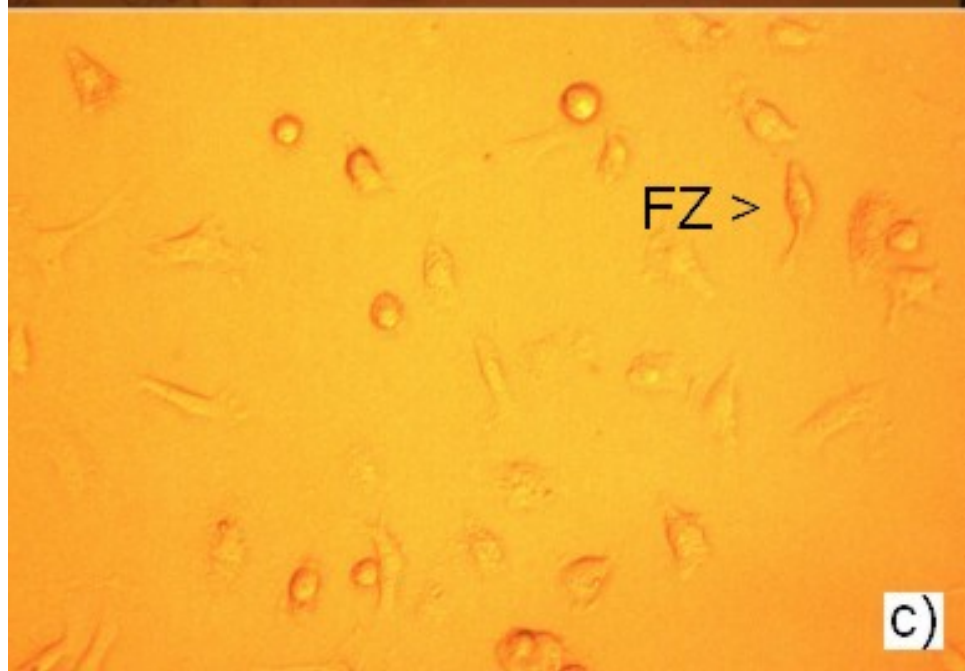

Abb. 3.4: Phasenkontrast-Darstellung von Ag8-, Hybridom- und Feederzellen

Die Abbildung (a) zeigt Ag8-Zellen in Hybridommedium nach einer Woche. (b) Hybridomzellen in HAT-Medium nach vier Wochen. (c) Feederzellen (FZ) in HAT-Medium nach 24 Std. Inkubation. 


\subsubsection{Isolierung von mAk sezernierenden Hybridomzellen}

Die Fusion von frisch entnommenen Milzzellen, der mit rbSFV immunisierten $\mathrm{PrP}^{0 / 0}$-Mäuse, mit Ag8-Zellen ergab zahlreiche Hybridomzellen, die im Selektionsmedium sehr gut wuchsen. Im Gegensatz dazu wurden bei der Fusion von eingefrorenen Milzzellen immunisierter Mäuse mit Ag8-Zellen keine Hybridklone gebildet. Auch aus den humanen und bovinen eingefrorenen Fusionsprodukten ließen sich keine Hybridomzellinien anlegen. Alle Zellen starben innerhalb einer Woche im Selektionsmedium ab. Eine mehrmalige Wiederholung des Versuchs, die Fusionsprodukte zu vermehren, die zu unterschiedlichen Zeiten eingefroren worden waren, brachte ebenfalls keine Proliferation der Zellen. Deshalb wurde in den folgenden Versuchen ausschließlich mit frisch fusionierten Zellen gearbeitet.

\subsubsection{Klonierung der Hybridomzellen}

Um die Monoklonalität der Antikörper produzierenden Zellen zu gewährleisten, wurden die Hybridomzellen so verdünnt, daß sich nach der Aussaat in jeder Vertiefung der 96-Napf-Platten zwischen 4 und 10 Zellen befanden. Dies wurde zwei bis viermal wiederholt, bis davon auszugehen war, daß die Hybridomzellen nur von einem Klon abstammten. Wenn in den Vertiefungen der 96-Napf-Platten weniger als vier Zellen waren, proliferierten sie nicht oder starben sogar ab.

Es konnten 8 unterschiedliche Hybridomzellinien (15G8, 16G8, 17G5, 19C6, 25E6, 25G6, 26B8 und 26E10) als stabile Zellinien etabliert werden, die mAk produzierten, die gegen verschiedene Epitope des Prionproteins gerichtet waren. Die mAk-haltigen Überstände aller acht Zellinien waren wiederholt in der Immunfluoreszenz positiv.

\subsubsection{Kultivierung mAk-produzierender Hybridklone zu hohen Zelldichten}

Um die Konzentration der Antikörper im Hybridomzellüberstand zu erhöhen, wurden einige der gegen das bovine PrP mAk (15G8, 26B8) und gegen das humane PrP (3B5 und 12F10) (Krasemann et al., 1996) gerichtete Hybridomklone im Minifermenter (Heraeus, Hanau) kultiviert. Die für dieses System erwartete Zelldichte von $3-5 \times 10^{7}$ Zellen/ml konnte nicht erreicht werden. Die Dichte der Klone $15 \mathrm{G} 8$ und $26 \mathrm{~B} 8$ erreichte $3-5 \times 10^{6}$ Zellen/ml. Die im Peptid-ELISA ermittelte Anti- 
körperkonzentration war im Vergleich zu normalen Kulturbedingungen in Flaschen zwei- bis dreimal höher.

Im Gegensatz dazu ließen sich die frisch aufgetauten Klone 3B5 und 12F10 nicht zu hohen Dichten kultivieren. Sämtliche Zellen starben innerhalb einer Woche nach Animpfen des Fermenters mit etwa $3 \times 10^{6}$ Zellen $/ \mathrm{ml} \mathrm{ab}$.

Für die mAk 16G8 und 25G6 brachte die Zelldichteerhöhung keinen Konzentrationsunterschied der mAk im Überstand im Peptid-ELISA. Obwohl die Zellen gut proliferierten, war die Signalstärke im Vergleich zu dem normalen Zellkulturüberstand um die Hälfte gesunken.

\subsection{Molekulare Charakterisierung der monoklonalen Antikörper}

\subsubsection{Antiseren immunisierter Mäuse binden an das bovine Prionprotein}

Die Bindung von spezifischen Antikörpern an das bovine Prionprotein wurde an PrP-überexprimierenden BHK-Zellen untersucht. Die BHK-Zellen waren zuvor mit einer in vitro hergestellten SFV-RNA, die die ORF-Region des Wildtypgens enthält, elektroporiert worden.

Alle Seren von nicht immunisierten $\operatorname{PrP}^{0 / 0}$-Mäusen und immunisierten $\mathrm{PrP}^{+/+}$Mäusen zeigten keine Reaktion mit dem Wildtyp-Prionprotein in BHK-Zellen. Im Gegensatz dazu zeigten alle mit Hilfe der Immunfluoreszenztechnik positiv gefundenen Immunseren von immunisierten $\mathrm{PrP}^{0 / 0}$-Mäusen eine spezifische Bindung.

\subsubsection{Nachweis der monoklonalen Antikörper mit der Immunfluoreszenz}

Viele bisher untersuchte Säugerzellen und Gewebe exprimieren eine geringe Menge an Prionprotein (Chesebro et al., 1985). Diese ist jedoch nicht ausreichend, um in der Immunfluoreszenz ein positives Signal zu erzeugen. Um die Menge an Prionprotein einer Zelle für den Nachweis von spezifischen Antikörpern zu erhöhen, wurde rekombinantes bovines Prionprotein aus überproduzierenden Zellen verwendet. Dazu wurden BHK-Zellen mit rbSFV-RNA, die die genetische Information für das Wildtyp-Priongen enthielten, und SFV-Helfer-II ko-elektroporiert. Anschließend wurden die transfizierten Zellen auf Mikrotiterplatten ausgesät und 
nach 24 Std. zum Nachweis im Immunfluoreszenztest zur Präsentation des Prionprotein-Antigens eingesetzt.

Insgesamt wurde die Sekretion prionprotein-spezifischer Antikörper von mehr als 800 unabhängigen Klonen untersucht. Um große Mengen an HybridomZellkulturüberständen in kurzer Zeit zu überprüfen, wurde zunächst der Immunfluoreszenztest eingesetzt. In der Abb. 3.5 ist die Reaktion eines mAk mit dem bovinen PrP zu erkennen. Zur Absicherung und Ergänzung dieser Daten wurde zusätzlich der Peptid-ELISA durchgeführt.

Die Bindung der mAk an das bovine Prionprotein wurde in weiteren Experimenten genauer untersucht. Außerdem wurde die RNA der Hybridomzellinie verwendet, um gentechnisch Einzelketten-Phagenantikörper (ScFv) herzustellen. 


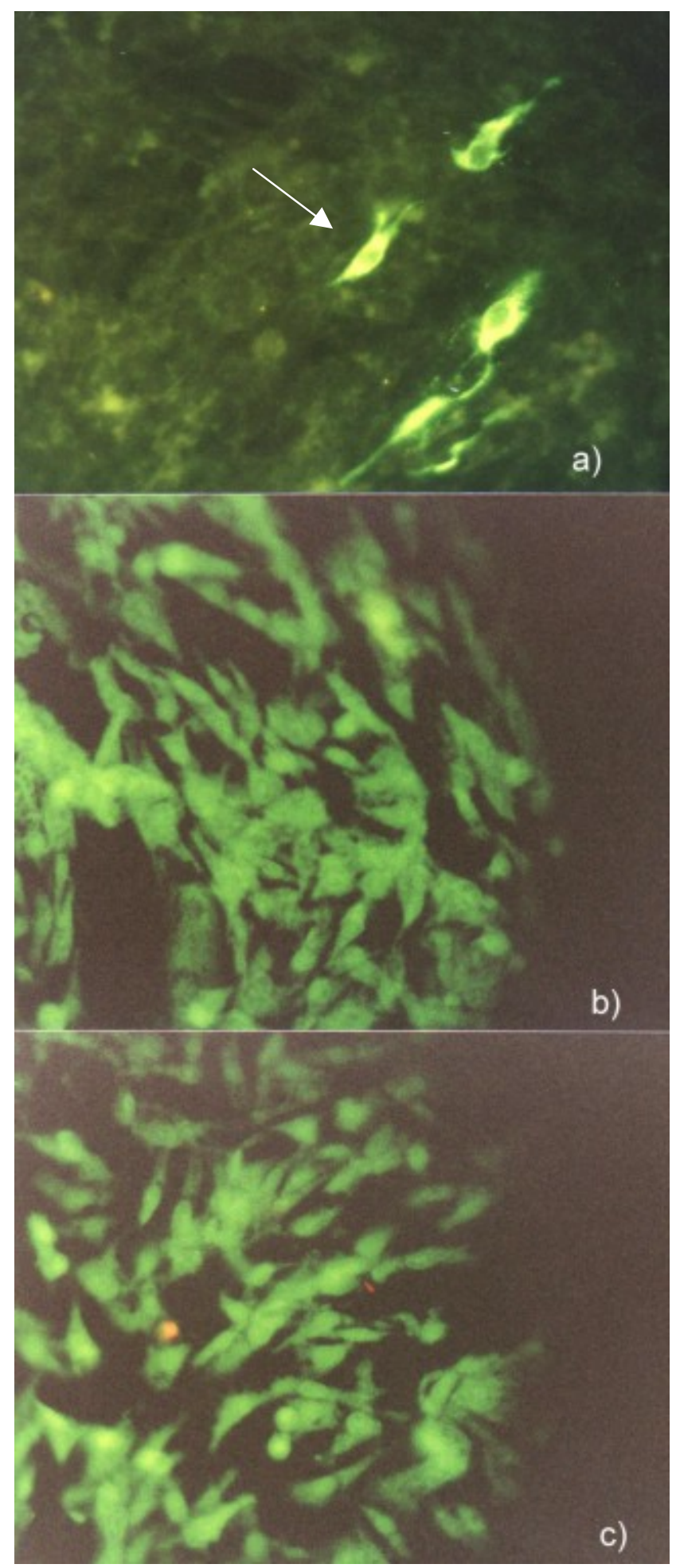

\section{Abb. 3.5: MAk $15 \mathrm{G} 8$ reagiert mit bovinem Prionprotein}

BHK-Zellen wurden mit rbSFV-Partikeln infiziert (siehe auch Abb. 3.3). Nach einer Wachstumsphase von 24 Std. wurden die Zellen mit Methanol fixiert und mit Überständen von (a) mAk 15G8, (b) Ag8-Zellen und ( $(-)$ ) Neu2A-Zellen inkubiert. Zur Färbung der Antikörper wurde ein zweiter FICT-gekoppelter Antikörper verwendet. Nur mit dem Überstand der 15G8 Hybridomzellen konnte hier ein positives Signal auf der Zelloberfläche erzeugt werden (Pfeil). 


\subsubsection{Untersuchung der Bindungseigenschaften der monoklonalen Antikör- per mit Hilfe von Peptiden}

Ein Peptid-ELISA ist geeignet, die Reaktivität eines Antikörpers gegen Teile eines bestimmten Proteins zu untersuchen. Darüberhinaus können die spezifischen Bindungsstellen, die Epitope, identifiziert werden, gegen die ein polyklonales Serum oder ein monoklonaler Antikörper gerichtet ist.

Zunächst wurden 16 verschiedene ovine Peptide ausgewählt, welche die gesamte Aminosäuresequenz des Prionproteins überlappend überspannen. Die letzten zwölf carboxyterminalen Aminosäuren sind im reifen Protein durch den GPI-Anker ersetzt. Im weiteren wurden 114 bovine Peptide synthetisiert, welche ebenfalls das ganze Prionprotein überlappend überspannen.

\subsubsection{Reaktion der mAk mit einem Gemisch der PrP-Peptide im ELISA}

Der Peptid-ELISA wurde für Schaf-Prionpeptide von M. Groschup (Bundesforschungsanstalt für Viruserkrankungen der Tiere, Tübingen) etabliert und in dieser Arbeit für die Verwendung boviner Peptide angepaßt.

Die 16 ovinen Peptide wurden zunächst gemischt und jeweils 200 ng Peptid pro Vertiefung in 96 Napf-Mikrotiterplatten einpipettiert. Die Lage der einzelnen Peptide im ovinen Protein sowie ein Sequenzvergleich dieser Bereiche mit anderen Spezies ist in der Abb. 3.6 zusammengefaßt. Nach einer Inkubation über Nacht dienten die so belegten Platten zur schnellen Überprüfung der Hybridomüberstände. In der Abb. 3.7 sind die optische Dichte der einzelnen mAk im ELISA dargestellt. Desweiteren wurden die Peptide vereinzelt bei der groben EpitopBestimmung eingesetzt. 
1

2

3

Rind $\overline{\text { MVKSHIGSWILVLFVAMWSDVGLCKKRPKPGGGWNTGGSRYP }}$

Schaf

Mensch

Maus

M.f.

Rind

Schaf

Mensch

Maus

M.f.

Rind

Schaf

Mensch

Maus

M.f.

Rind ANL- - CWM- - - - $-\mathrm{T}---\mathrm{I}$

$-\mathrm{ANL}--\mathrm{Y}-\mathrm{L}-\mathrm{A}---\mathrm{T}-\mathrm{T}-$

$-\mathrm{ANL}-\mathrm{-}$ CWM - - - - - T - - - I

3

4

5

GQGS PGGNRYP PQGGGGWGQPHGGGWGQPHGGGWGQPHGGGW

Schaf

Mensch

Maus

M.f.

Rind

Schaf

Mensch

Maus

M. f .

Rind

Schaf

Mensch

Maus

M. f .
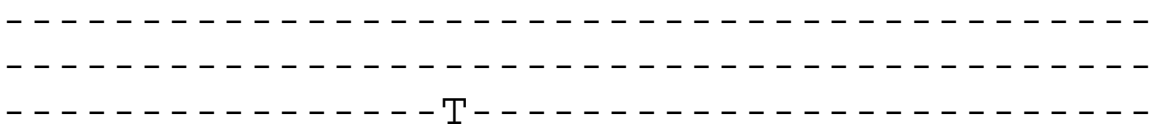

5

6

7

8

GQPHGGGWGQPHGGGWGQWGQGGTHGQWNKPSKPKTNMKHVA
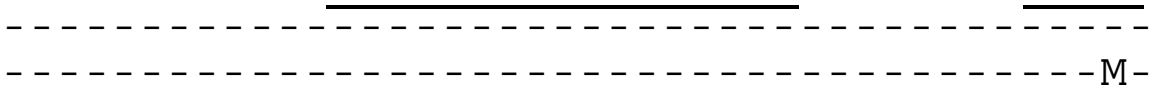

$----------------------------\mathrm{L}----$

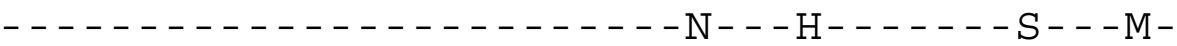

8

9

10

GAAAAGAVVGGLGGYMLGSAMSRPLIHFGSDYEDRYYRENMH

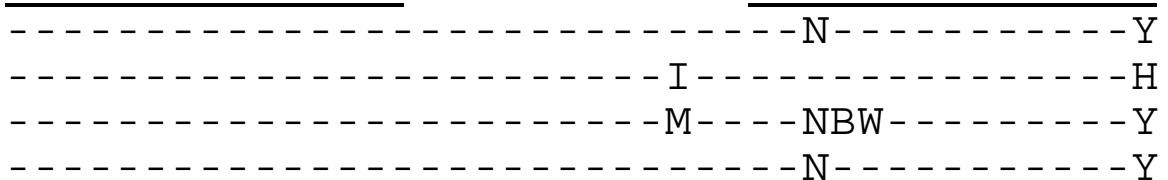

$\begin{array}{llll}10 & 11 & 13 & 14\end{array}$

RYPNQVYYRPVDQYSNQNNFVHDCVNITVKEHTVTTTTKGEN

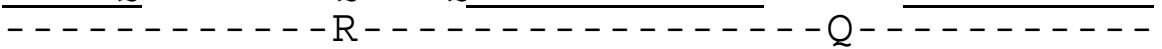

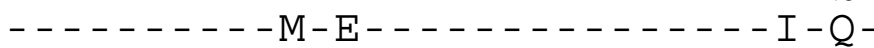

- - - - - - - - - - - - - - - - - - - - - - - - - - - -

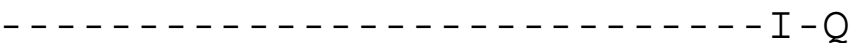

14

15

16

FTETDIKMMERVVEQMCITQYQRESQAYYQRGASVILFSSPP
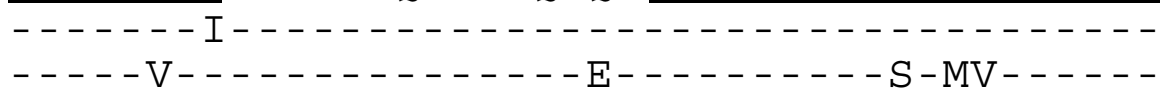

- - - - - - - - - - - - - V- - - K - - - - DG - R- - ST- - - -

- - - - V - - . - . - - - - EK- - - - - - S-MV - - - -

16

Rind VILLISFLIFLIVG

Schaf -..........

Mensch

Maus

M.f.

\section{Abb. 3.6: Aminosäure Sequenzen der Prionproteine}

Gezeigt sind PrP-Sequenzen von fünf Spezies im Vergleich zueinander. Die Lage der Peptide für den ELISA-Test sind durch Unter- bzw Überstreichen der ovinen Sequenzabschnitte markiert. Die sechzehn Peptide überspannen überlappend das gesamte Protein. (M.f) Macacca fasicularis (Schätzl, H. M et al., 1995). 


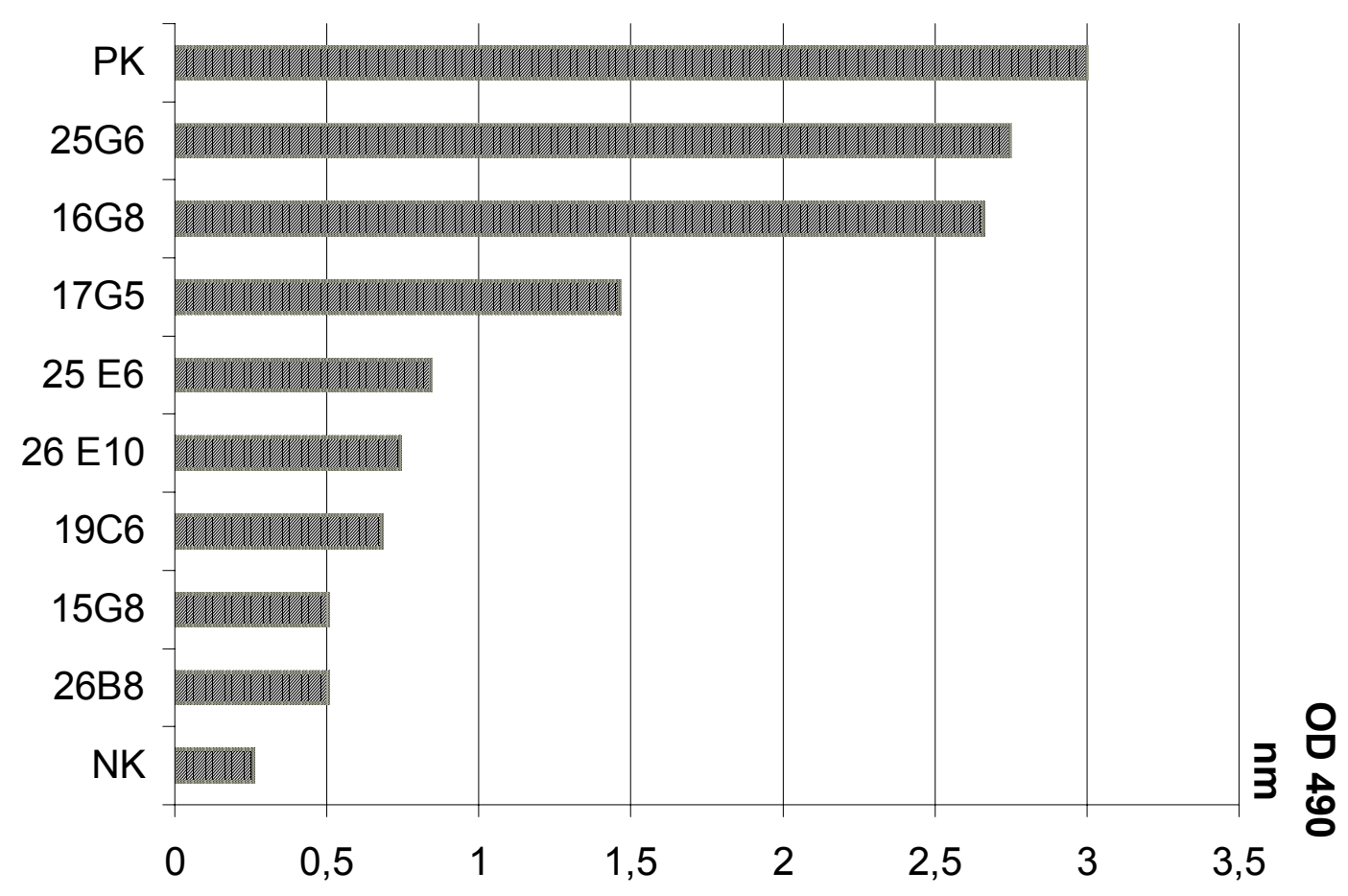

\section{Abb. 3.7: Reaktivität der acht zu stabilen Ziellinie etablierten Hybridomzellen im Peptid-ELISA}

Der Überstand der Hybridomzellen wurde in einem Peptid ELISA mit einem Gemisch der 16 Peptide aus der Sequenz des bovinen Prionproteins untersucht. Als Positivkontrolle (PK) wurde der mAk 3B5, der nur das Peptid 5 erkennt und als Negativkontrolle (NK) Ag8-Zellüberstand verwendet.

\subsubsection{Epitopspezifische Bindung von Antikörpern im Peptid-ELISA}

Mit jedem dieser 16 Peptide, welche die gesamte Aminosäuresequenz des ovinen Prionproteins überspannen, wurde je eine Vertiefung einer Mikrotiterplatte beschichtet und die Bindung der mAk untersucht. Dieser Test wird als gridded array bezeichnet.

Die fünf mAk 15G8, 19C6, 25E6, $25 \mathrm{G} 6$ und 26E10 reagieren mit einer $\mathrm{N}$ terminal gelegenen Region in der repetitiven Domäne, die den Peptiden 4 und 5 entspricht. Die drei weiteren mAk 16G8, 17G5 und 26B8 binden an eine Region, die an die zweite Helixregion angrenzt (Peptid 10). In der Abb.3.8 ist die spezifi- 
sche Reaktion der mAk 15G8 und 17G5 mit p5 bzw p10 gezeigt. Fünf, aus insgesamt acht mAk, reagierten mit Peptid 5. Das Peptid 5 enthält die repetitive Aminosäuresequenz und ist bei fast allen bisher untersuchten Spezies identisch.

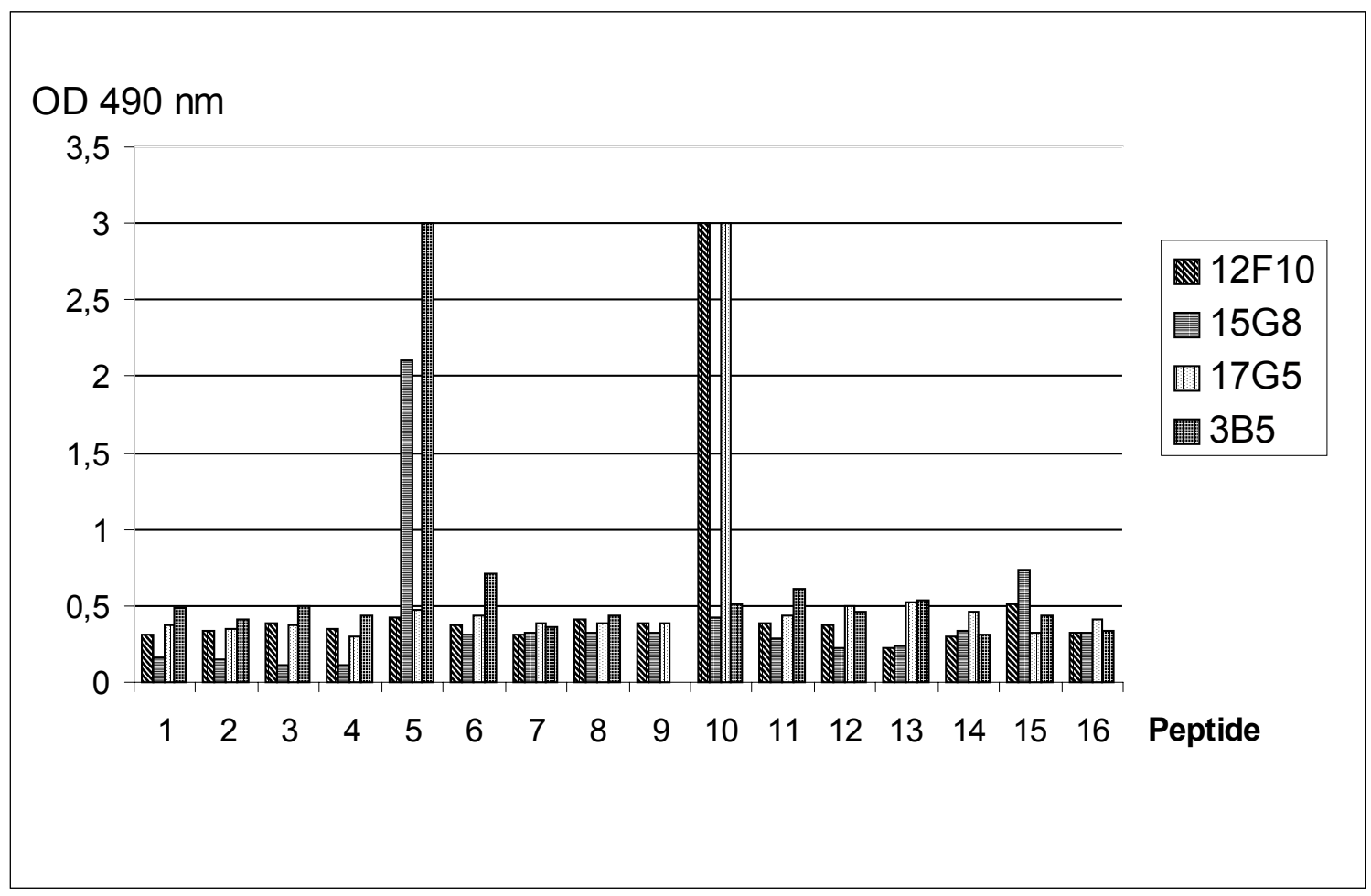

Abb. 3.8: Reaktivität von mAk 15G8 und 17G5 im Peptid ELISA.

Die monoklonalen Antikörper, die von den Hybridomzellen 15G8 und 17G5 produziert worden waren, wurden in einem ELISA mit 16 verschiedenen Peptiden untersucht. MAk $15 \mathrm{G} 8$ und der als Positivkontrolle mitgeführte mAk 3B5 erkennen Peptid 5. MAk 17G5 erkennt Peptid 10. Hier wurde als eine zweite Positivkontrolle der nur gegen Peptid 10 gerichtete mAk 12F10 eingesetzt.

\subsubsection{Epitop-Kartierung der Antikörper mit einem 114 Peptide enthaltenden Gridded-Arrays}

In diesem modifizierten Peptid-ELISA wurden die Antikörper-AntigenBindungen genauer charakterisiert. Dazu wurden 114 Peptide aus je 13 Aminosäurenlängen, die das bovine Prionprotein überlappend überspannten, synthetisiert (EMC ECHAZ Microcollections). Dabei war jedes nachfolgende Peptid gegenüber dem N-terminalen Peptid um jeweils 2 Aminosäuren zum C-terminalen Bereich verschoben. Mit diesen Peptiden wurden die Vertiefungen einer Mikroti- 
terplatte beschichtet und die Bindung der mAk 15G8, 19C6, 25E6, 25G6, 26E10, 16G8, 17G5 und 26B8 untersucht.

Die Reaktion der fünf mAk 15G8, 19C6, 25E6, $25 \mathrm{G} 6$ und 26E10 mit der repetitiven Aminosäuresequenz (AS 47-AS101) ergab wieder ein sehr starkes Signal. Zusätzlich wurden aber andere Epitope (AS 197-220, und AS 221-AS 233) von den gleichen mAk erkannt. In der Abb. 3.9 ist die Reaktivität der mAk gegen die unterschiedlichen Bereiche der bovinen PrP dargestellt. Diese Epitope stellen diskontinuierliche Epitope dar, die auf Grund der Faltung des Proteins entstehen. Besonders auffällig war 15G8, der als einziger mAk mit der C-terminalen Region (AS 220-259) reagierte. Die drei mAk 16G8, 17G5 und 26B8 binden an je zwei unterschiedliche Regionen, die in der Mitte des Prionproteins liegen (AS 150 - AS 179 und AS 215 - AS 240). 


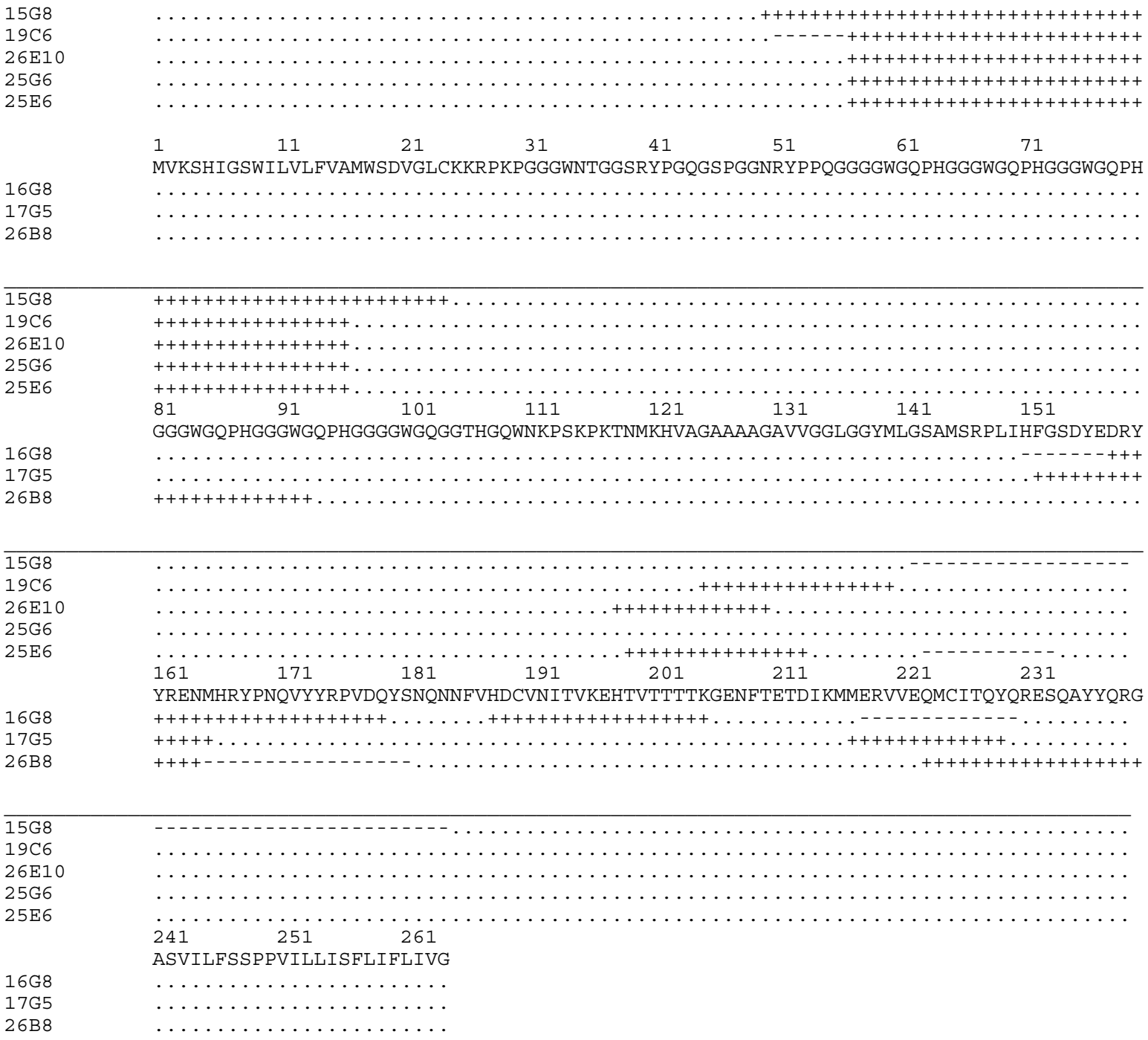

Abb. 3.9: Epitop-Detektion mit unterschiedlichen monoklonalen Antikörpern.

Die Abbildung zeigt die von 1 bis 264 numerierte AS-Sequenz des bovinen Prionproteins. Die Reaktivität der acht Hybridomzellen ist durch ein Plus für ein starkes und ein Minus für ein schwaches Signal symbolisiert. Oberhalb der Sequenz sind die fünf Hybridomzellinien, die gegen den Bereich (AS 51-101) reagierten. Unterhalb der Sequenz sind die drei Hybridomzellinien, die gegen den Bereich (AS 151-235) reagierten.

\subsubsection{Charakterisierung der Antikörperklasse}

Die Antikörperklasse bzw Subklasse gibt Auskunft über die Natur der Immunantwort auf die Immunisierung. Ihre Bestimmung ist entscheidend für die Auswahl geeigneter Reinigungsverfahren für den Antikörper. Zur Identifizierung wurde der IsoStrip Mouse Monoclonal Antibody Isotyping Kit (Boehringer Mann- 
heim) verwendet. Abweichend von den Angaben des Herstellers konnte ein Ergebnis erst nach 20 Min abgelesen werden. Dies läßt sich mit der geringen Konzentration der Antikörper im Hybridomzellüberstand erklären. Die Antikörper ließen sich als lgG $\kappa$ (Kappa) klassifizieren. Kappa bezeichnet hierbei eine der zwei Typen der leichten Kette.

\subsubsection{In vitro Synthetisierung von bovinen PrP im Retikulozytenlysat}

Bei der Immunpräzipitation wird die Fähigkeit eines Antiserums oder Antikörpers untersucht, native Proteine zu erkennen. Um bovine Prionproteine für Immunpräzipitationen bereitzustellen, wurden humane und bovine Wildtyp-Priongene über die Restriktionsenzyme Hind III und Xba I in den zur in vitro Transkription geeigneten Riboprobe-Vektor $\mathrm{pBS}^{+}$(Stratagene, Heidelberg) kloniert. Die durch Sequenzanalyse überprüften Vektoren wurden durch gekoppelte in vitro Transkription unter Kontrolle des T3-RNA-Polymerase-Promotors und in vitro Translation im Kaninchen-Retikulozyten-System $\mathrm{TNT}^{\mathrm{TM}}$ (Coupled Reticulocyte Lysate System; Promega, USA) in Protein umgesetzt. Als Kontrolle diente eine Reaktion ohne DNA-Zugabe und eine weitere Reaktion, in der ein Kontrollvektor mit dem Luziferasegen eingesetzt wurde. Zur radioaktiven Markierung der in vitro synthetisierten Proteine wurde die Reaktion unter Zugabe von 35S-Methionin durchgeführt. Die in vitro Assays wurden nach Angaben des Herstellers durchgeführt, die Proteine im 12,5\%igen PAGE aufgetrennt und durch Autoradiographie nachgewiesen. Prionspezifische Banden der erwarteten Größe zeigten sich nur bei Verwendung von Vektoren mit dem Prion ORF.

In vitro synthetisiertes Prionprotein wurde mit polyklonalen Mausimmunseren sowie Hybridomüberständen inkubiert und die Immunkomplexe anschließend über Protein A Sepharose präzipitiert. Da im Kaninchen-Retikulozyten-System keine Glykosylierung der Proteine stattfindet, erhält man in der SDS-PAGE nur eine Bande, deren Größe aus der Addition der Gewichte der einzelnen Aminosäuren berechnet wurde. Die kalkulierte unglykolysierte Massen von PrP betragen 23,1 kDa und stimmen mit der PrP-Bande, die auf der Abbildung $3.10 \mathrm{zu}$ beobachten sind überein. 
Die Präzipitate wurden im SDS-PAGE getrennt und durch Autoradiographie nachgewiesen. Die Abb. 3.10 zeigt die erwarteten Größe des in Retikulozytenlysat exprimierten Prionproteins.

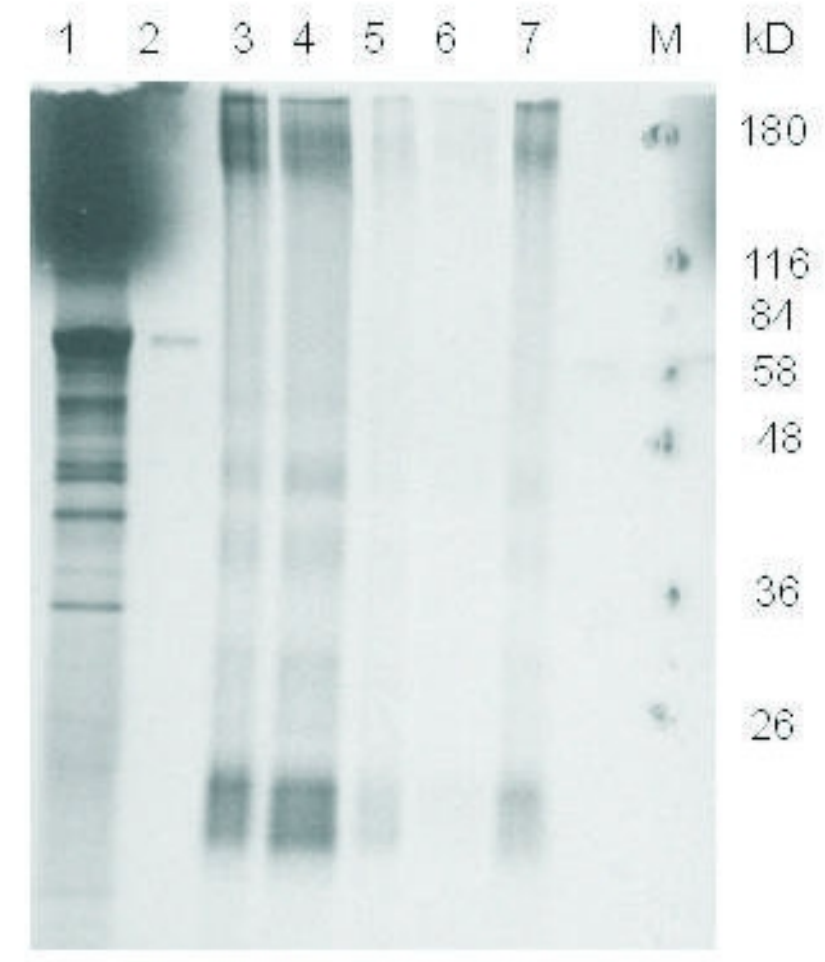

\section{Abb. 3.10: Radioimmunpräzipitation von PrP}

Die Wildtyp-PrP wurden während der in vitro Synthese im Kaninchenretikulozytenlysat metabolisch mit ${ }^{35}$ S-Methionin markiert und wie folgt präzipitiert. Spur (1) Kontroll DNA. Spur (2) Kontroll DNA gewaschen. Spur (3) mAk 3B5. Spur (4) mAk 12F10. Spur (5) mAk 14D3. Spur (6) Ohne Antikörper. Spur (7) mAk 8G8. (M) Marker. Die Antigen-Antikörperkomplexe wurden an Protein A Sepharose gebunden, durch PAGE aufgetrennt und die Proteine durch Radioautographie sichtbar gemacht. Der Pfeil markiert die kalkulierte unglykolysierte Masse des $\operatorname{PrP}(23,1 \mathrm{kDa})$. 


\subsection{Isolierung von Einzelketten-Phagenantikörpern (ScFv) gegen bovine Prionproteine}

Die ScFv-Technik ermöglicht es im Gegensatz zur Hybridomtechnik, die Bindungseigenschaften eines isolierten Antikörpers zu verändern und gegebenenfalls zu verbessern. Dabei werden die Gene für die ScFv aus Hybridomzellen oder auch aus der RNA der Milzzellen von immunisierten Tieren gewonnen. Das Prinzip ist in der Abb. 3.11 dargestellt. Die Antikörpergene aus klonierten Hybridomzellen zeigen alle die gleiche Sequenz, während die Antikörpergene aus den Milzzellen sehr unterschiedlich sind (Dübel et al., 1994). Daher kann man aus Milzzellen kombinatorische Antikörpergenbibliotheken isolieren. Darunter versteht man die zufällige gemeinsame Einfügung verschiedener Gene für die schwere und leichte Kette eines Antikörpers in einen Expressionsvektor. 
schwere Kette

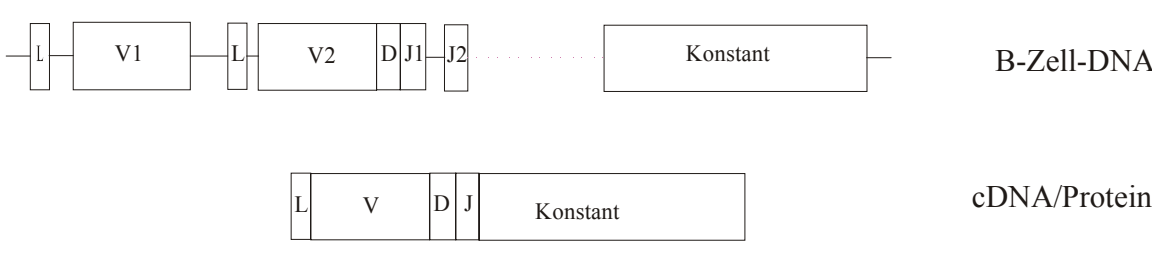

leichte Kette

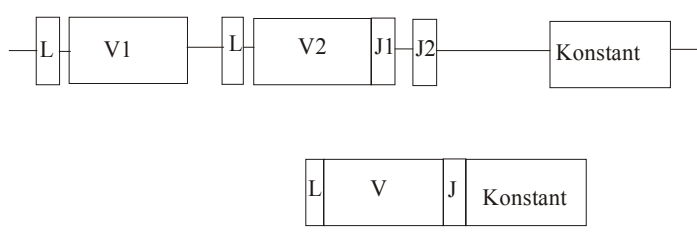

B-Zell-DNA

cDNA/Protein

Kombination verschiedener Genstücke zu single-chain Fv.Fragmenten

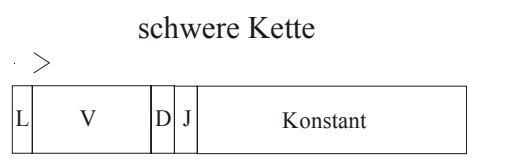
leichte Kette

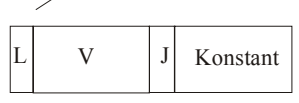

Not I

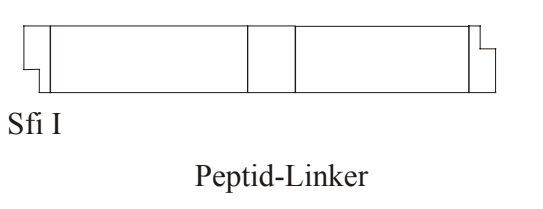

scFv-Antikörperfragment

Antikörper-Anteil

B-Zell-cDNA

\section{Abb. 3.11: Die Quelle der Antikörpergene}

Die Abbildung zeigt schematisch den Zusammenbau des ScFv-Antikörperfragments. Während der natürlichen Entwicklung des B-Lymphozyten-Repertoires entwickelt jeder B-Lymphozyt durch Rekombination der V-, J- und ggf. D-Sequenzen die Gene für seinen spezifischen Antikörper. Die Information für alle diese Antikörpergene befindet sich in ihrer mRNA. Daraus kann sie mit Hilfe der PCR gewonnen werden. Mit je zwei Oligonukleotidprimern -hier durch Pfeile- dargestellt, die an die beiden Enden des gewünschten Genstückes hybridisieren, werden die Vs- und $V_{\mathrm{L}}$-Gene der Antikörper vervielfältigt. Die so gewonnenen Genstücke werden mit DNA-Fragmenten aus anderen Organismen kombiniert und zu ScFv-Fragmenten zusammengesetzt. Die beiden Antikörperketten werden durch ein Peptid von 15 Aminosäuren zu einem einzigen Protein verbunden. 


\subsubsection{Klonierung und Sequenzierung der variablen Gen-Domänen der Hybri- domzellinien}

Als Quelle für die Antikörpergene wurden in dieser Arbeit die Hybridomzellinien 15G8, 16G8, 19C6, 25E6, 25G6 und 26B8 verwendet. Aus diesen Zellen wurde die RNA mit dem RNAesy RNA-Isolierungskit (Qiagen, Hilden) isoliert und mit Hilfe der Reversen Transkriptase in cDNA umgeschrieben. Außerdem wurde die RNA aus den Milzzellen einer immunisierten Maus isoliert und daraus eine cDNA-Bank angelegt. Diese wurde zur Weiterbearbeitung Herrn A. Strom zur Verfügung gestellt. In der Abb. 3.12 ist die Isolierung der RNA von fünf Hybridomklonen dargestellt. Im nächsten Schritt konnten die variablen Genregionen für leichte $\left(\mathrm{V}_{\mathrm{L}}\right)$ und schwere Ketten $\left(V_{S}\right)$ mit Hilfe der PCR-Primer (Pharmacia RPAS System) aus den Zellinien 15G8, 16G8, 25G6 und 26B8 amplifiziert werden. Im Anschluß wurden die Gene für die leichte und schwere Kette über ein präparatives Agarosegel isoliert und gereinigt. Die Abb. 3.13 A zeigt die DNA der leichten und schweren Ketten von vier mAk. Die Genregionen der variablen $\mathrm{V}_{\mathrm{L}}$ - und $\mathrm{V}_{\mathrm{S}}-$ Ketten der Hybridomzellinien 16G8, $25 \mathrm{G} 6$ und 26B8 wurden mit Hilfe eines kurzen Oligonukleotidlinkers in einer weiteren PCR-Reaktion verknüpft. An die Enden der so ligierten ScFv-Moleküle wurden mit einer dritten PCR-Reaktion zwei Restriktionsschnittstellen für Sfi I und Not I eingebaut. Nach Restriktionsverdau mit diesen Restriktionsenzymen wurde die zuvor aus dem Agarosegel isolierte DNA in den Expressionsvektor pCANTAB 5 E (verdaut mit Sfi I und Not I) ligiert. Die drei Ligationsansätze wurden dann in E. coli TG1 elektroporiert, auf LB-AMP-Platten ausplattiert und über Nacht bei $37^{\circ} \mathrm{C}$ inkubiert. Am nächsten Tag konnten die Phagenantikörper pC16G8 und der pC26B8 isoliert werden. Nach einer Minipräpatation der Phagemid-DNA ließen sich das Vorhandensein der 750 bp langen ScFv-Inserts durch Verdauung mit Sfi I und Not I wie in der Abb. 3.13 B dargestellt bestätigen.

Die ScFv-Fragmente der pC16G8 und pC26B8 DNA wurden nun vollständig sequenziert. Die Abb. 3.14 zeigt die DNA Sequenz der Phagenantikörper pC16G8. Diese DNA-Sequenz wurde mit Hilfe des Computerprogramms DNASIS in die in Abb. 3.15 dargestellte Proteinsequenz übersetzt. Durch einen Computervergleich mit der SWISSPROT Datenbank konnten die hypervariablen Domänen-CDRs (engl. complementary determining regions) der $\mathrm{V}_{\mathrm{L}}$ - und $\mathrm{V}_{\mathrm{S}}-$ Ketten identifiziert werden. Die Abb. 3.16 stellt die verschiedenen Bereiche, die bei der Erkennung der 
Antigene beteiligten variablen Regionen der Antikörper dar. Es fällt auf, daß die Aminosäuresequenz der CDR 3-Region der schweren Kette nur von den vier Aminosäuren YTSQ bei pC16G8 und den acht Aminosäuren DSGTGFAY bei pC26B8 aufgebaut werden. Die CDR 3 Region ist in der Regel zwischen 3-25 Aminosäuren lang und für die Affinität eines mAk entscheidend.

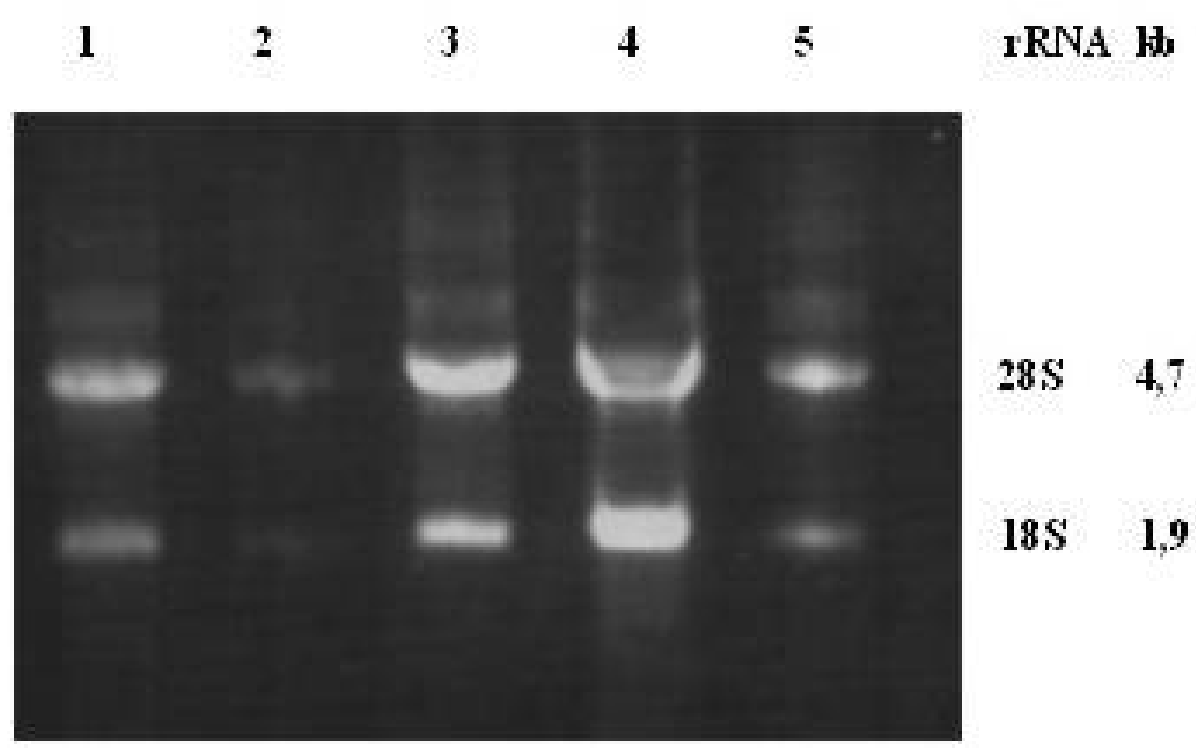

\section{Abb. 3.12: Gesamt-RNA der Hybridomzellen}

Die Abbildung zeigt die gesamte RNA der mAK in Spur (1) 25G6, Spur (2) 16G8, Spur (3) 19C6, Spur (4) 26B8 und in Spur (5) 25E6. Die ribosomalen RNA-Banden 28S und $18 \mathrm{~S}$ bei $4,7 \mathrm{bzw} 19 \mathrm{kB}$ sind als distinkte Banden zu sehen. Sie dienten als Anhalt für den Erfolg der RNA-Isolierung. 

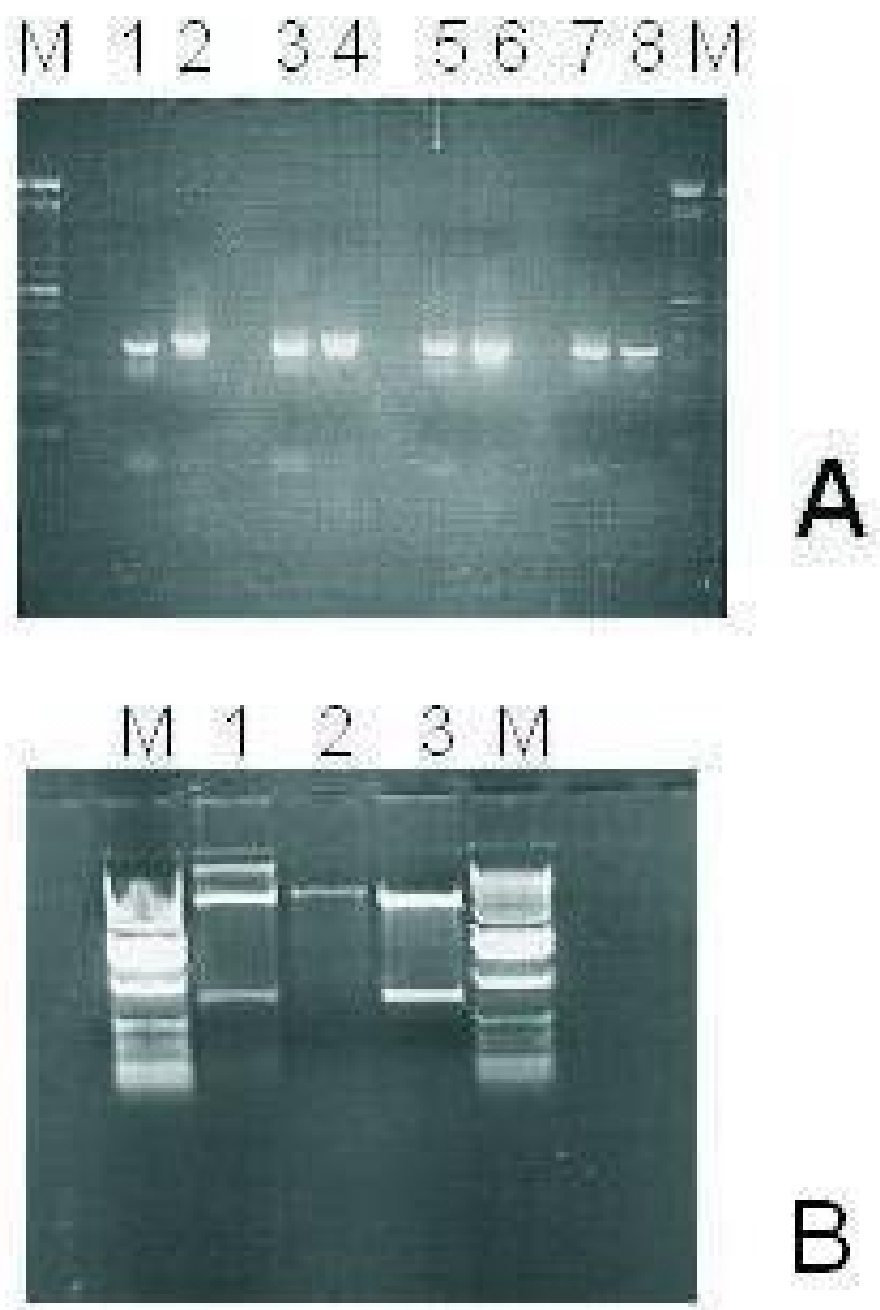

\section{Abb. 3.13: Die schweren und leichten Ketten der Hybridome und Nachweis der inserierten Fragmente}

(A) Die DNA der leichten und schweren Kette der mAk $25 G 6$ (1), (2), $16 \mathrm{G8}$ (3), (4), 26B8 (5), (6) und 15G8 (7), (8) und 100 bp Marker (M) wurde auf ein 1\%iges Agarosegel aufgetragen.

(B) Zur Überprüfung der inserierten Fragmenten wurde das Plasmid durch Sfi I und Not I verdaut. Phagenantikörper pC16G8 und pC26B8 sind in Spur (1) bzw in Spur (3) gezeigt. In Spur (2) ist die unverdaute pC26B8 aufgetragen. (M) 1 kB Marker. 


\begin{tabular}{|c|c|c|c|c|c|}
\hline $\mathrm{GT}$ & C & CССАТTCAGA & & & 50 \\
\hline TTGTTCTGCG & GCCCCGTGAT & GGTGATGATG & ATGTGCGGCC & GCACCTAGGA & 100 \\
\hline CGGTCAGCTT & GGTCCCTCCG & CCGAATACAG & ССТТАССАСТ & GCTGTCCCGG & 150 \\
\hline GAGTTACAGT & AATAGTCAGC & СТСАТСТТСС & GCCTGAGCCC & CAGTGATGGT & 200 \\
\hline CAAGGAAGCT & GTGTTTCCTG & AGCTGGAGCC & AGTGAATCGG & TCTGGGATCC & 250 \\
\hline CTGAGGGCCG & GTTGTTTTTA & CCATAGATGA & CAAGTACAGG & GGCCTGTCCT & 300 \\
\hline GGCTTCTGCT & GGTACCAGCT & TGCATAATAG & СTTCTGAGGC & TGTCTCCTTG & 350 \\
\hline GCATGTGATC & CTGACTGTCT & GTCCCAAGGC & CACAGACACA & GCAGGGTCCT & 400 \\
\hline GAGTCAGCTC & AGAAGAAAGT & GCACTACCGC & CAGAGCCACC & TCCGCCTGAA & 450 \\
\hline CCGCCTCCAC & CACTCGAGAC & GGTGACCAGG & GTACCTTGGC & CCCACTGCGA & 500 \\
\hline AGTATATCTT & GCTCAGTAAT & ACACGGCCGT & GTCCGCGGCG & GTCACAGAGC & 550 \\
\hline TCAGCTTCAG & GGAGAACTGG & TCTTGGACCT & GTCTACTGAT & ATGGTGACTC & 600 \\
\hline GACTCTTGAG & GGACGGGTTG & TAGTAGGTGC & TСССАСТАТG & ATAGATGTAC & 650 \\
\hline ССААТССАСТ & CCAGGCCCTT & CCCTGGTGGC & ГGCCGGATCC & AGCTCCAGGA & 700 \\
\hline GTAACCACCA & CTGCTGATGG & AGCCACCAGA & ACAGCGCAT & जTGAGGACAG & 750 \\
\hline CTGTGAA & GGCTTC & ГССТTGAАG & ECCCGACTT & ССTTGCCAG & 80 \\
\hline ГTGCACCCT & GGCCCCATG & CGGCTGGG & GTTA & ААССAАТTС & 850 \\
\hline
\end{tabular}

\section{Abb. 3.14: DNA-Sequenz der ScFv-Fragment von pC16G8}

Die Abbildung zeigt die Insert DNA-Sequenz, die in den Vektor pCANTAB 5E kloniert wurde. Neben anderen Motiven für z.B. CDR-1 nt 692 bis nt 736 und CDR-2 nt 602 bis nt 649 findet sich das CDR-3 Motiv der schweren variablen Kette von nt 495 bis 506.

EAGXELVXNLXGXXPGHGXQGCKLAREVGGFKDWSLHRPCXXTCAVSGGS ISSGGYSWSWI RQPPGKGLEWIGYIYHSGSTYYNPSLKSRVTISVDRSKNQFSLKLSSVTAADTAVYYARYT SQWGQGTLVTVSSGGGGSGGGGSGGSALSSELTQDPAVSVALGQTVRITCQGDSLRSYYAS WYQQKPGQAPVLVIYGKNNRPSGI PDRFTGSSSGNTASLTITGAQAEDEADYYCNSRDSSG KAVFGGGTKLTVLGAAAHHHHHHGAAEQKLISEEDLNGAVIDC

\section{Abb. 3.15: Proteinsequenz des ScFv-Fragmentes pC16G8}

Die in Abb. 3.14 dargestellte DNA-Sequenz wurde mit dem Programm DNAsis (Version 2.5, Hitachi Software, San Francisco, CA, USA) anslysiert. 
Schwere Kette

\begin{tabular}{|c|c|c|c|c|c|c|c|}
\hline & FR1 & CDR1 & FR2 & $\mathrm{CDR} 2$ & FR3 & CDR3 & FR4 \\
\hline pC16G8 & EVGGFKDWDLHRPCTC & AVSGGSISSGGYSWS & WIRQPPGKGLEWIG & YIYHSGSTYYNPSLKS & RVTISVDRSKNQFSLKLSSVTAADTAVVYCAR & YTSQ & WGQGTLVTVSS \\
\hline pC26B8 & SCQPSGIHFQEANAQC & LWGF & RPDSKKKGCEVGPI & HKWWLHLLLQNTVKG & RFTISKDNARNTLYLQMSSLKSEDTAMYYCTR & $\overline{\text { DSGTGFAY }}$ & WGQGITVIVSSS \\
\hline
\end{tabular}

Leichte Kette

\begin{tabular}{|llllll|}
\hline & FR1 & CDR1 & FR2 & CDR2 & FR3 \\
\hline pC16G8 & QDPAVSVALGQTVRITC & QGDSLRSYYAS & WYQQKPGQAPVLVIY & GKNNRRS & GIPDRFTGSSSGNTASLTITGAQAEDEADYYC \\
\hline pC26B8 & QSLSSLTVTAGEKVTMSCKSE & SLLNSGNQKNYLT & WYQQKPGQPPKLLIY & WASTRES & NVRDSSGKAV FRG FGGTKLTVLG \\
\hline
\end{tabular}

\section{Abb. 3.16: Proteinsequenz der ScFv-Fragmente pC16G8 und 26B8}

Die in Abb. 3.15 dargestellte Proteinsequenz des ScFv-Fragments pC16G8 wurde nach Martin A.C.R (1996) analysiert. Ebenso wurde mit dem in den Abbildungen 3.14 und 3.15 nicht dargestellten ScFv-Fragment p26B8 verfahren.

\subsubsection{Expression und Nachweis der ScFv-Antikörper}

Die ScFv-Technik beinhaltet die Klonierung und Expression der Antikörpergene in den filamentösen Phagemidvektor pCANTAB 5E. Dieser einzelsträngige DNA-Phage ist in Gegenwart des Helferphagen M13K07 in der Lage, sich in E. coli Zellen zu replizieren und infektiöse Phagenpartikel zu bilden. Der Phage trägt fünf Kopien des Hüllproteins cplll an seiner Spitze, deren Funktion in der Anheftung an die bakteriellen F-Pili besteht. Das aus $16 \mathrm{G} 8$ isolierte ScFv-Fragment wurde zusammen mit dem cp3-Gen als Fusionsprotein auf der Oberfläche der Bakteriophage exprimiert. Daher war es möglich, den Phagen, der den gewünschten Antikörper exprimiert, aus einer Mischung von vielen anderen Phagen zu selektieren (engl.: panning).

Als Antigen wurde eine Mischung aus 16 verschiedenen 10-40mer Peptiden verwendet, welche die gesamte Aminosäuresequenz des ovinen Prionproteins überspannen. Mit dieser Peptidmischung wurden Mikrotiterplatten beschichtet und anschließend mit den drei isolierten Phagenantikörpern pC16G8, pC25G6 und C26B8 inkubiert. Die nicht gebundenen Phagen wurden abgewaschen. Die Phagen, die das ScFv-Gen des Phagenantikörpers auf der Phagenoberfläche exprimierten, wurden vermehrt, indem mit ihnen wiederum Bakterien infiziert wurden (engl.: phage rescue). Nachfolgend wurde die Bindung des pC16G8 im PeptidELISA mit Hilfe von Peroxidase-markierten Anti-Phagen-Antikörpern nachgewiesen. 


\subsubsection{Spezifische PrP-Erkennung im Westernblot}

Die Fähigkeit der Phagenantikörper, PrP zu erkennen, wurde im Westernblot untersucht. Dazu wurde die Proteinfraktion einer 3T3 Zelle extrahiert. Die 3T3 Zellen tragen das humane FFI-Gen stabil und durch Tetracykline induzierbar im Genom. Diese murinen Zellen wurden von Dr. A. W. Stuke, DPZ zur Verfügung gestellt. Es wurden $1 \times 10^{6}$ Zellen in $40 \mu$ LSEB-Puffer aufgeschlossen und in einem 12\%igen SDS-PAGE Gel aufgetrennt. Alle eingesetzten Phagenantikörper, pC16G8, pC26B8 und pC25G6, binden spezifisch an die drei charakteristischen Prionproteinbanden. Diese sind die nicht glykosylierte bei 23-27 kDa und die einfach und doppelt glykosylierten bei 28-30 bzw 33-42 kDa. Der Film wurde nach nur einer Sek nach dem Auflegen auf die Nitrozellulosemembran entwickelt. Die Abb. 3.17 zeigt die spezifische PrP-Bindung der drei Phagenantikörper im Westernblot. In der Tab. 3.1 sind die Ergebnisse der molekularen Charakterisierung zusammengefaßt. 


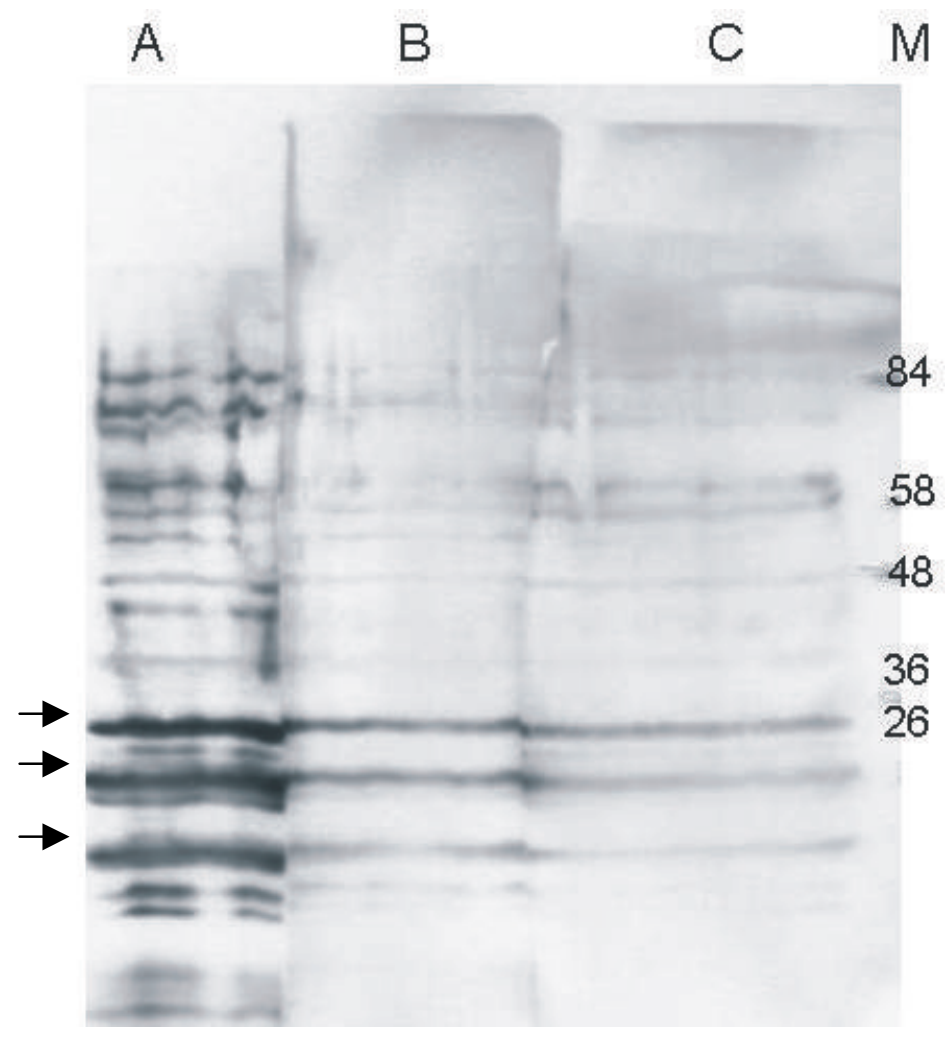

\section{Abb. 3.17: ECL-Westernblot mit rekombinantem humanen PrP}

Für die Westernblotanalyse wuchs der Zellklon 3T3-Tet-Off-17+ in Medium ohne Tetracykline. Die murinen Zellen produzieren konditional rekombinantes humanes murines PrP. Die Bindungseigenschaft der Phagenantikörper an das PrP wurde mit dem ganzen Zellextrakt der Zellen in einem 12\%igen SDS-PAGE Gel analysiert. Nach Transfer der Proteine auf eine Nitrozellulose, der Membran wurde mit den Phagenantikörpern pC16G8 in Spur (A), pC26B8 Spur (B) und pC25G6 Spur (C) zuerst über Nacht und dann mit HRP-konjugiertem anti M13-Antikörper für 2 Std. inkubiert. (M) Marker Nach einer Exposition von einer Sek waren die drei typischen PrP-Glykoformen (un-, einmal- und zweimal glykosyliert) zu sehen (s Pfeile). 
Tab. 3.1 Eigenschaften der der gewonenen PrP-spezifischen monoklonalen und Phagenantikörper

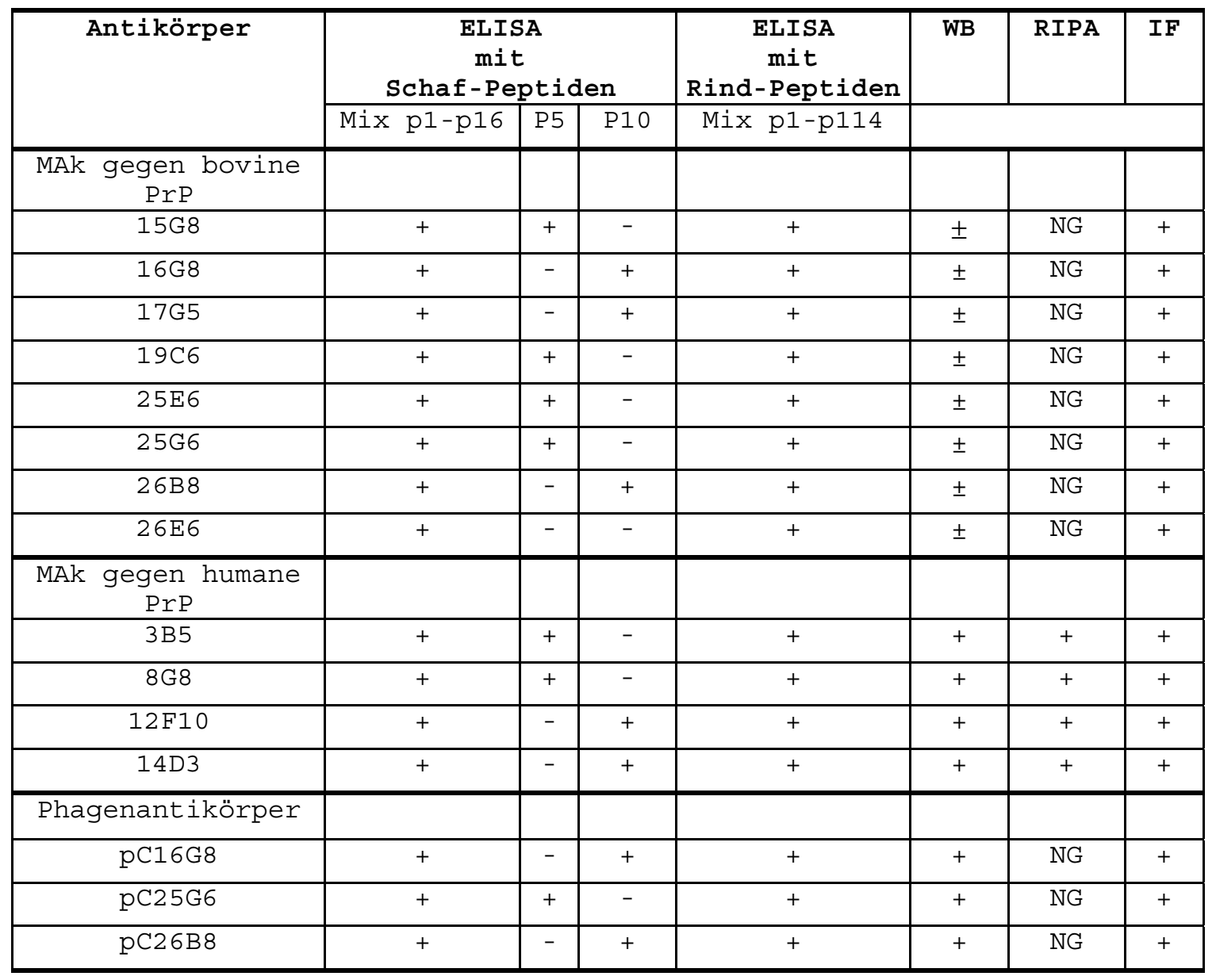

(+) Positiv, (-) Negativ , ( \pm ) schwach und (NG) nicht getestet. 


\section{Diskussion}

Monoklonale Antikörper sind wertvolle Hilfsmittel nicht nur in der Immunologie, sondern auch für Diagnosezwecke und in der Grundlagenforschung geworden (Gavilondo und Larrick, 2000). Um Antikörper gegen Prionproteine unter Anwendung der klassischen Techniken herzustellen, sind in den letzten Jahren viele Versuche durchgeführt worden. Zum ersten Mal konnten auch mittels einer DNAvermittelten Immunisierung zahlreiche Antikörper gegen PrP hergestellt werden (Krasemann et al., 1996). Alle Experimente zeigten, daß es jedoch schwierig war, einen speziespezifischen Antikörper zu isolieren, der dazu auch noch zwischen den unterschiedlichen Isoformen differenzieren kann.

Das Prionprotein kommt in zwei unterschiedlichen Isoformen vor. Die beiden Isoformen des PrP haben die gleiche Primärstruktur, obwohl sie unterschiedlich gefaltet werden. Die Umwandlung findet wahrscheinlich mit Hilfe eines unbekannten Kofaktors während der Replikation des Prionproteins statt (Liautard, 1991, Carr, 1993, Telling et al., 1995, Priola et al., 1995, Edenhofer et al., 1996, Kaneko et al., 1997). Durch diese Veränderung erlangt der Erreger eine partielle Verdaubarkeit durch Proteinase $\mathrm{K}$, einen vermehrten beta-Faltblattstrukturanteil und wird in nicht-denaturierenden Detergenzien wie Triton-X100 unlöslich. Da chemisch keine Unterschiede zwischen beiden Proteinen festgestellt werden konnten, muß es sich um Konformationsisomere handeln. Zwar gibt es NMR-Strukturen von einem verkürzten murinen PrP (AS 121-231) (Riek et al., 1996) und einem bovinen PrP (Lopez et al., 2000), welche rekombinant in E. coli exprimiert wurden. Von $\mathrm{PrP}^{\mathrm{SC}}$ gibt es dagegen aber bisher nur computergestützte Strukturmodelle (Abb. 1.2). Neuerdings wurden verschiedene Glykosylierungmuster für die beiden Isoformen beschrieben (Zuegg und Greedy, 2000).

Prion-Erkrankungen sind übertragbare neurodegenerative Krankheiten bei Menschen und Tieren (Prusiner, Fields Virology, 1996). Wie bereits erwähnt ist der infektiöse Erreger eine Isoform des zellulären Prionproteins. Das Vorhandensein der unterschiedlich gefalteten konformationellen Isoformen des normalen Wirtsproteins sollte zur Folge haben, daß Epitope auf der Oberfläche von $\operatorname{PrP}^{\mathrm{SC}} \mathrm{zu}$ finden sind, die nicht auf der $\operatorname{PrP}^{C}$ Oberfläche vorkommen. Diese $\operatorname{PrP}^{\mathrm{SC}}$ spezifi- 
schen Epitope sind daher vermutlich an der Krankheitsentwicklung beteiligt. Ihre Identifizierung ist daher für ein besseres Verständnis der TSE-Pathogenese wichtig. Außerdem sollten faltunsspezifische Epitope nach einer Immunisierung durch die humorale Immunantwort erkannt werden. Bei den natürlichen oder experimentellen Infektionen von Wildtyp-Tieren mit den Erregen der Prion-Krankheiten konnte keine humorale und zelluläre Immunantwort gefunden werden (Kascsak et al., 1987). Dies liegt entweder an der Toleranz gegen eigene Proteine, oder der Suppression der humoralen Immunantwort oder an anderen bisher unbekannten Mechanismen.

Obwohl, wie bereits erwähnt, bis heute viele Versuche von unterschiedlichen Arbeitsgruppen durchgeführt wurden, um mAk gegen Prionproteine mit Hilfe der klassischen, der DNA-vermittelten und der Partikel-Immunisierungstechnik zu isolieren, führten diese Ansätze zu keinem einzigen Antikörper, der zwischen den beiden Isoformen unterscheiden kann. (Bendheim et al., 1984, Kascsak et al., 1987, Barry et al., 1988, Barry et al., 1986, Gabizon et al., 1988, Serban et al., 1990, Rogers et al., 1991, Ulmer et al., 1993, Krasemann et al., 1996, Yokoyama et al., 1996, Korth et al., 1997, Harmeyer et al., 1998).

In Wildtyp-Mäusen wurden zunächst mAk gegen PrP hergestellt, die mit aus Hamsterhirnen gereinigten hochinfektiösen $\mathrm{PrP}^{\mathrm{SC}}$ immunisiert worden waren (Bendheim et al., 1984, Kascsak et al., 1987, Williamson et al., 1996). Diese mAk sowie weitere mit Hilfe des Vaccinia Virus Expressionssystems hergestellte mAk (Rogers et al., 1991) erkannten nur lineare und keine $\mathrm{PrP}^{\mathrm{SC}}$ spezifischen diskontinuierlichen Epitope. Die große Schwierigkeit, einen mAk herzustellen, der nur mit der Krankheit-assoziierten Isoform reagiert, ist die Folge der gleichen primären Proteinsequenz von $\operatorname{PrP}^{\mathrm{C}}$ und $\operatorname{PrP}^{\mathrm{SC}}$.

In PrP-Knockout Mäusen (Prusiner et al., 1993) konnte die Induktion einer Immunantwort mit gereinigtem $\operatorname{PrP}^{\mathrm{SC}}$ (Williamson et al., 1996) und mittels einer DNA oder Partikel-Immunisierung (Ulmer et al., 1993, Krasemann et al., 1996) erreicht werden, und führte zur Herstellung von zahlreichen mAk. Auch diese mAk erkannten alle die beiden PrP-Isoformen. Eine mögliche Erklärung dafür wäre eine Konformationsveränderung von $\mathrm{PrP}^{\mathrm{SC}}$ während der Isolierung, die in der Regel unter denaturierenden Bedingungen stattfindet.

Der Gedanke, daß einige Epitope bei $\operatorname{PrP}^{\mathrm{C}}$ verborgen sind, aber bei $\mathrm{PrP}^{\mathrm{SC}}$ auf der Oberfläche erscheinen, führte dazu, daß einige Arbeitsgruppen mit Peptiden 
Kaninchen oder Wildtyp-Mäuse immunisiert haben (Barry et al., 1986, Yokoyama et al., 1996). Auch diese Experimente haben bis heute nicht zum gewünschten Erfolg geführt. Es ist jedoch nicht auszuschließen, daß eine Peptid-Immunisierung mit Sequenzen, die nur auf der Oberfläche von $\operatorname{PrP}^{\mathrm{SC}}$, aber nicht auf der von $\operatorname{PrP}^{\mathrm{C}}$ vorkommen, zur Induktion dieser Antikörper führen könnte. Wildtyp-Mäuse, die Toleranz gegen Maus-PrP zeigen, produzierten mAk gegen das PrP von Schafen, wenn sie mit synthetischen Schaf-Peptiden immunisiert worden waren, da die Schaf-Peptide eine abweichende Aminosäuresequenz haben (Harmeyer et al.,1998).

\subsection{Immunisierung von $\mathrm{PrP}^{0 / 0}$-Mäusen mit rbSFV Partikeln und Isolierung von monoklonalen Antikörpern}

In dieser Arbeit wurde zum ersten mal die rbSFV Partikel-vermittelte Immunisierung zur Isolierung von Anti-PrP mAk angewandt. Diese neue Methode bietet gegenüber der Immunisierung mit Proteinen, mit synthetischen Peptiden, oder mit nackter RNA oder DNA viele Vorteile (Berglund et al., 1993). Die in die Mäuse injizierte nackte DNA oder RNA kann durch die zelleigenen Nukleasen abgebaut werden, bevor es zur Proteinexpression kommt. Während bei der Immunisierung mit Proteinen die native Konformation des Immunogens durch die Aufreinigungstechnik zerstört werden kann, wird bei der Immunisierung mit SFV-Partikeln das Antigen in vivo synthetisiert. Der Expression des Proteins in den infizierten Mauszellen sollten sich dann die authentische Prozessierung, der Transport und die MHC-Präsentation anschließen. Die Verwendung von SFV Vektoren war auch wegen der großen Virusvermehrung, des hohen Partikeltiters und der Wirtsbreite attraktiv. Da bei dieser Immunisierung der Kontakt mit dem pathogenen PrP umgangen wird, ist die biologische Sicherheit bei der Arbeit mit dem SFV-Vektoren gewährleistet (Liljeström und Garoff, 1991). Während bei der Immunisierung mit gereinigten $\mathrm{PrP}^{\mathrm{SC}}$ eine Verunreinigung der Präparation mit anderen Proteinen nicht ausgeschlossen werden kann, kann bei der Partikelimmunisierung das Antigen ohne Kontaminationen präsentiert werden. Daher ist die mit dieser Methode induzierte Immunantwort hoch spezifisch gegen PrP.

Um rbSFV Partikel herzustellen wurde zuerst der offene Leserahmen (ORF) des bovinen Priongens in die Hind III und Xba I Schnittstellen von SFV kloniert. 
Dieses rbSFV und der Helfer SFV II, der die Hüllproteine von SFV enthält und die Verpackung der SFV RNA-Sequenzen ermöglicht, wurden mit Spe I linearisiert und durch in vitro Transkription in RNA umgeschrieben. Um rbSFV Partikel für die Immunisierung der $\mathrm{PrP}^{0 / 0}$-Mäuse zu produzieren, wurden mit dem Transkriptionsansatz BHK-Zellen elektroporiert. Da wildtyp Mäuse immuntolerant sind, wurden in dieser Arbeit $\mathrm{PrP}^{0 / 0}$-Mäuse immunisiert. Von diesen Mäusen war bereits bekannt, daß sie nach einer Immunisierung mit murinen Prionen eine polyklonale Immunantwort aufbauen (Prusiner et al., 1993). Zur Produktion der mAk wurden die Milzzellen von sechs Mäusen nach vier Auffrischungsimmunisierungen entnommen und mit permanent wachsenden Myelomzellen durch PEG fusioniert. Die Größe der Milz der immunisierten $\mathrm{PrP}^{0 / 0}$-Mäuse hatte sich verdoppelt, während die der immunisierten Wildtyp Mäuse unverändert blieb.

Die aus der Fusion resultierenden Hybridklone wurden dann auf ihre Fähigkeit getestet, Antikörper gegen Prionproteine zu sezernieren. Zunächst wurde dazu die Bindung der mAk an bovines Prionprotein an PrP-überexprimierenden BHK-Zellen im Immunfluoreszenztest untersucht. Hierfür waren die BHK-Zellen zuvor mit in vitro hergestellter rekombinanter boviner SFV-RNA elektroporiert worden. Mit dieser Methode wurde die Sekretion prionproteinspezifischer Antikörper von insgesamt mehr als 800 unabhängigen Klonen untersucht. Die Ergebnisse der Immunfluoreszenz zeigten, daß diese Art der Immunisierung die Biosynthese von polyklonalen Antiseren gegen das bovine Prionprotein zur Folge hatte. Die AntikörperAntigen-Bindung der Hybridomkulturüberstände und der mAk wurden mit PeptidELISAs, der Immunfluoreszenz und teilweise mit der Radioimmunpräzipitation untersucht. Die Peptid-ELISA-Technik weist Antikörper nach, die spezifisch lineare Epitope des Prionproteins erkennen. Die beiden anderen Nachweismethoden können auch Antikörper identifizieren, die Epitope auf dem nativen Prionprotein binden. Diese Epitope können sowohl linear als auch diskontinuierlich sein. Für den Peptid-ELISA wurden 16 ovine Peptide ausgewählt, welche die gesamte Aminosäuresequenz des Prionproteins abdecken. Für den ELISA wurde eine Mischung der Peptide an die Oberfläche von Mikrotiterplatten gebunden. Von den 800 untersuchten Hybridklonen wurden mit Hilfe des ELISAs und der Immunfluoreszenz insgesamt 510 Hybridklone identifiziert. Damit ist die Anzahl PrPspezifischer Hybridklone hier sehr viel höher als die von Kascsak (1987) und die von Krasemann (1996) beschriebene Fusionsausbeute. Die erste Arbeitsgruppe 
untersuchte über 400 Hybridklonen und identifizierte nur drei PrP-spezifische Antikörper, von denen nur eine als stabile Zellinie etabliert werden konnte. Dieser mAk 3F4 reagiert sowohl mit dem humanen als auch dem PrP des Hamsters (AS109111). In der zweiten Arbeit reagierten von 274 untersuchten Hybridklonen 21 gegen das humane PrP positiv. Die meisten mAk reagierten mit der repetetiven $\mathrm{Re}-$ gion des PrP. Nur der mAk $12 \mathrm{~F} 10$ erkennt sowohl das humane als auch das bovine PrP und bindet an AS150-165 (Bodemer, 1999). In dieser Arbeit konnten von 510 Hybridklonen insgesamt acht unterschiedliche Hybridomzellinien als stabile Zellinien etabliert werden (15G8, 16G8, 17G5, 19C6, 25E6, 25G6, $26 \mathrm{~B} 8$ und 26E10), wobei die Monoklonalität durch Verdünnung und mehrmalige Klonierung gewährleistet wurde. Die Antikörper ließen sich als IgGк (Kappa) klassifizieren, wobei Kappa hierbei eine der zwei Typen der leichten Kette bezeichnet. Um die Konzentration der mAk im Zellüberstand zu erhöhen, wurden die gegen das bovine PrP gerichteten mAk $15 \mathrm{G} 8$ und 26B8 und die gegen das humane PrP gerichteten mAk 3B5 und 12F10 in einem Minifermenter kultiviert. Obwohl die Konzentration der mAk 3B5 und 12F10 mit diesem System nicht gesteigert werden konnte, hatte sich diejenige der mAk $15 \mathrm{G} 8$ und 26B8 verdoppelt.

Mit Hilfe der Elektronenmikroskopie konnten in der Kultur von mAk 3B5 endogene A-Partikel-Retroviren nachgewiesen werden (persönliche Mitteilung, W. Lüke, DPZ). Diese Aktivierung der endogenen Viren könnte zur Wachstumsbeschränkung der Kulturen geführt haben. Außerdem könnte eine Kontamination der in Mäusen hergestellten mAk mit Retroviren deren therapeutische Anwendung beeinträchtigen. Alternativ zum Minifermenter ließe sich eine Erhöhung der mAk Ausbeute auch mittels der in vivo Vermehrung von Hybridklonen durch Injektion in Mäuse erreichen. So können 5-10 mg Antikörper/ml aus der Ascitesflüssigkeit einer Maus aufgereinigt werden. Aus Tierschutzgründen ist dieses in Deutschland aber nicht möglich.

\subsection{Charakterisierung der Bindungseigenschaften der monoklo- nalen Antikörper}

Die Bindungsepitope der acht mAk wurden in einem modifizierten PeptidELISA (114 Peptid Gridded-Array) genauer untersucht. Dazu wurden 114 synthetische Peptide von je 13 Aminosäuren Länge, die das bovine Prionprotein abdek- 
ken, synthetisiert. Diese Epitop-Kartierung dient zur Identifizierung der genauen Aminosäureposition, an die der mAk bindet. Die Konformationsänderung von $\mathrm{PrP}^{\mathrm{C}}$ zu PrP ${ }^{\mathrm{SC}}$ kann mit Hilfe von monoklonalen Antikörpern auf molekularer Ebene detailliert analysiert werden, wie das für das Krebssupressor-Protein p53 der Fall war (Milner und Midcalf, 1991). Für das Verständnis der Pathogenese und der Infektiosität wäre es eine große Hilfe, wenn wir die Umwandlung des normalen zum pathogenen PrP und den Biosyntheseweg von PrP genau verstehen würden (Bodemer 1999). Daher wurde in dieser Arbeit auf eine genaue Charakterisierung der mAk Wert gelegt. Außerdem ließen sich mit gut charakterisierten mAk Formen von $\operatorname{PrP}$ erkennen, die vielleicht noch zwischen $\operatorname{PrP}^{\mathrm{C}}$ und $\mathrm{PrP}^{\mathrm{SC}}$ existieren (Eigen, 1996). Die Ergebnisse der Epitop-Kartierungen der mAk sind in der Tab. 4.1 zusammenfassend dargestellt.

Die fünf in dieser Arbeit hergestellten mAk 15G8, 19C6, 26E10, $25 G 6$ und 25E6 binden an dem N-terminalen Bereich des bovinen PrP (AS 50 - 105). Dieser Bereich wird auch von mAk 3B5 beim humanen PrP erkannt. Der N-Terminus hat im Gegensatz zum übrigen PrP keine definierte Konformation (Lopez et al., 2000) und besteht ab AS 47 aus fünf Oktarepeats. Dieser Bereich bindet beim $\operatorname{PrP}^{C}$ Kupfer (Whittal, et al., 2000). Daher könnten diese mAk, die an den N-terminalen Bereich binden, zum Verständnis der biologischen Funktion des Kupfers beitragen. Die Bindung an die repetitive Aminosäuresequenz (AS 47-101) ergab im ELISA mit allen fünf mAk ein sehr starkes Signal. Diese Region liegt N-terminal von der ersten beta-Faltbalattstruktur des $\operatorname{PrP}^{\mathrm{C}}$. Außerdem könnte mit diesen mAk der proteolytische Prozeß, der zwischen AS112-121 stattfindet, untersucht werden. Weiterhin könnten sie dazu verwendet werden, im Westernblot die normale von der pathogenen PrP-Form zu unterscheiden. Dies ist möglich, da diese mAk gegen den Bereich gerichtet sind, der nach der PrP-Isolierung infolge einer Inkubation mit Proteinase $\mathrm{K}$ abgedaut wird. Zusätzlich zeigten die gleichen mAk aber auch mit anderen Epitopen (AS 197 - 220, AS 221 - AS 233) ein schwaches Signal. Besonders auffällig war mAk 15G8, der zusätzlich auch noch schwach mit der Cterminalen Region (AS 220-259) reagierte. Der mAk $15 \mathrm{G} 8$ kreuzreagierte außerdem mit den AS 79-92 und AS142-160 des humanen PrP (persönliche Mitteilung, J. Grassi, Service de Pharmacologie et d'Immunologie, Frankreich,). Die Kreuzreaktivität der mAk mit nativem PrP verschiedener Spezies sollte ebenfalls untersucht werden. In weiteren Experimenten sollte untersucht werden, ob ein mAk wie 
$15 G 8$ auch zwischen den Konformationen von $\operatorname{PrP}^{\mathrm{C}}$ und $\operatorname{PrP}^{\mathrm{SC}}$ differenzieren kann. MAk, welche lineare Epitope binden, sollten nicht zwischen den PrPIsoformen unterscheiden können, da die Primärsequenz beider Formen gleich sind. Hingegen sollten mAk, welche diskontinuierliche oder konformationelle Epitope binden, verschiedene Konformationen von PrP erkennen (Eigen, 1996, Post, 1998).

Die drei in dieser Arbeit hergestellten mAk 16G8, 17G5 und $26 B 8$ sind, wie der mAk 12F10, der mAk 15B3 und 6H4 (Korth et al., 1997), der mAk p4 und L42 (Harmeyer et al., 1998) und der polyklonale Antikörper 3F4 (Kascsak 1987) gegen die Proteinase K resistente Kernregion des PrP (PrP 27-30 oder PrP ${ }^{\text {res}}$ ) gerichtet. Diese drei mAk binden an je zwei unterschiedliche Regionen, die in der Mitte (AS 150 - AS 179) und am Ende (AS 215 - AS 240) des Prionproteins liegen. Beide Regionen sind auch bei dem mit Proteinase K verdauten PrP 27-30 vorhanden. Der mAk 15B3 von Korth et al. (1997) bindet ebenfalls an diesen C-terminalen Bereich von $\operatorname{PrP}^{\mathrm{C}}$, PrP 27-30 und $\operatorname{PrP}^{\mathrm{SC}}$. Mak 15B3 ist aber nicht $\operatorname{PrP}^{\mathrm{SC}}$ spezifisch (persönliche Mitteilung A. Aguzzi, Univers. Zürich). Vermutlich können daher auch die mAk 16G8, $17 \mathrm{G} 5$ und 26B8 mit der Krankheit assoziierten PrP ${ }^{\mathrm{SC}}$ Form reagieren. Eine experimentelle Überprüfung war leider nicht möglich, da geeignetes BSE-Material bei Abschluß der Arbeit noch nicht zur Verfügung stand. Mit großer Wahrscheinlichkeit können deshalb auch die in dieser Arbeit hergestellten mAk, wie alle anderen bisher in der Literatur beschriebenen mAk, nicht zwischen den postulierten Isoformen differenzieren. Nach der Expression des in den injizierten SFV-Partikeln vorhandenen PRNP-Genes, sollten gegen eine Vielzahl verschiedener boviner PrP-Epitope gerichtete Antikörper induziert werden. Da die $\operatorname{PrP}^{0 / 0}$ Mäuse nicht infiziert waren und das bovine Gen keine krankheitsassoziierten Mutationen hatte, wurden folglich auch keine $\operatorname{PrP}^{\mathrm{SC}}$ spezifischen Epitope präsentiert. Wenn Mäuse dagegen mit einem bestimmten Peptid immunisiert sind, werden Antikörper induziert, die nur ein lineares Epitop erkennen. Diese Antikörper können jedoch eine Konformationsänderung des ganzen Proteins nicht erfassen (Gobizon et al., 1996, Harmeyer et al.,1998).

Die Bindung der gegen das humane PrP gerichteten mAk 3B5, 12F10, 14D3 und 8G8 wurde in Radioimmunpräzipitationen untersucht. Um natives Prionprotein für die Immunpräzipitation bereitzustellen, wurde das humane $\operatorname{PrP}^{\mathrm{C}}$ Priongen über die Restriktionsenzyme Hind III und Xba I in den Riboprobe-Vektor pBS ${ }^{+}$kloniert. 
Der Klon wurde durch gekoppelte in vitro Transkription und Translation unter Kontrolle des T3-RNA-Polymerase-Promotors im Kaninchen-Retikulozyten-System in Prionprotein umgesetzt. Zur radioaktiven Markierung des synthetisierten PrP wurde die Reaktion in Gegenwart von 35S-Methionin durchgeführt. In vitro synthetisiertes PrP wurde mit den Hybridomüberständen von mAk 3B5, 12F10, 14D3 und $8 G 8$ inkubiert. Anschließend wurden die Immunkomplexe über Protein A Sepharose präzipitiert. Da im Retikulozyten-System keine Glykosylierung des PrP stattfindet, zeigte der Westernblot nach der SDS-PAGE nur eine Bande. Die Masse des unglykosylierten PrP wurde aus der Addition der Gewichte der einzelnen Aminosäuren berechnet. Die kalkulierte Masse beträgt 23,1 kDa und stimmt damit mit der Masse der PrP-Bande überein, die in der Abbildung 3.10 zu sehen ist. Da alle mAk sowohl im Peptid-ELISA als auch in der Radioimmunpräzipitation die Peptide bzw das Protein erkennen, können wir folgern, daß die mAk nicht an die Zuckerstrukturen sondern direkt an die Aminosäuren des PrP binden. 
Tab. 4.1 Epitop-Kartierung der mAk und Phagenantikörper

\begin{tabular}{|c|c|c|c|}
\hline Antikörper & Immunisierung & Epitope & Literatur \\
\hline $15 \mathrm{G} 8$ & \multirow[t]{8}{*}{ rbSFV-Partikel } & $\begin{array}{c}47-101 \\
197-220 \\
220-259^{a}\end{array}$ & \multirow[t]{8}{*}{ siehe 3.2 .3 .2} \\
\hline $26 \mathrm{E} 6$ & & $\begin{array}{c}47-101 \\
197-220\end{array}$ & \\
\hline $19 \mathrm{C6}$ & & & \\
\hline $25 \mathrm{E} 6$ & & & \\
\hline $25 \mathrm{G} 6$ & & & \\
\hline $26 \mathrm{~B} 8$ & & $\begin{array}{l}150-179 \\
215-240\end{array}$ & \\
\hline $17 \mathrm{G} 5$ & & & \\
\hline $16 \mathrm{G} 8$ & & & \\
\hline 15B3 & \multirow{3}{*}{$\begin{array}{l}\text { In Bakterien } \\
\text { hergestelltes } \\
\text { bovines rekom- } \\
\text { binantes PrP }\end{array}$} & $\begin{array}{l}142-148 \\
162-171\end{array}$ & \multirow[t]{3}{*}{ Korth et al., (1997) } \\
\hline & & $214-227$ & \\
\hline $6 \mathrm{H} 4$ & & $144-152^{a}$ & \\
\hline $\begin{array}{l}\mathrm{P} 4 \\
\mathrm{~L} 42\end{array}$ & Schaf-PrP & $\begin{array}{r}89-104 \\
145-163\end{array}$ & Harmeyer et al., (1998) \\
\hline $\begin{array}{c}3 \mathrm{~B} 5 \\
12 \mathrm{~F} 10\end{array}$ & Humane PrP-DNA & $\begin{array}{c}57-105 \\
150-165^{b}\end{array}$ & Krasemann et al., (1996) \\
\hline $3 \mathrm{~F} 4$ & \multirow{2}{*}{$\begin{array}{l}\text { Hamster-PrP } \\
\text { Immunisierung }\end{array}$} & $109-111^{a}$ & \multirow{2}{*}{$\frac{\text { Kascsak et al., (1987) }}{\text { Literatur }}$} \\
\hline Phagenantikörper & & Epitope & \\
\hline $\begin{array}{l}\text { pC16G8 } \\
\text { pC26B8 }\end{array}$ & \multirow[t]{2}{*}{$\begin{array}{l}\text { Aus Hybridom- } \\
\text { zellen cDNA }\end{array}$} & $\begin{array}{l}150-179 \\
215-240\end{array}$ & \multirow[t]{2}{*}{ siehe 3.2 .3 .2} \\
\hline $\mathrm{pC} 25 \mathrm{G} 6$ & & $\begin{array}{c}47-101 \\
197-220\end{array}$ & \\
\hline R1 & \multirow[t]{3}{*}{$\begin{array}{l}\text { SHaPrP } 27-30 \\
\text { CDNA aus Milz }\end{array}$} & $225-231$ & \multirow[t]{3}{*}{ Williamson et al., (2000) } \\
\hline R2 & & $225-231$ & \\
\hline R10 & & $96-104$ & \\
\hline
\end{tabular}

${ }^{a}$ bovine Peptide, ${ }^{b}$ humane Peptide

\subsection{Isolierung und Charakterisierung von ScFv-Phagenantikör- pern}

Um die in den Hybridomzellklonen vorhanden Antikörpergene zu sichern und um eine zukünftige gentechnische Veränderung zu ermöglichen, wurden Einzelketten-Phagenantikörper (ScFv) gegen bovine Prionproteine isoliert und charakterisiert. Bisher wurde nur von einer Forschergruppe die Isolierung von gegen das PrP gerichtete rekombinate Antikörper beschrieben (Williamson et al., 1996, Peretz et al., 1997, Williamson et al., 1998, Kanyo et al., 1999).

Zur Isolierung der Phagenantikörper wurde die RNA der in dieser Arbeit produzierten murinen Hybridomzellinien verwendet. Die RNA wurde aus den Hybridom- 
zellen isoliert, in vitro zu cDNA transkribiert und zur PCR eingesetzt. Wegen der genetischen Vielfalt der rearrangierten Antikörpergene sind nicht alle Oligonukleotidprimer zur Vervielfältigung dieser Gene geeignet. Wie einleitende Experimente zeigten, konnten die von Dübel et al. (1994) beschriebenen und neuerdings häufig eingesetzten Primerpaare nur die leichte variable Region der Antikörpergene vervielfältigen, jedoch nicht die schwere variable Region. Mit Hilfe der im „Recombinant Phage Antibody System“ (RPAS) der Fa. Pharmacia enthaltenen Primerpaare ließen sich jedoch die DNA-Sequenzen beider Regionen amplifizieren. Daher wurde dieses System in allen weiteren Experimenten angewandt.

Als Quelle für die Antikörpergene wurden die Hybridomzellinien 15G8, 16G8, 19C6, 25E6, 25G6 und 26B8 verwendet. Zusätzlich wurde die RNA aus den Milzzellen einer mit rbSFV Partikeln immunisierten $\operatorname{PrP}^{0 / 0}$-Maus isoliert und daraus eine cDNA-Bank im pCANTAB 5E Vektor angelegt. Diese wurden zur Isolierung von weiteren Anti-PrP Phagenantikörpern Herrn A. Strom (DPZ) zur Verfügung gestellt. Aus den Hybridomzellen wurde die Gesamt-RNA isoliert und mit Hilfe der Reversen Transkriptase in cDNA umgeschrieben. Im nächsten Schritt konnten die variablen Genregionen für die leichte $\left(V_{L}\right)$ und die schwere Kette $\left(V_{S}\right)$ mit Hilfe der PCR-Primer aus den Zellinien 15G8, 16G8, 25 G6 und 26B8 amplifiziert werden. Im Anschluß wurden diese Genfragmente über ein präparatives Agarosegel isoliert und gereinigt. Die Genregionen der variablen $V_{L}$ - und $V_{S}-K e t t e n$ von 16G8, $25 G 6$ und 26B8 wurden mit Hilfe eines kurzen Linkers (Gly $\left.{ }_{4} S e r\right)_{3}$ in einer weiteren PCRReaktion verknüpft. An die Enden der so ligierten ScFv-Moleküle wurden mittels einer dritten PCR-Reaktion zwei Restriktionsschnittstellen für Sfi I und Not I eingebaut. Nach dem Verdau wurden die ScFv-Fragment in den Phagemidexpressionsvektor pCANTAB 5E (McCafferty et al., 1990) ligiert und in E. coli elektroporiert. Nach Koinfektion mit M13KO7 Helferphagen wurden die so isolierten Phagenantikörper dann zuerst in dem zur Detektierung der mAk verwendeten Peptid ELISA untersucht. Im Ergebnis konnten die drei Phagenantikörper pC16G8, pC25G6 und pC26B8 isoliert werden.

Die ScFv-DNA von pC16G8 und pC26B8 wurde vollständig sequenziert und mit Hilfe des Computerprogramms DNASIS in die Proteinsequenz übersetzt. Mit Hilfe eines Computervergleiches wurden die CDR Regionen identifiziert (Martin, 1996). Die Aminosäuresequenz der CDR 3 Region der schweren Kette wird von den vier Aminosäuren YTSQ bei pC16G8 und den acht Aminosäuren DSGTGFAY 
bei pC26B8 aufgebaut. Die CDR 3-Region ist in der Regel zwischen 3-25 Aminosäuren lang und für die Affinität eines mAk entscheidend (Kabat et al., 1987). Eine der in der Arbeitsgruppe von Williamson et al. (1998) isolierten und sequenzierten CDR 3-Regionen besteht ebenfalls aus den acht Aminosäuren HDGYPFAY. Wie ein Sequenzvergleich zeigte, waren die letzen drei Aminosäuren FAY dieselben, wie die der CDR 3-Region von pC26B8.

Anschließend wurden die Phagenantikörper mittels des „114 Peptid GriddedArrays“ und der Westernblot-Technik genauer charakterisiert. Die Ergebnisse der Epitop-Kartierungen der Phagenantikörper sind in der Tab. 4.1 dargestellt. Im Gridded-Array reagierte der Phagenantikörper pC16G8, wie zu erwarten, mit dem gleichen Epitop, wie der mAk $16 \mathrm{G} 8$ (AS 150 -179). Auch pC26B8 und mAk 26B8 erkannten dieses Epitop. Peretz et al. (1997) berichten, daß ihre Phagenantikörper vorwiegend mit C-terminalen Epitopen von $\operatorname{PrP}^{\mathrm{C}}$ und $\operatorname{PrP}^{\mathrm{SC}}$ kreuzreagieren. Zusätzlich zu diesen Epitopen wurden in Richtung des N-terminalen Bereiches von PrP aber von anderen Phagenantikörpern Epitope bei $\operatorname{PrP}^{C}$ erkannt, die bei $\operatorname{PrP}^{\mathrm{SC}}$ nicht detektiert wurden. Diese Beobachtung läßt sich durch den Konformationsunterschied der beiden PrP-Isoformen erklären. Durch die Umwandlung von $\operatorname{PrP}^{\mathrm{C}}$ zu $\mathrm{PrP}^{\mathrm{SC}}$ müssen diese Epitope verborgen worden sein. Der größte Teil der Konformationsveränderung, der für den Erwerb der Infektiosität von $\mathrm{PrP}^{\mathrm{SC}}$ erforderlich ist, findet in den N-terminalen Bereich von PrP statt (Huang et al., 1994, 1996). Daher können vermutlich bevorzugt an den N-terminalen Bereich bindende Antikörper sowohl zur Detektierung, als auch zur Neutralisierung von PrP verwendet werden. Zudem ist die Sequenzvariabilität in dieser N-terminalen Region bei allen bisher untersuchten Spezies am größten (Borough et al., 1996, Schätzl et al., 1995).

Das native PrP ist in vivo auf der Zelloberfläche durch den GPI-Anker gebunden. Die Fähigkeit der Phagenantikörper, natives PrP nach der Denaturierung zu erkennen, wurde im ECL-Westernblot untersucht. Der ECL-Westernblot ist bis zu 10fach empfindlicher als der herkömmliche HRP-Westernblot (Nachweisgrenze 1 pg). Mit einem von Lee et al. (2000) durchgeführten Westernblot konnten mittels alkalischer Phosphatase noch 5 pg PrP 27-30 (oder 10 ng murines HirnÄquivalent) detektiert werden. Zunächst wurde das Protein aus dem 3T3-Tet-Off17+ Zellklon mit denaturierendem LSEB-Puffer extrahiert und dann durch SDSGelelektrophorese von den anderen Proteinen getrennt. Der 3T3 Klon trägt das 
humane FFI-Gen stabil im Genom. Die Expression dieses Gens kann durch das Antibiotikum Tetracyclin reversibel reprimiert werden. Das in diesen Zellen exprimierte PrP ist Proteinase K sensitiv (persönliche Mitteilung A. W. Stuke, DPZ). Wie in der Abb. 3.17 zu sehen, binden die drei Phagenantikörper pC16G8, pC26B8 und pC25G6 spezifisch an die drei charakteristischen Prionproteinbanden, die nicht-glykosylierte 23-27 kDa Bande, die einfach-glykosylierte 28-30 kDa Bande und die doppelt-glykosylierte 33-42 kDa Bande.

Das native PrP ist in vivo auf der Zelloberfläche durch den GPI-Anker gebunden. Die Fähigkeit der Phagenantikörper, natives PrP nach der Denaturierung zu erkennen, wurde im Westernblot untersucht. Dazu wurde das Protein aus dem 3T3-Tet-Off-17+ Zellklon mit denaturierendem LSEB-Puffer extrahiert und dann durch SDS-Gelelektrophorese von den anderen Proteinen getrennt. Der 3T3 Klon trägt das humane FFI-Gen stabil und durch das Antibiotikum Tetracyclin induzierbar im Genom. In diesen Zellen expremiete PrP ist Proteinase K sensitiv (persönliche Mitteilung A. W. Stuke, DPZ). Wie in der Abb. $3.17 \mathrm{zu}$ sehen, binden die drei Phagenantikörper, pC16G8, pC26B8 und pC25G6 spezifisch an die drei charakteristischen Prionproteinbanden. Diese sind die nicht-glykosylierte 23-27 kDa Bande, die einfach-glykosylierte 28-30 kDa Bande und die doppelt-glykosylierte 33-42 kDa Bande. 


\section{Zusammenfassung}

Zur Induktion von Antikörpern gegen bovines $\operatorname{PrP}$ wurden $\mathrm{PrP}^{0 / 0}$-Mäuse intraperitoneal mit in vitro hergestellten rekombinanten bovinen SFV Partikeln (rbSFV) immunisiert. Um rbSFV Partikel herzustellen, wurde zuerst der offene Leserahmen (ORF) des bovinen Priongens in SFV kloniert. Dann wurden das rbSFV und das Helfer SFV II mit Spe I linearisiert und in vitro in RNA transkribiert. Anschließend wurden damit BHK-Zellen infiziert und die produzierten Partikeln zur Immunisierung von $\mathrm{PrP}^{0 / 0}$-Mäusen verwendet. Weil die BHK-Zellen PrP auf ihren Oberflächen überexprimierten, wurden sie im Immunfluoreszenztest eingesetzt.

Zur Produktion der mAk wurden die Milzzellen der immunisierten Mäuse entnommen, und mit Myelomzellen fusioniert. Mehr als 800 Hybridklone wurden selektiert und auf das Sezernieren von Antikörpern zuerst in der Immunfluoreszenz und danach in einem Peptid ELISA auf ihre Epitopspezifität getestet. Es konnten insgesamt acht unterschiedliche Hybridomzellinien (15G8, 16G8, 17G5, 19C6, 25E6, 25G6, 26B8 und 26E10) als stabile Zellinien etabliert werden. Die Monoklonalität der antikörperproduzierenden Zellen wurde durch Verdünnung und mehrfache Klonierung gewährleistet. Um die Konzentration der mAk im Hybridomzellüberstand zu erhöhen, wurden einige der gegen das bovine $\operatorname{PrP}(15 G 8,26 B 8)$ und einige der gegen das humane PrP (3B5 und 12F10) gerichteten Hybridomklone im Minifermenter kultiviert. Die fünf mAk 15G8, 19C6, 25E6, $25 G 6$ und 26E10 reagieren mit einer $\mathrm{N}$-terminal gelegenen Region in der repetitiven Domäne, die den Aminosäuren 47-101 entspricht. Die Reaktion der fünf mAk mit der repetitiven Aminosäuresequenz ergab ein sehr starkes Signal. Zusätzlich wurden aber auch andere Epitope (AS 197 - 220, und AS 221 - AS 233) von diesen mAk erkannt. Besonders auffällig war 15G8, der als einziger mAk zusätzlich mit der C-terminalen Region (AS 220-259) reagierte. Die drei weiteren mAk 16G8, $17 G 5$ und 26B8 binden an eine Region (AS 197 - 220), die an die zweite Helixregion angrenzt. Alle acht Antikörper ließen sich als IgG $\kappa$ (Kappa) klassifizieren.

Um bovines PrP im Retikulozytenlysat in vitro zu synthetisieren, wurden humane und bovine $\operatorname{PrP}^{\mathrm{C}}$ Priongene in den $\mathrm{pBS}^{+}$Vektor kloniert und im KaninchenRetikulozyten in vitro transkribiert. Dieses Lysat wurde mit polyklonalen Mausim- 
munseren sowie Hybridomzellüberständen inkubiert und anschließend über Protein A Sepharose präzipitiert. Die kalkulierte unglykolysierte Masse von PrP beträgt 23,1 kDa und stimmt mit der im Westernblot identifizierten Bande überein. Daher reagierten diese mAk nicht mit Zuckeranteil des PrP

Um Einzelketten-Phagenantikörper (ScFv) gegen das bovine Prionprotein aus den etablierten Hybridomzellinien zu isolieren, wurde die RNA isoliert und in cDNA umgeschrieben. Dann wurden die variablen Genregionen der leichten $\left(\mathrm{V}_{\mathrm{L}}\right)$ und schweren Ketten $\left(V_{S}\right)$ amplifiziert, in einer weiteren PCR-Reaktion verknüpft, in einen Vektor ligiert und anschließend in E. coli elektroporiert. Es konnten die Phagenantikörper pC16G8, pC25G6 und pC26B8 isoliert werden. Ihre DNA wurde sequenziert und in die Proteinsequenz übersetzt. Die Aminosäuresequenz der CDR 3-Region der schweren Kette wird von den vier Aminosäuren YTSQ bei pC16G8 und den acht Aminosäuren DSGTGFAY bei pC26B8 aufgebaut. Alle Phagenantikörper erkannten im Westernblot die drei charakteristischen Prionproteinbanden. 


\section{Ausblick}

Die im Rahmen dieser Arbeit hergestellten mAk und Phagenantikörper binden an lineare Epitope im Peptid-ELISA und an Bereiche auf dem nativen PrP im Westernblot und in der Immunfluoreszenz. In späteren Arbeiten sollten lösliche ScFv Fragmente isoliert werden. Diese kleinere Fragmente könnten zur Untersuchung der Biosynthese des PrP und der Pathogenese der Krankheit eingesetzt werden. Die ersten Experimente in diese Richtung sind bereits bei der Herstellung von Phagenantikörper aus dem Hybridomzellen begonnen worden. Die ScFv Fragmente können in die Zellen eindringen und an das $\operatorname{PrP}^{\mathrm{SC}}$ binden. So können die Kontaktstellen, die für das Umklappen des PrP notwendig sind, blockiert werden. Um die Ausbreitung der PrP-Infektion zu verhindern, soll die Eignung der isolierten mAk für die Diagnostik an Gewebeschnitten oder Blut infizierter Tiere im weiteren untersucht werden. Um einen Antikörper herzustellen, der sowohl speziesspezifisch ist als auch zwischen dem $\operatorname{PrP}^{\mathrm{C}}$ und $\operatorname{PrP}^{\mathrm{SC}}$ unterscheidet kann, sind Bindungsstudien an nativem, mit Pathogenität assoziiertem $\mathrm{PrP}^{\mathrm{SC}}$ notwendig. Ein Antikörper der nur an das $\operatorname{PrP}^{\mathrm{SC}}$ bindet, könnte in Säugetiere therapeutisch, ohne Beeinträchtigung der $\operatorname{PrP}^{\mathrm{C}}$ Funktion, eingesetzt werden.

Zur Zeit läßt sich das infektiöse PrP, mit Hilfe von Antikörper, noch nicht in Kuhmilch, Muskelfleisch oder Blut vor der Ausbruch der Krankheit aufspüren. Um die Sensitivität des Tests zu erhöhen sollten empfindlichere Detektierungsmethoden angewendet werden. Mit der von Sano et al. (1992) publizierte Methode der Immuno-PCR bei der Antikörper mit einem DNA-Fragment verknüpft wird, konnte das Zielantigen in sehr geringere Menge in Körperflussigkeiten nachweisen. 


\section{Literaturverzeichnis}

Aguzzi, A. und Weissmann, C. (1996a): A suspicious signature. Nature, 383, 666667

Aguzzi, A., Brandner, S., Marino, S. und Steinbach, S.P. (1996b): Transgenic and knockout mice in the study of neurodegenerative diseases. J. Mol. Med., $74,111-126$

Alpers, M. (1987): Epidemology and clinical aspects of kuru. In: Prions: Novel infectious pathogens causing Scrapie and Creutzfeldt-Jakob disease. Edited by S.B. Prusiner und M.P. McKinlley, San Diego: Academic Press, 451-465

Anderson, R. M., Donnelly, C. A., Ferguson, N. M., Woolhouse, M. E., Watt, C. J., Udy, H. J., MaWhinney, S., Dunstan, S. P., Southwood, T. R., Wilesmith, J. W., Ryan, J. B., Hoinville, L. J., Hillerton, J, E., Austin, A. R. und Wells, G. A. (1998): Transmission dynamics and epidemiology of BSE in British cattle. Nature, 29: 382(6594): 779-788

Barry, R. A. und Prusiner, S. B. (1986): Monoclonal antibodies to the cellular and scrapie prion proteins. J. Infect. Dis. 154: 518-512

Basler, K., Oesch, B., Scott, M., Westaway, D., Wälchli, M., Groth, D.F., McKinley, M.P., Prusiner, S.B., und Weissmann, C. (1986): Scrapie and cellular PrP isoforms are encoded by the same chromosomal gene. Cell, 417-428, 1986

Beekes, M., Otto, M., Wiltfang, J., Bahn, E., Poser, S. und Baier, M. (1999): Late increase of serum S100 beta protein levels in hamsters after oral or intraperitoneal infection with scrapie. J. Infect. Dis. 180(2): 518-520

Bellinger-Kawahara, C., Cleaver, J.E., Diener, T.O. und Prusiner, S.B. (1987a): Purified scrapie prions resist inactivation by UV irradiation. J. Virol. 61, 159-166 
Bellinger-Kawahara, C., Diener, T.O., McKinley, M.P., Groth, D.F., Smith, D.R. und Prusiner, S.B. (1987b): Purified scrapie prions resist inactivation by procedures that hydrolyze, modify or shear nucleic acids. Virology, 160, 271-274

Bendheim, P. E., Barry, R. A., DeArmond, S. J., Stites, D. P. und Prusiner, S. B. (1984): Antibodies to a scrapie prion protein. Nature, 310, (5976): 418421

Berglund, P., Sjöberg, M., Garoff, H., Atkins, G.J., Sheahan, B.J. und Lijeström, P. (1993): Semliki Forest Virus expression system: Production of conditionally infectious recombinant particles. Bio. Technology, 11, 916-920

Blum, B., Bakalara, N. und Simpson, L. (1990): A model for RNA editing in kinetoplastid mitochondria: guide RNA molecules transcribed from maxicircle DANN provide edited information. Cell, 60, 189-198

Bodemer, W., Niller, H.H., Nitsche, N., Scholz, B., und Fleckenstein, B. (1986): Organization of the Thymidylate synthase gene of Herpesvirus Saimiri. J. Virology, 60, 114-123

Bodemer, W. The use of monoclonal antibodies in human prion Disease. Naturwissenschaften review articles: 212-220

Bolton, D.C., McKinley, M.P. und Prusiner, S.B. (1982): Identification of a protein that purifies with the scrapie prion. Science, 218, 1309-1911

Bolton, D.R., Meyer, R.K. und Prusiner, S.B. (1985): Scrapie PrP 27-30 is a sialoglycoprotein. J. Virol, 53, 596-606

Borchelt, D.R., Taraboullos, A., Stahl, N. und Prusiner, S.B. (1990): Scrapie and cellular prion proteins differ in their kinitics of synthesis and topology in cultured cells. J. Cell biol., 110, 743-752

Borchelt, D.R., Taraboullos, A.. und Prusiner, S.B. (1992): Evidence for synthesis of scrapie prion proteins in the endocytic pathway. J. biol. chem., 267, 6188-6199

Brandner,S., Isenmann, S., Raeber, A., Fischer, M., Sailer, A., Kobayashi, Y., Marino, S., Weismann, C. und Aguzzi (1996): Normal host prion protein necassary for scrapie-induced neurotoxicity, Nature, 379, 339-343 
Brown, P., Cathala, F., Castaigne, P. und Gajdusek, D.C. (1986): CreutzfeldtJakob disease: clinical analysis of a consecutive series of 230 neuropathologically verified cases. Ann. Neurol., 20, 597-602

Brown, P., Goldfarb, L.G., Kevanen, J., Haltia, M., Cathala, F., Sulima, M., Gibbs, C.R.Jr. und Gajdusek, D.C. (1992): Phenotype charateristics of familial Creutzfeldt-Jakob disease associated with the codon 178 Asn PRNP mutation. Ann. Neurol., 31, 282-285

Bruce, M. E., Will, R. G., Ironside, J. W., McConnell, I., Drummond, D., Suttie, A., McCardle, L., Chree, A., Hope, J., Birkett, C., Cousens, S., Fraser, H. und Bostock, C. J. (1997): Transmission to mice indicate that 'new variant' CJD is caused by the BSE agent. Nature,389: 498-501

Bruce, M. E., Will, R. G., Ironside, J. W., McConnell, I., Drummond, D., Suttie, A., McCardle, L., Chree, A., Hope, J., Birkett, C., Cousens, S., Fraser, H. und Bostock, C. J. (1999): Transmissions to mice indicate that 'new variant' CJD is caused by the BSE agent. Nature 2: 389(6650): 498-501

Buchanan, C.R., Preece, M.A. und Milner, R.D.G. (1991): Mortality, neoplasia and Creutzfeldt-Jakob disease in patients treated with pituitary growth hormone in the United Kingdom. Br. med. J., 302, 824-828

Bueler, H., Aguzzi, A., Sailer, A., Greiner, R.A., Autenried, P., Aguet, M. und Weismann, C. (1993): Mice devoid of PrP are resistant to scrapie. Cell, 73, 1339-1347

Bueler, H., Fischer, M., Lang, Y., Bluethmann, H., Lipp, H.P., DeArmond, S.J., Prusiner, S.B., Aguet, M. und Weismann, C. (1992): Normal development and behaviour of mice lacking the neuronal cellsurface PrP protein. Nature, 356, 577-582

Burger, D. und Hartsough, G.R. (1965): Tranmissible encephalopathy of mink: In: Gajdusek, D.C., Gibbs, C.R.Jr. und Alpers, M., eds, slow, latent and temperate virus infections. National Institute of Neurological Diseases and Blindness. Monograph no 2. Washington, DC: US Department of Health, Education and Welfare, 297-305

Carr, K. (1993): A question of conformation. Nature, 365, 386 
Cathala, F. und Baron, H. (1987): Clinical aspects of Creutzfeldt-Jakob disease. In: Prions: Novel infectious pathogens causing Scrapie and CreutzfeldtJakob disease. Edited by S.B. Prusiner and M.P. McKinley, San Diego: Academic Press, 467-509

Caughey, B. und Raymond, G.J. (1991): The scrapie-associated form of PrP is made from a cell-surface precursor that is both protease- and phospholipase-sensitive. J. biol. chem., 266, 18217-18223

Caughey, B., Raymond, G.J., Ernst, D. und Race, R.E. (1991): N-terminal truncation of the scrapie-associated form of PrP by lysosomal protease(s): implication regarding the site of conversion of PrP to the protease-resistant state. J. Virol., 65, 6597-6603

Chandler, R.L. (1961): Encephalopathy in mice produced by inoculation with scrapie brain material. Lancet, 1, 1378-1379

Chandler, R.L. und Fisher, J. (1963): Experimental transmission of scrapie to rats. Lancet, 1, 1072

Chazot, G., Broussolle, E., Lapras, C., Blätter, T., Aguzzi, A. und Kopp, N. (1996): New variant of Creuzfeldt-Jakob disease in a 26-year-old French man. Lancet, 347:1181

Chien, A., Edgar, D. B. und Trela, J. M. (1976): Desoxyribonucleic acid polymerase from the extreme thermophile Thermus aquaticus. J. Bacteriol. 127, 1550-1557

Cohen, S. N., Chang, A. C. Y. und Hsu, L. (1972): Nonchromosomal antibiotic resistance in bacteria: Genetic transformation of $E$. coli by R-factor DNA. Proc. Natl. Acad. Sci. USA 69, 2110-2114

Coller, H. A und coller, B. S. (1983): Poission statistical analysis of repetetive subcloning by the limiting dilution technique as a way of assessing hybridoma monoclonality. In: Langone, J. j., van Vunakis, H. (eds) Meths Enzymol, vol 121, Academic Press, New York, p412-417

Collinge, J. (1996): New diagnostic tests for prion diseases (ed. coment). N. Eng. J. Med., 335, 963-965 
Collinge, J., Harding, A.E., Owen, F., Poulter, M., Lofthouse, R., Boughey, A.M., Shah, T. und Crow, T.J. (1989): Diagnosis of Gerstmann-SträusslerSyndrom in familial dementia with prion protein gene analysis. Lancet (ii), $15-17$

Collinge, J., Palmer, M.S. und Dryden, A.L. (1991): Genetic predisposition to iatrogenic Creutzfeldt-Jakob disease. Lancet, 337, 1441-1442

Collinge, J., Sidle, K.C.L., Meads, J., Ironside, J. und Hill, A. (1996): Molecular analysis of prion strain variation and the aetiology of 'new variant CJD. Nature, 383, 685-690

Collinge, J., Whittington, M.A., Sidle, K.C.L., Smith, C.J., Palmer, M.P., Clarke, A.R. und Jefferys, J.G.R. (1994): Prion protein is necessary for normal synaptic function. Nature, 370, 295-297

Corth, C., Stierli, P., Streit, M., Moser, M., Schaller, O., Fischer, R., SchulzSchaeffer, W., Kretzschmar, H., Raeber, A., Braun, U., Ehrensberger, F., Hornemann, S., Glockshuber, R., Riek, R., Billeter, M., Wüthrich, K. und Oesch, B. (1997): Prion ( $\operatorname{PrP}^{\mathrm{sc}}$ )-specific epitope defined by monoclonal antibody. Nature, Vol. 390, 74-77

Creutzfeldt, H.G. (1920): Über eine eigenartige herdförmige Erkrankung des Zentralnervensystems. Z. ges. Neurol. Psychat. 57, 1-18

Cuille, J und Chelle, P.L. (1939): Experimental tranmission of trembling to the goat. C. r. hebd. Seanc. Acad. Sci., Paris, 208, 1058-1060

Davis, H. I., Michel, M. L., Mancini, M., Schleef, M. und Whalen, R. G. (1994): Direct gene transfer in skeletal muscle; plasmid DNA-based immuniziation against the hepatitis B virus surface antigen. Vaccine 12, 1503-1509

Diringer, H., Braig, H.R. und Czub, M. (1988): Scrapie: a virus induced amyloidosis of the brain. Ciba Found Symp., 135, 135-145

Dlouhy, S.R., Hsiao, K., Farlow, M.R., Foroud, T., Conneally, P.M., Johnson, P., Prusiner S.B., Hodes, M.E. und Ghetti, B. (1992): Linkage of the Indiana kindred of Gerstman-Strässler-Scheinker disease to the prion protein gene. Nature Genet., 1, 64-67 
Dohura, K., Tateishi, J., Sasaki, H., Kitamoto, T. und Sakaki, Y. (1989): Pro-Leu change at position 102 of prion protein is the most common but not the sole mutation related to Gerstmann-Sträussler syndrome. Biochem. biophys. Res. Commun., 163, 974-979

Edenhofer, F., Rieger, R., Wendler, W., Weiss, S und Winnacker, E.L. (1996): Prion protein PrPC interacts with molecular chaperons of the Hsp60 family. J.Virol., 70, 4724-4728

Eigen, M. (1996): Prionics or the kinetic basis of prion diseases. Biophys. Chem. 63(1): 1-18

Endo, T., Groth, T., Prusiner, S.B. und Kobata, A. (1989): Diversity of oligosaccharide structures linked to asparagines of the scrapie prion protein. Biochemistry, 28, 8380-8388

Evans, H. J. und Vijayalaxmi (1991): Induction of 8-Azaguanine resistance and sister chromitid exchange in human lymphocytes exposed to mitomycin $\mathrm{C}$ and $X$ In vitro. Nature 292, \&01-605

Farlow, M.R., Yee, R.D., Dlouhy, S.R., Conneally, P.M., Azzarelli, B. und Ghette, B. (1989): Gerstmann-Sträussler-Scheinker disease. Extending the clinical spectrum. Neurology, 41, 1647-1650

Feinberg, A.P. und Vogelstein, B. (1983): A technique for radiolabeling DNA restriction endonuclease fragments to high specific activity, Anal. Biochem., $132,6-13$

Fischer, B. M., Roeckl, C., Parizek, P., Schwarz, P. H. und Aguzzi, A. (2000): Binding of disease-associated prion protein to Plasminogen. Nature, 408: 479-483

Fleetwood, A.J. und Furley, C.W. (1988): Spongiform encephalopathy in an eland. Vet. Rec., 126, 408-409

Fradkin, J.E., Schonberger, L.B. Mills, J.L., Gunn, W.J., Piper, J.M., Wysowski, D.K., Thomson, R., Durako, S. und Brown, P. (1991): Creutzfeldt-Jakob disease in pitiutary growth hormone recipients in the United States. J. Am. med. Ass., 265, 880-884 
Gabizon, R., Telling, G., Meiner, Z., Halimi, M., Kahana, I. und Prusiner, S. B. (1996): Insoluble wild-type and protease-resistant mutant proin protein in brains of patients with inherited prion disease. Nature Medicine 2, 59-64

Gajdusek, D.C., Gibbs, C.J. Jr. und Alper, M. (1966): Experimental transmission of a kuru-like syndrome to chimpanzees. Nature 209, 794-796

Gavilondo, J. V. und Larrick, J. W. (2000): Antibody engineering at the millennium. Biotechniquew 29(1): 128-132

Gertsmann, J., Sträussler, E. und Scheinker, I. (1939): Über eine eigenartige hereditär-familiäre Erkrankung des Zentralnervensystems. Zugleich ein Beitrag zur Frage des vorzeitigen Alterns. Z. ges. Neurol. Psychat., 154, 736762

Gertz, H.J., Henkees, H. und Cervos-Navarro, J. (1988): Creutzfeldt-Jakob Disease: Correlation of MRI and neuropathological findings. Neurology, 38, 1481-1482

Gibbs, C.J.Jr., Gajdusek, D.C., Asher, D.M. Alpers, M.P., Beck, E., Daniel, P.M. und Matthews, W.B. (1968): Creutzfeldt Jakob disease (spongiform encephalopathy): transmission to the chimpanzee. Science, 161, 388-389

Gibbs, C.J.Jr., Joy, A., Heffner, R., Frank, M., Miyazaki, M., Asher, D.M., Parisi, J.E., Brown, P.W. und Gajdusek, D.C. (1985): Clinical and pathological features and laboratory confirmation of Creutzfeldt-Jakob disease in a recipient of pituitary-derived human growth hormone. N. Eng. J. Med., 313, 734-738

Gjdusek, D.C. (1977): Unconventional viruses and the orign and disappearance of kuru. Science, 197, 943-960

Goldfarb, L.G., Brown, P., Goldgaber, D., Asher, D.M., Rubenstein, R., Brown, W.T., Piccardo, P., Kascsak, R.J., Boellard, J.W. und Gajdusek, D.C. (1990b): Creutzfeldt-Jakob disease and kuru patients lack a mutation consistently found in the Gerstmann-Sträussler-Scheinker syndrome. Expl. Neurol., 108, 247-250 
Goldfarb, L.G., Brown, P., McCombie, W.R., Goldgaber, D., Swergold., Wills, P.R., Cervenakova, L., Baron, H., Gibbs, C.J. Jr. und Gajdusek, D.C. (1991a): Transmissible familial Creutzfeldt-Jakob disease associated with five, seven and eight extra octapeptide coding repeats in the PRNP gene. Proc. Natl. Acad. Sci., 88, 10926-10930

Goldfarb, L.G., Haltia, M., Brown, P., Nieto, A., Kovanen, J., McCombie, W.R., Trapp, S. und Gajdusek, D.C. (1991b): New mutation in scrapie amyloid precursor gene (at codon 178) in Finnish Creutzfeldt-Jakob kindred. Lancet, 33,425

Goldfarb, L.G., Korcyn, A., Brown, P., Chapman, J. und Gajdusek, D.C. (1990a): Mutation in codon 200 of scrapie amyloid precursor gene linked to Creutzfeldt-Jakob disease in Sephardic Jews of Lybian and non-Lybian origin. Lancet, 336, 637.638

Goldfarb, L.G., Mitrova, E., Brown, P., Toh, B.H. und Gajdusek, D.C. (1990c): Mutation in codon 200 of scrapie amyloid protein gene in two clusters of Creutzfeldt-Jakob disease in slovakia. Lancet, 336, 514-515

Gordon, W.S. (1966): Variation in susceptibility of sheep to scrapie and genetic implications. In: Report of scrapie seminar, ARS 91-93, pp. 53-67, Washingthon, DC.: US Department of Agriculture

Green, A. J., Jachmann, R., Marshall, T. A. und Thompson, E. J. (1996): Increased S-100b in the Cerebtrospinal Fluid of Some Cattle with Bovine Spongiform Encephalopathy. Veterinary Record, 145: 107-108

Haraguchi, T., Fisher, S., Olofsson, S., Endo, T., Groth, D., Tarantino, A., Borchelt,, D.R., Teplow, D., Hood, L., Burlingame, A., Lycke, E., Kobata, A. und Prusiner, S.B. (1989): Asparagine-linked glycosylation of the scrapie and cellular prion proteins. Arch. Biochem. Biophys. 274, 1-13

Hay, B., Barry, R.A., Lieberburg, I., Prusiner, S.B. und Lingappa, V.R. (1987a): Biogenesis and transmembrane orientation of the celluar isoform of the scrapie prion protein. Molec. Cell Biol., 7, 914-920

Hay, B., Prusiner, S.B. und Lingappa, V.R. (1987b): Evidence for a secretory form of the cellular prion protein. Biochemistry, 26, 8110-8115 
Hill, A. F.,Desbruslais. M., Joiner, S., Sidle, K. C. L., Gowland, I.und Collinge, J.(1997): The same prion strain causes vCJD and BSE. Nature Vol. 389, 448-450.

Hill, A. F., Joiner, S.,Linehan J., Desbruslais, M., Lantos, P. L., and Collinge, J.(2000) Species-barrier-independent prion replication in apparently resistant species. Proc. Natl. Acad. Sci. USA, Vol. 97, Issue 18, 1024810253.

Hill, A.F., Zeidler, M., Ironside, J., Collinge, J. (1997): Diagnosis of new variant Creutzfeldt-Jakob disease by tonsil biopsy. Lancet, 349, 99-100

Hlinak, A., Jahn, S., Grunow, R., Mehl, M., Heider, G. und von Baehr, R. (1987): Optimierungsversuche von Maus-Maus und Mensch-Maus-Hybridomen unter Verwendung verschiedener Feederzelltypen. Mh. Vet. -Med. 42, 801-804

Hope, J., Morton, L. J., Farquhar, C. F., Multhaup, G., Beyreuther, K. und Kimberlin, R. H. (1986): The major polypeptide of scrapie-associated fibrils (SAF) has the same size, charge distribution and $\mathrm{N}$-terminal protein sequence as predicted for the normal protein (PrP). EMBO J. 5(10), 2591-2597

Horwitz, J. P., Chua, J., Curby, R. J., Tomson, A. J., DaRooge, M. A., Fisher, B. E., Muaricio, J. und Klundt, I.(1994): Substrates for cytochemical demonstration of enzyme activity. I. Some susbstituted 3-indolyl-ß-Dglycopyranosides. J. Med. Chem. 7, 574

Hsaio, K.K., Dloughy, S., Ghetti, B., Farlow, M., Cass, C., DaCosta, M., Conneally, M., Hodes, M.E. und Prusiner, S.B. (1992): Mutant prion proteins in Gerstmann-Sträussler-Scheinker disease with neurofibrillary tangles. Nature Genet., 1, 68-71

Hsiao, K.K., Baker, H.F., Crow, T.J., Poulter, MM., Owen, F., Terwillinger, J.D., Westaway, D., Ott, J. und Prusiner, S.B. (1989): Linkage of a prion protein missense variant to Gerstmann-Sträussler syndrome. Nature, 338, 342-345 
Huang, Z., Gabriel, J.-M., Baldwin, M.A., Fletterick, R.J., Prusiner, S.B. und Cohen, F.E. (1994): Proposed three-dimensional structure for the cellular prion protein. Proc. Natl. Acad. Sci., 91, 7139-7143

Jakob, A. (1921a): Über eigenartige Erkrankungen des Zentralnervensystems mit bemerkenswerten anatomischen Befunde (spastische PseudoskleroseEncephalomyelopathie mit disseminierten Degenerationsherden). Dtsch. Z. Nervenheilk., 70, 132

Jakob, A. (1921b): Über eine der multiplen Sklerose klinisch nahestehenden Erkrankung des Zentralnervensystems (spastische Pseudosklerose) mit bemerkenswerten anatomischen Befunde: Mitteilung eines vierten Falls. Med Klin., 17, 372

Jakob, A. (1923): Die extrapyramidalen Erkrankungen mit besonderer Berücksichtigung der pathologischen Anatomie und Histologie und der Pathophysologie der Bewegungsstörungen. Julius Springer, Berlin, S. 215

Jeffrey, M. und Wells, G.H.A. (1988): Spongiform encephalopathy in nyala (Tragelaphus angasi). Vet Pathol., 25, 398-399

Jones, V., Martin, T., Keyes, P. und Dawson, M. (1996): Protein Markers in Cerebrospinal Ffluid from BSE-Affected Cattle. Veterinary Record, 139: 360365

Kabat, E. A., Wu, T. T., Reid M.,Perry, H. M. und Gottesman, K. S. (1987): Sequences of Proteins of Immunological Interest. U. S. Department of Health and Human Services, Public Health Service National Institutes of Health.

Kane, P.M., Yamashiro, C.T., Wolczyk, D.F., Neff, N., Goebl, M und Stevens, T.H. (1990): Protein splicing concerts the yeast TFP1 gene product to the 69 $\mathrm{kD}$ subunit of the vacuolar $\mathrm{H}+$ adenosine triphosphatase. Science, 250, 651-657

Kascsak, R. J., Rubenstein, R., Merz, P. A., Tonna-DeMasi, M., Fresko, R., Carp, R. I., Wiesniewski, H. M. und Diringer, H. (1987): Mouse Polyclonal and monoclonal antibody to scrapie-associated fibril proteins. J. Virol. 61, 3688-3693 
Kearney, J. F., Radbruch, A., Liesegang, B. B:, und Rajewski, K. (1979): A mouse myeloma cell line that has lost immunglobulin expression but permits the construction of antibody-secreting hybridoma cell lines. J. Immunol. 123, 1548-1558

Kimberlin, R.H. (1990a): Scrapie and possible relationship with viroids. Sem. Virol. $1,153-162$

Kimberlin, R.H. (1990b): Transmissible encephalopathies in animals. Can. J. Vet. Res., 54, 30-37

Kirkwood, J.K., Wells, G.A.H., Wilesmith, J.W., Cunningham, A.A. und Jackson, S.I. (1990): Spongiform encephalopathy in an Arabian oryx (Oryx leucoryx) and a greater kudu (Tragelaphus strepsiceros). Vet. Rec., 126, 408409

Klatzo, I., Gajdusek, D.C. und Zigas, V. (1957): Pathology of kuru. Lab. Invest., 8, 799-847

Knight, R. und Stewart, G. (1998): The new variant form of Creutzfeldt-Jakob disease. FEMS Immunol Med Microbiol., 21(2): 97-100

Kraseman, S., Groschup, M., Harmeyer, S., Hunsmann, G.und Bodemer, W. (1996): Generation of monoclonal antibodies agains Human prion proteins in $\mathrm{PrP}^{0 / 0}$ mice. Mol. Med., Vol 2, 725-734

Kraseman, S., Groschup, M., Hunsmann, G.und Bodemer, W. (1996): Induction of antibodies against human prion proteins (PrP) by DNA-mediated immunization of $\mathrm{PrP}^{0 / 0}$ mice. Journal of immuological methods

Kraseman, S., Zerr, I., Weber, T., Poser, S., Kretzschmar, H., Hunsmann, G. und Bodemer, W. (1995): Prion disease associated with a novel nine octapeptide repeat insertion in the PRNP gene. Mol. Brain Res., 34, 173-176

Kretzschmar, H.A., Kufer, P., Riethmüller, G., DeArmond, S.J., Prusiner, S.B. und Schiffer, D. (1991): Prion protein mutation at codon 102 in an Italian family with Gerstmann-Sträussler-Scheinker syndrome. Neurology, 42, 809810 
Kretzschmar, H.A., Stowring, L.E., Westaway, D., Stubbelbine, W.H., Prusiner, S.B. und DeArmond, S.J. (1986): Molecular cloning of a human prion protein cDNA. DNA 5, 315-324

Lasmezas, C.I., Deslys, J.P., Robain, O., Jargly, A., Beringue, V., Peyrin, J.-M., Fournier, J.-G., Hauw, J.-J., Rossier, J. und Dormont, D. (1997): Transmission of the BSE Agent to mice in the absence of detectable abnormal prion protein. Science, 275, 402-405

Laurent, M. (1996): Prion diseases and the 'prion only' hypothesis: a theoretical dynamic study. Biochem. J., 318, 35-39

Lee, D. C., Stenland, C. J., Hartwell, R. C., Ford, E. K., Cai, K., Miller, J. L., Gilligan, K. J., Rubenstein, R. , Fournel, M. und Petteway, S. R. (2000): Monitoring plasma processing steps with a sensitive western blot assay for the detection of the prion protein. J. Virol. Methods, 84(1): 77-89

Lee, K. H. und Harrington, M. G.(1997): The assay development of a molecular marker for transmissible spongiform encephalopathies. Electrophoresis. 18(3-4):502-506

Liao, Y.-C. J., Lebo. R.V., Clawson, G.A. und Smuckler, E.A. (1986): Human prion protein cDNA: Molecular cloning, chromosomal mapping, and biological implications. Science, 233, 364-367

Liautard, J.P. (1991): Are prions misfolded molecular chaperons ? FEBS Letter, 249(3), 155-157

Liljeström, P. und Garoff, H. (1991): A new generation of animal cell expression vectors based on the Semliki Forest Virus replicon. Biotechnology, 9, 1356-1361

Lopez, G. F., Zahn, R. Riek, R. und Wthrich, K. (2000): NMR structure of the bovine prion protein. Proc. Natl. Acad. Sci. USA, 97, 15, 8334-8339

Lugaresi, E., Medori, R., Montagna, P., Baruzzi, A., Cortelli, P., Lugaresi, A., Tinuper, P., Zucconi, M. und Gambetti, P. (1986): Fatal familial insomnia and dysautonomia with selective degeneration of thalmic nuclei. New Eng. J. Med. 315, 997-1003 
MaCullough, K. C., Butcher, R. N und Parkinson, D. (1983): Hybridoma cell lines secreting monoclonal antibodies against foot-and-mouth disease virus (FMDV). II Cloning conditions. J. Biol. Stand 11, 183

Major, M. E., Vivitski, L., Mink, M. A., Schleef, M., Whalen, R. G., Trepo, C. und Inchaupse, g. (1995): DNA-based immunization with chimeric vectors for the induction of immune responses against the Hepatitis C Virus nucleocapsid, J. Virology 69, 5798-5805

Manson, J. C., Clarke, A. R., McBride, P. A., McConnell, I. und Hope, J. (1994): PrP gene dosage determines the timing but not the final intensity or distribution of lesions in scrapie pathology. Neurodegeneration. 3(4): 331340

Manuelides, L., Sklaviadis, T., Akowitz, A. und Fritsch, W. (1995): Viral particles are required for infection in neurodegenerative Creutzfeld Jakob disease. Pro. Natl. Acad. Sci., 92, 5124-5128

Manuelidis, L., Murdoch, G. und Manuelidis, E.E. (1988): Potential involvment of retroviral elements in human dementias. Ciba Found. Symp., 135, 117134

Martin, A.C.R. Accessing the Kabat Antibody Sequence Database by Computer PROTEINS: Structure, Function and Genetics, 25 (1996), 130-133

Masters, C.L., Gajdusek, D.C. und Gibbs, C.J. Jr. (1981): The familial occurrence of Creutzfeldt-Jakob disease and Alzheimers disease. Brain, 104, 535558

Masters, C.L., Gajdusek, D.C., Gibbs, C.J. Jr., Bernouili, C. und Asher, D.M. (1979): Familial Creutzfeldt-Jakob disease and other familial dementias: an inquiry into possible models of virus-induced familial diseases. In: Slow transmissible diseases of the nervous system, vol. 1 (ed. S.B. Prusiner and W.J. Hardlow), pp. 143-194. New York: Academic Press

McCafferty, J., Griffiths, A. D., Winter, G. und Chiswell, D. J. filamentous phage displaying antibody variable domains. Nature 6, 348(6301), pp 552-554 
McKinley, M.D., Taraboulos, A., Kenaga, L., Serban, D., Stieber, A., DeArmond, S.J., Prusiner, S.B. und Gonates, N. (1991): Ultrastructural localization of scrapie prion proteins in cytoplasmic vesicles of infected cultured cells. Lab. Invest., 65, 622-630

McKinley, M.P., Bolton, D.C. und Prusiner, S.B. (1983a): A protease-resistant protein is a structural component of the scrapie prion. Cell, $35,57-62$

McKinley, M.P., Masiarz, F.R., Isaacs, S.T., Hearts, J.E. und Prusiner, S.B. (1983b): Resistance of the scrapie agent inactivation by psoralens. Photochem. Photobiol. 37, 539-545

Mednick, A.S., Reder, A.T., Spire, J.P., Van Cauter, p., Brown, P., Wollmann, R.L., Golgfarb, L.G., Garau, A., Ovsiew, F., Gajdusek, C. und Roos, R.P. (1994): Fatal familial insomnia (FFI). Neurology, 44, 285

Medori, R., Montagna, P., Tritschler, H.J., LeBlanc, A., Cortelli, P., Tinuper, P., Lugaresi, E. und Gambetti, P. (1992a): Fatal familial insomnia: A second kindred with mutation of prion protein gene at codon 178. Neurology, 42, $669-670$

Medori, R., Tritschler, H.J., LeBlanc, A., Vilare, F., Manetto, V., Chen, H.Y., Xue, R., Leal, S., Montagna, P., Cortelli, P., Tinuper, P., Avoni, P., Mochi, M., Baruzzi, A., Hauw, J.J., Ott, J., Lugaresi, E., $\quad$ Autillo-Gambetti, L. und Gambetti, P. (1992b): Fatal familial insomnia, a prion disease with a mutation at codon 178 of the prion protein gene. N. Engl. J. Med., 326, $444-449$

Meyer, N., Rosenbaum, V., Schmidt, B., Gilles, K., Mirenda, C., Groth, D., Prusiner, S.B. und Riesner, D. (1991): Search for a putative scrapie prion genome in purified prion fractions reveals a paucity of nucleic acid. J. Gen. Virol., 72,37

Meyer, R.K., McKinley, M.P., Bowman, K.A., Braunfeld, M.B., Barry, R.A. und Prusiner, S.B. (1986): Separation and properties of cellular and scrapie prion proteins. Proc. Natl. Acd. Sci., 83, 2310-2314 
Milner, J. und Medcalf, E. A. (1991): Cotranslation of activated mutant p53 with wild type drives the wild-type p53 protein in the mutant conformation. Cell, $65,765.774$

Moore, R. C., Lee, I. J., Silverman, G. L., Harrison, P. M., Strome, R., Heinrich, C., Karunaratne, A., Pasternak, S. H., Chisti, M. A., Liang, Y., Mastrangelo, P., Wang, K., Smit, A. F. A., Katamine, S., Carlson, G. A., Cohen, F. E., Prusiner, S. B., Melton, D. W., Tremblay, P., Hood, L. E. und Westaway, D. (1999): Ataxia in prion protein (PrP)-deficient mice is associated with upregulation of the novel PrP-like protein doppel. J. Mol. Biol., 292(4):797-817

Mouillet-Richard, S., Ermonval, M., Chebassier, C., Laplanche, JL., Lehmann, S., Launay, JM., Kellermann (2000): Signal transduction through prion protein. Science 15: 289(5486): 1925-1928

Moynagh, J. und Schimmel, H. (1999): Tests for BSE Evaluated, Nature, 400, 105: European Commission, The Evaluation of Tests for the Diagnosis of Transmissible Spongiform Encephalopathies in Bovines, http://europa.eu.in/comm/dg24/health

Mullis, K. B. und Falcoona, F. A. (1987): Specific synthesis of DNA in vitro via a polymerase-catalyzed chain reaction: Methods of Enzymol. 155, 335-350

Oesch, B., Westaway, D., Wälchli, M., McKinley, M.P., Kent, S.B., Aebersold, S.B.H., Barry, R.A., Tempst, P., Teplow, D.B., Hood, L.E., Prusiner, S.B., und Weissmann, C. (1985): A cellular gene encodes scrapie PrP 27-30 protein. Cell, 40, 735-746

Owen, F., Poulter, M., Collinge, J., Leach, M., Lofthouse, R., Crow, T.J. und Harding, A.E. (1992): A dementing illness associated with a novel insertion in the prion gene. Mol. Brain Res. 13, 155-157

Owen, F., Poulter, M., Collinge, J., Leach, M., Shah, T., Lofthouse, R., Chen, Y.F., Crow, T.J., Harding, A.E. und Hardy, J. (1991): Insertions in the prion gene in atypical dementias. Expl. Neurol., 112, 240-242 
Owen, F., Poulter, M., Lofthouse, R., Collinge, J., Crow, T.J., Risby, D., Baker, H.F., Ridley, R.M., Hsiao, K. und Prusiner, S.B. (1989): Insertion in prion gene in familial Creutzfeldt-Jakob disease. Lancet (I), 51-52

Owen, F., Poulter, M., Shah, T., Collinge, J. Lofthouse, R. Baker, H., Ridley, R., McVey, J. und Crow, T.J. (1990): An in-frame insertion in the prion protein gene in familial Creutzfeldt-Jakob disease. Mol. Brain Res. 7, 273-276

Pan, K.-M., Baldwin, M., Nguyen, J., Gasset, M., Serban, A., Groth, D., Mehlhorn, I., Huang, Z., Fletterick, R.J., Cohen, F.E. und Prusiner, S.B. (1993): Conversion of alpha-helices into beta-sheets features in the formation of the scrapie prion proteins. Proc. Natl. Acad. Sci., 90, 10962-10966

Parkin, E. T., Turner, A. J. und Hooper, N. M. (1999): Amyloid precursor protein, although paritially detergent-insoluble in mouse cerebral cortex, behaves as an atypical lipid raft protein. Biochem. J. 344(1): 23-30

Parry, H.B. (1983): Recorded occurence of scrapie from 1750. In: Oppenheimer DR. ed. Scrapie disease in sheep. London: Academic Press, 31-59

Pattison, .H. (1988): Fifty years with scrapie: a personal reminiscence. Vet. Rec., $123,661-666$

Priola, S.A., Caughey, B., Wehrly, K., und Chesebro, B. (1995) A 60-kDa prion protein (PrP) with properties of both the normal and scrapie-associated forms of PrP. J. Biol.Chem., 270, 3299-3305

Prusiner, S. B., McKinley, M. P., Groth, D. F., Bowman, K. A., Mock, N. I., Cochran, S. P., Masiarz, F. R. (1981): Scrapie agent contains a hydrophobic protein. Proc. Natl. Acad. Sci. 78, 6675-6679

Prusiner, S.B. (1982): Novel proteinacious particles cause scrapie. Science, 216, 136-144

Prusiner, S.B. (1987): Prions causing degenerative neurological diseases. Ann. Rev. Med., 38, 381-391

Prusiner, S.B. (1989): Scrapie prions. Annu. Rev. Microbiol., 43, 345-374

Prusiner, S.B. (1991a): Molecular biology and transgenics of prion diseases. Biochem. Mol. Biol., 260, 397-438 
Prusiner, S.B. (1991b): Molecular biology of prion diseases. Science, 252, 15151522

Prusiner, S.B., Scott, M., Foster, D., Pan, K.-M., Groth, D., Mirenda, C., Torchia, M., Yang, S.L. und DeArmond (1993): Ablation of the prion protein (PrP) gene in mice prevents scrapie and facilitates production of anti PrP antibodies. Pro. Natl. Acad. Sci., 90, 10608-10612

Prusiner, S.B., Scott, M., Foster, D., Pan, K-M., Groth, D., Mirenda, C., Torchia, M., Yang, S.-L., Serban, D., Carlson, G. A., Hoppe, P.C., Westaway, D. und DeArmond, S.J. (1990): Transgenic studies implicate interactions between homologous PrP isoforms in scrapie prion replication. Cell, 63, 673-686

Puckett, C., Concannon, P., Casey, C. und Hood (1991): Genomic structure of the human prion protein gene. J. Hum. Genet., 49, 320-329

Post, K., Pitschke, M., Schafer, O., Wille, H., Apple, T. R., Kirch, D., Milhorn, I.,Serban, H., Prusiner, S. B., und Riesner, D. (1998): Rapid acquisition of beta-sheet structure in prion protein prior to multimer formation. Bio. Chem., 379, (11) 1307-1317

Roos, R., Gajdusek, D.C., und Gibbs, C.J. Jr. (1973): The clinical characteristics of transmissible Creutzfeldt-Jakob disease. Brain, 96, 1-20

Rogers, M., Serban, D., Gyuris, M., Scott, T., Torchia und Prusiner, S. B. (1991): Epitope mapping of the syrian hamster prion protein utilizing chimeric and mutant genes in a vaccinia virus expression systems. J. Immunol. 147: 3568-3574

Safar, J., Geroni, M., Piccardo, P., Liberski, P.P., Miyazaki, M., Gajdusek, D.C. und Gibbs, C.J. Jr. (1990): Subcellular distribution and physicochemical properties of scrapie associated precursor protein and relationship with scrapie agent. Neurology, 40, 503-508

Sambrook, J., Fritsch, E. F. und Maniatis, T. (1989). Molecular cloning: A laboratory manual. Cold Spring Harbor Laboratory Press, New York. 
Sarkozi, E., Askanas, V., und Engel, W.K., (1994): Abnormal accumulation of prion protein $\mathrm{m}$ RNA in muscle fibers of patients with sporadic inclusion body myositis and hereditary inclusion body myopathy, Am. J. Path, 145, 12801284.

Schätzl, H.M., Da Costa, M.A., Taylor, L., Cohen, F.E., Prusiner, S.B. Prion Protein Gene Variation Among Primates JMB, 245, 362-374 (1995)

Schmerr, M. J., Jenny, A. L., Bulgin, M. S., Miller, J. M., Hamir, A. N., Cutlip, R. C. und Goodwin, K. R. (1999): Use of capillary electrophoresis and fluorescent labeled peptides to detect the abnormal prion protein in the blood of animals that are infected with transmissible spongiform encephalophathy. J. Chromatogr. A. 853(1-2): 207-214

Schneider, J., Yamamoto, N., Hinuma, Y. und Hunsmann, G. (1984): Sera from adult $\mathrm{T}$-cell leukemia patients react with envelope and core polypeptides of adult T-cell leukemia virus. Virology 132, 1-11

Stahl, N., Borchelt, D.R., Hsiao, K. und Prusiner, S.B. (1987): Scrapie prion protein contains a phosphatidylinositol glycolipid. Cell, 51, 229-240

Stahl, N., Baldwin, M.A., Burlingame, A.L. und Prusiner, S.B. (1990a): Identification of glycoinositol phospholipit-linked and truncated forms of the scrapie prion protein. Biochemistry, 29, 8879-8884

Stahl, N., Baldwin, M.A., Hecker, R., Pan, K.-M., Burlingame, A.L. und Prusiner, S.B.(1992a): Glycosylinositol phospholipid anchors of the scrapie and cellular prion proteins contain sialic acid. Biochemistry, 31, 5043-5053

Stahl, N., Borchelt, D.R. und Prusiner, S.B. (1990b): Differential release of cellular and scrapie prion proteins from cellular membranes by phosphatidylinositol-specific phospholipase C. Biochemistry, 29, 5405-5412

Stahl, N., Baldwin M. A., Te'plow, D. B., Hood, L., Gibson, B. W., Burlingame, A. L. und Prusiner, S. B. Structural studies of the scrapie prion protein using mass spectrometry and amino acid sequencing. (1993) : Biochemistry, 32(8): 19912002 
Takeishi, K., Kaneda, S., Ayusawa, D., Shimizu, K., Gotoh, O. und Seno, T. (1995) Nucleotide sequence of a functional cDNA for human thymidylate synthase. Nucleic. Acids Res., 13, 2035-2043

Taraboulos, A., Raeber, A., Borchelt, D.R., Serban, D. und Prusiner, S.B. (1992): Synthesis and trafficking of prion proteins in cultured cells. Molec. Biol. Cell, 3, 851-863

Taraboulos, A., Rogers, M., Borchelt, D.R., McKinley, M.P., Scott, M., Serban, D. und Prusiner, S.B. (1990a): Acquisation of protease resistance by prion proteins in scrapie-infected cells does not require asparagine-linked glycosylation. Proc. Natl. Acd. Sci, 87, 8262-8266

Taraboulos, A., Serban, D. und Prusiner, S.B. (1990b): Scrapie prion proteins accumulate in the cytoplsama of persistently-infected cultured cells. J. Cell Biol., 110, 2117-2132

Telling, G.C., Scott, M., Hsiao, K.K., Foster, D., Yang, S.-L., Torchia, M., Sidle, K.C.L., Collinge, J., DeArmond, S.J. und Prusiner, S.B. (1994): Transmission of Creutzfeld-Jakob disease from humans to transgenic mice expressing chimeric human-mouse prion protein. Proc. Natl. Acad. Sci., 91, 9936-9940

Towbin, H., Staehelin, T. und Gordon, J (1979):Electrophoretic transfer of proteins from polyacrylamid gels to nitrocellulose sheets: Procedure and some applications. Proc,natl. Acad. Sci. 76, 4350-4354

Ullmann, A., Jacob, F. und Monod, J. (1967): Characterisation by In vitro complementation of a peptide corrosponding to an operator-proximal segment of the ß-galactosidase structural gene of Escherichia coli. J. Mol. Biol., 24, 339

Ulmer, J. B., Donnelly, J. J., Parker, S. E., Rhodes, G. H., Felgner, P. L., Dwarki, V. J., Gromgowski, S. H., Deck, R. R., Dewitt, C. M., Friedman, A., Hawe, L. A., Leander, K. R., Martinez, D., Perry, H. C., Shiver, J. W., Montgomery, D. L., und Liu, M. A. (1993): Heterologous protection against influenza by injection of DNA encolding a viral protein. Science 259, 1745-1749 
Wadsworth, J. D. F., Jackson, G. S., Hill, A. F. und Collinge. J. (1999): Molecular biology of prion propagation. Current Opinion in Genetics and Developement, 9, 338-345

Weissmann, C. (1991b): A "unified theory" of prion propagation. Nature, 352, 679_ 682.

Wells, G.A., Scott, A.C., Johnson, C.T., Gunning, R.F., Hancock, R.D., Jeffrey, M., Dawson, M. und Bradley, R. (1987): A novel progressive spongiform encephalopathy in cattle. Vet. Res., 121, 419-420

Westaway, D., Goodman, P.A., Mirenda, C.A., McKinley, M.P., Carlson, G.A. und Prusiner, S.B. (1987): Distinct prion proteins in short and long scrapie incubation period mice. Cell, 51,651-662

Westaway, D., Mirenda, C.A., Foster, D., Zebarjadian, Y., Scott, M., Torchia, M., Yang, S. L., Serban, H., DeArmond, S.J., Ebeling, C., Prusiner S.B. und Carlson, G.A. (1991): Paradoxical shortening of scrapie incubations times by expression of prion protein transgenes derived from long incubation period mice. Neuron, 7, 59-68

Whittal, R. M., Ball, H. L., Cohen, F. E., Burlingame, A. L., Prusiner, S. B., und Baldwin, M. A. (2000): Copper binding to octarepeat peptides of the prion monitored by mass spectometry. Protein Sci. 9(2): 332-343

Wilesmith, J.W. und Wells, G.A.H. (1991): Bovine spongifom encephalopathy. Curr. Top. Microbiol. Immunol. 172, 21-38

Will, R.G., Ironside, J.W., Zeidler, M. (1996): A new variant of Creutzfeldt-Jakob diesease in U.K. Lancet, 347, 921-925

Williams, E.S. und Young, S. (1982a): Chronic wasting disease of captive mule deer: a spongiform encephalopathy. J. Wildl. Dis., 16-89-98

Williams, E.S. und Young, S. (1982b): Spongiform encephalopathy of Rocky Mountain elk. J. Wildl. Dis., 16, 89-98

Wyatt, J.M., Pearsom, G.R., Smerdon, T., Gruffydd-Jones, T,J. und Wells, G.A.H. (1990): Spongiform encephalopathy in cat. Vet. Res., 126, 513 
Xiang, Z. Q.,Spitalnik, S., Tran, M., Wunner, W. H., Cheng, J. und Ertl, H.c. (1994): Vaccination with a plasmid vector carring the rabies virus glycoprotein gene induces protective immunity against rabies virus. Virology 199, 132140

Yalow, R. S. und Berson, S. A. (1960):Immunoassay of endogenous plasma insulin in human. J. Clin. Invest. 39, 1157-1175

Yanisch-Perron, C., Vieira, J. und Messing, J. (1985): Improved M13 phage cloning vectors and host strains: Nucleotids sequence of the M13mp18 und pUC19 vectors. Gene, 33, 103

Zlotnik, I. (1963): Experimental transmission of scrapie to golden hamster. Lancet 1,1072

Zerr, I., Schulz-Schaeffer, W. J., Giese, A., Bodemer, M., Schroter, A., Henkel, K., Tschampa, H. J., Windl, O., Pfahlberg, A., Steinhoff, B. J., Gefeller, O., Kretzschmar, H. A. und Poser, S. (2000): Current clinical diagnosis in Creutzfeldt-Jakob disease: identification of uncommon variants. Ann. Neurol. 48(3): 323-329

Zuegg and J.E.Gready (2000) Molecular dynamics simulations of human prion protein including the N-linked oligosaccharides and GPI anchor. Glycobiology 10: 959-974 


\section{Anhang}

Tab. A1: Für den „gridded array assay“ im ELISA verwendete bovine PrPPeptide (P1-P114).

\begin{abstract}
P1 MVKSHIGSWI
P2 LVLFVAMWSD

P3 VGLCKKRPKP

P4 GGGWNTGGSRYPG

P5 GWNTGGSRYPGQG

P6 NTGGSRYPGQGSP

P7 GGSRYPGQGSPGG

P8 SRYPGQGSPGGNR

P9 YPGQGSPGGNRYP

P10 GQGSPGGNRYPPQ

P11 GSPGGNRYPPQGG

P12 PGGNRYPPQGGGG

P13 GNRYPPQGGGGWG

P14 RYPPQGGGGWGQP

P15 PPQGGGGWGQPHG

P16 QGGGGWGQPHGGG

P17 GGGWGQPHGGGWG

P18 GWGQPHGGGWGQP

P19 GQPHGGGWGQPHG

P2 0 PHGGGWGQPHGGG

P21 GGGWGQPHGGGWG

P22 GWGQPHGGGWGQP

P23 GQPHGGGWGQPHG

P2 4 PHGGGWGQPHGGG

P25 GGGWGQPHGGGWG

P26 GWGQPHGGGWGQP

P2 7 GQPHGGGWGQPHG

P2 8 PHGGGWGQPHGGG

P2 9 GGGWGQPHGGGWG

P30 GWGQPHGGGWGQP

P31 GQPHGGGWGQPHG

P32 PHGGGWGQPHGGG

P33 GGGWGQPHGGGGW

P3 4 GWGQPHGGGGWGQ

P35 GQPHGGGGWGQGG

P36 PHGGGGWGQGGTH

P37 GGGGWGQGGTHGQ

P38 GGWGQGGTHGQWN

P39 WGQGGTHGQWNKP
\end{abstract}

$\begin{array}{ll}\text { P40 } & \text { QGGTHGQWNKPSK } \\ \text { P41 } & \text { GTHGQWNKPSKPK } \\ \text { P42 } & \text { HGQWNKPSKPKTN } \\ \text { P43 } & \text { QWNKPSKPKTNMK } \\ \text { P44 } & \text { NKPSKPKTNMKHV } \\ \text { P45 } & \text { PSKPKTNMKHVAG } \\ \text { P46 } & \text { KPKTNMKHVAGAA } \\ \text { P47 } & \text { KTNMKHVAGAAAA } \\ \text { P48 } & \text { NMKHVAGAAAAGA } \\ \text { P49 } & \text { KHVAGAAAAGAVV } \\ \text { P50 } & \text { VAGAAAAGAVVGG } \\ \text { P51 } & \text { GAAAAGAVVGGL } \\ \text { P52 } & \text { AAAGAVVGGLGGY } \\ \text { P53 } & \text { AGAVVGGLGGYML } \\ \text { P54 } & \text { AVVGGLGGYMLGS } \\ \text { P55 } & \text { VGGLGGYMLGSAM } \\ \text { P56 } & \text { GLGGYMLGSAMSR } \\ \text { P57 } & \text { GGYMLGSAMSRPL } \\ \text { P58 } & \text { YMLGSAMSRPLIH } \\ \text { P59 } & \text { LGSAMSRPLIHFG } \\ \text { P60 } & \text { SAMSRPLIHFGSD } \\ \text { P61 } & \text { MSRPLIHFGSDYE } \\ \text { P62 } & \text { RPLIHFGSDYEDR } \\ \text { P63 } & \text { LIHFGSDYEDRYY } \\ \text { P64 } & \text { HFGSDYEDRYYRE } \\ \text { P65 } & \text { GSDYEDRYYRENM } \\ \text { P66 } & \text { DYEDRYYRENMHR } \\ \text { P67 } & \text { EDRYYRENMHRYP } \\ \text { P68 } & \text { RYYRENMHRYPNQ } \\ \text { P69 } & \text { YRENMHRYPNQVY } \\ \text { P70 } & \text { ENMHRYPNQVYYR } \\ \text { P71 } & \text { MHRYPNQVYYRPV } \\ \text { P72 } & \text { RYPNQVYYRPVDQ } \\ \text { P73 } & \text { PNQVYYRPVDQYS } \\ \text { P74 } & \text { QVYYRPVDQYSNQ } \\ \text { P75 } & \text { YYRPVDQYSNQNN } \\ \text { P76 } & \text { RPVDQYSNQNNFV } \\ \text { P77 } & \text { VDQYSNQNNFVHD } \\ \text { P78 } & \text { QYSNQNNFVHDCV }\end{array}$

P79 SNONNFVHDCVNI

P80 QNNFVHDCVNITV

P81 NFVHDCVNITVKE

P82 VHDCVNITVKEHT

P83 DCVNITVKEHTVT

P84 VNITVKEHTVTTT

P85 ITVKEHTVTTTTK

P86 VKEHTVTTTTKGE

P87 EHTVTTTTKGENF

P88 TVTTTTKGENFTE

P89 TTTTKGENFTETD

P90 TTKGENFTETDIK

P91 KGENFTETDIKMM

P92 ENFTETDIKMMER

P93 FTETDIKMMERVV

P94 ETDIKMMERVVEQ

P95 DIKMMERVVEQMC

P96 KMMERVVEQMCIT

P97 MERVVEQMCITQY

P98 RVVEQMCITQYQR

P99 VEQMCITQYQRES

P100 QMCITQYQRESQA

P101 CITQYQRESQAYY

P102 TQYQRESQAYYQR

P103 YQRESQAYYQRGA

P104 RESQAYYQRGASV

P105 SQAYYQRGASVIL

P106 AYYQRGASVILFS

P107 YQRGASVILFSSP

P108 RGASVILFSSPPV

P109 ASVILFSSPPVIL

P110 VILFSSPPVILLI

P111 LFSSPPVILLISF

P112 SSPPVILLISFLI

P113 PPVILLISFLIFL

P114 VILLISFLIFLIVG 
Tab. A2: Im ELISA verwendete Schaf PrP-Peptide (P1-P16).

\begin{tabular}{|c|c|l|}
\hline $\begin{array}{l}\text { Peptid- } \\
\text { nummer }\end{array}$ & $\begin{array}{l}\text { Aminosäuren- } \\
\text { nummer }\end{array}$ & Aminosäurensequenz \\
\hline 1 & $1-16$ & MVKSHIGSWILVLFVA \\
2 & $14-32$ & FVAMWSDVGLCKKRPKPGG \\
3 & $29-46$ & KPGGGWNTGGSRYPGQGS \\
4 & $40-56$ & RYPGQGSPGGNRYPPQG \\
5 & $57-72$ & GGGWGQPHGGGWGQPH \\
5 & $73-88$ & GGGWGQPHGGGWGQPH \\
6 & $89-104$ & GGGGWGQGGSHSQWNK \\
7 & $98-113$ & SHSQWNKPSKPKTNMK \\
8 & $113-131$ & KHVAGAAAAGAVVGGLGGY \\
9 & $128-148$ & LGGYMLGSAMSRPLIHFGNDY \\
10 & $145-163$ & LGGYEDRYYRENMYRYPNQ \\
11 & $160-179$ & YPNQVYYRPVDRYSNQNNFV \\
12 & $176-189$ & NNFVHDCVNITVKQ \\
13 & $186-194$ & TVKQHTVTT \\
14 & $191-208$ & TVTTTTKGENFTETDIKI \\
15 & $209-228$ & MERVVEQMCITQYQRESQAY \\
16 & $224-244$ & ESQAYYQRGASVILFSSPPVI \\
\hline
\end{tabular}




\title{
Poster 101
}

\section{Generation of recombinant phage antibodies for the detection of inducible expressed and purified prion proteins}

\author{
O. Ahmad-Omar, G. Hunsmann and A.W. Stuke \\ German Primate Centre, Department of Virology and Immunology, Kellnerweg 4. 37077 \\ Göttingen, Germany \\ phone: +49-551-3851-153, fax: +49-551-3851-184, e-mail: astuke@www.dpz.gwdg.de
}

To investigate the structure and function of the prion protein (PrP), eight monoclonal antibodies (MAbs) and three recombinant single-chain variable fragment (ScFv) antibodies against the bovine prion protein were generated. Therefore, the bovine wild-type gene was cloned into a Semliki-Forest virus (SFV) plasmid (provided by P. Liljeström), transcribed in vitro and the resulting RNA was co-electroporated with pSFV-Helper2 into BHK cells. The infected BHK cells served as a rich source of recombinant $\operatorname{PrP}$ antigen. $\operatorname{Pr} \mathrm{P}^{0 / 0}$ mice (provided by C. Weissmann) were immunized intraperitoneally with SFV particles, boosted subcutaneously each month and after four month splenocytes were fused with myeloma cells (the protocol was successfully applied by W. Bodemer for the production of Mabs against the human prion protein). The MAb production of the resulting hybidoma cells was first analysed by immunofluorescence using SFV infected BHK cells which expressed the wild-type bovine prion protein. Subsequently, to confirm the MAb production, the hybridoma cells were screened in an ELISA assay by using a mixture of overlapping peptides covering the entire bovine PrP as antigen. Eight cell lines stably producing MAbs were isolated and used for the isolation of the antibody genes.

The total RNA was isolated from three of the hybridoma cell lines (Quiagen RNeasy Kit) and transcibed in vitro by RT-PCR (GibcoBRL SuperScript Kit). The DNA regions coding for the two antibody chains were amplified by PCR using one primer pair for the light and another pair for the heavy chain (applying the Pharmacia recombinant phage antibody system). During the assembly reaction, both DNA fragments were linked with a specially constructed linker DNA and cloned into the pCANTAB5E phagemid vector. To express the phage-displayed recombinant antibodies, competent E. coli TG1 cells were transformed with the phagemid clones and superinfected with M13K07 helper phage. The phage antibodies were purified by PEG precipitation and used for further analysis. To obtain the soluble form of the recombinant antibodies, E. coli HB2151 cells were infected with the antigen-positive clones. In additional experiments, the DNA from the three ScFv phages was isolated, sequenced and the CDR regions were identified by computer comparisions. Since the ScFv molecules can be modified using recombinant DNA technology, they may be useful tools to examine the conformational conversion of PrP. Subsequently, the binding specificities of the three ScFv phage antibodies and the eight MAbs was determined in an ELISA assay with bovine PrP peptides as antigens. Therefore, a mapping of the PrP epitopes which were recognized by the MAbs and ScFv antibodies was performed with a gridded array of 114 synthetic 13 mer peptides. This high resolution assay clearly identified different core epitopes on the bovine PrP. To prove the binding properties of the MAb and phage antibodies we performed detailed Western blot studies. In order to isolate the proteins, $1 \times 10^{7}$ cells of $3 \mathrm{~T} 3 \mathrm{~L} 1$ Tet-Off clone $17+$-grown in tetracycline free medium- were treated with low salt extraction buffer (LSEB). In this cell line, the murine Prnp ORF was exchanged against the human fatal familial insomnia (FFI) ORF by targeted gene replacement at one allele. Furthermore, the expression level of the FFI protein can be regulated in this cell line by the amount of tetracycline added into the medium. After the protein extraction, the samples were loaded on $12 \%$ denaturing PAGE gels, electroblotted onto nitrocellulose membranes and incubated with the phage antibodies (16G8, 26B8, and 25G6). The second antibody was HRP-conjugated anti M13. The typical three PrP bands were clearly visible with the chemiluminescent ECL detection system (Amersham) after 1 second of exposure time. In other Western blots, purified murine wild-type $\mathrm{PrP}^{\mathrm{Sc}}$ was used as antigene and showed positive signals. To sum it up it can be said that the three phage-displayed antibodies clearly showed strong signals of the three PrP specific bands in an ECL Western blot. In a peptide ELISA assay they also identified different epitopes on the bovine prion protein.

This study was supported by grants PL95-1185, PL97-2679 and PL97-6040 (Biomed II) from the EU. 


\section{DANKSAGUNG}

Herrn Prof. Dr. G. Hunsmann danke ich für die Bereitstellung der guten Arbeitsmöglichkeiten am DPZ und die Betreuung meiner Dissertation.

Herrn Prof. Dr. G. Gottschalk danke ich für die Übernahme des Referats und Prof Dr. B. Bowien für die Übernahme des Korreferats im Fachbereich Biologie der Georg-AugustUniversität Göttingen.

Herrn Dr. A. W. Stuke danke ich ganz besonders für die Themenvergabe, die gute Zusammenarbeit und einfach für alles was er für mich getan hat. Ohne seine brüderliche Betreuung wäre diese Arbeit erfolglos geblieben.

Mein besonderer Dank gilt Prof. Dr. W. Bodemer, der mich im ersten Drittel der Arbeit betreut hat. Ich bedanke mich auch bei Frau Dr. Krasemann und bei Thomas Jürgens für ihre Unterstützung am Anfang dieser Arbeit.

Mein Dank gilt außerdem Frau Jutta Gloth für die tatkräftige Unterstützung meiner praktischen Arbeit im Labor. Bei der Firma Seqlab bedanke ich mich für die Sequenzierungsarbeit.

Ein persönliches Dankeschön gilt Giesela Feldmann, Thomas Cramer, Christina Peinberg, Ulrike Reichmut und Ben Salam für das Korrekturlesen des Manuskriptes.

Den anderen (auch ehemaligen) Mitarbeitern des Labors 311-314 möchte ich für die angenehme und oft lustige Arbeitsatmosphäre danken.

Meinen Schwestern Zahra, Jimma und Suad danke ich für die finanzielle und moralische Unterstützung meines bisherigen wissenschaftlichen Werdegangs.

Bei meiner Frau Nagat Asaali möchte ich mich besonders bedanken. Sie hat mich mit viel Liebe und Geduld durch alle Motivationstiefs begleitet und mir bei der Dissertation zusammen mit unseren Kindern Ahmad und Mohammad viel Freude gebracht. 


\section{Lebenslauf}

Name

Vorname

Anschrift

Geburtsdatum und -ort

Staatsangehörigkeit

Familienstand

\section{Schulausbildung}

1973 - 1978

$1979-1984$

1985

1988

\section{Studium}

$1989-1995$

$1996-2001$
Ahmad-Omar

Omar

Lilienthalstraße 14

D-37073 Göttingen

Tel.: (0551) 71421

2. März 1968 in Ghinda (Eritrea)

deutsch

verheiratet, zwei Kinder

Elementary School in Eritrea

Secondary School

Einreise nach Deutschland

Abitur in Kassel

Biologiestudium in Göttingen

Diplomarbeit angefertigt am Deutschen

Primatenzentrum (DPZ) in Göttingen.

Thema: Untersuchungen zur

Synthesegenauigkeit verschiedener Reversen

Transkriptasen von Immundefizienzviren und von

zellulären DNA-Polymerasen

Doktorarbeit angefertigt am Deutschen

Primatenzentrum (DPZ) in Göttingen.

Thema: Produktion von monoklonalen

Antikörpern und Phagenantikörpern gegen das

Rinder-Prionprotein durch SFV Partikel-

vermittelte Immunisierung von $\mathrm{PrP}^{0 / 0}$-Mäusen 